\title{
Trillions Gained and Lost: Estimating the Magnitude of Growth Episodes
}

Lant Pritchett, Kunal Sen, Sabyasachi Kar, Selim Raihan CID Working Paper No. 279

March 2014

(C) Copyright 2014 Pritchett, Lant; Sen, Kunal; Kar, Sabyasachi; Raihan, Selim; and the President and Fellows of Harvard College
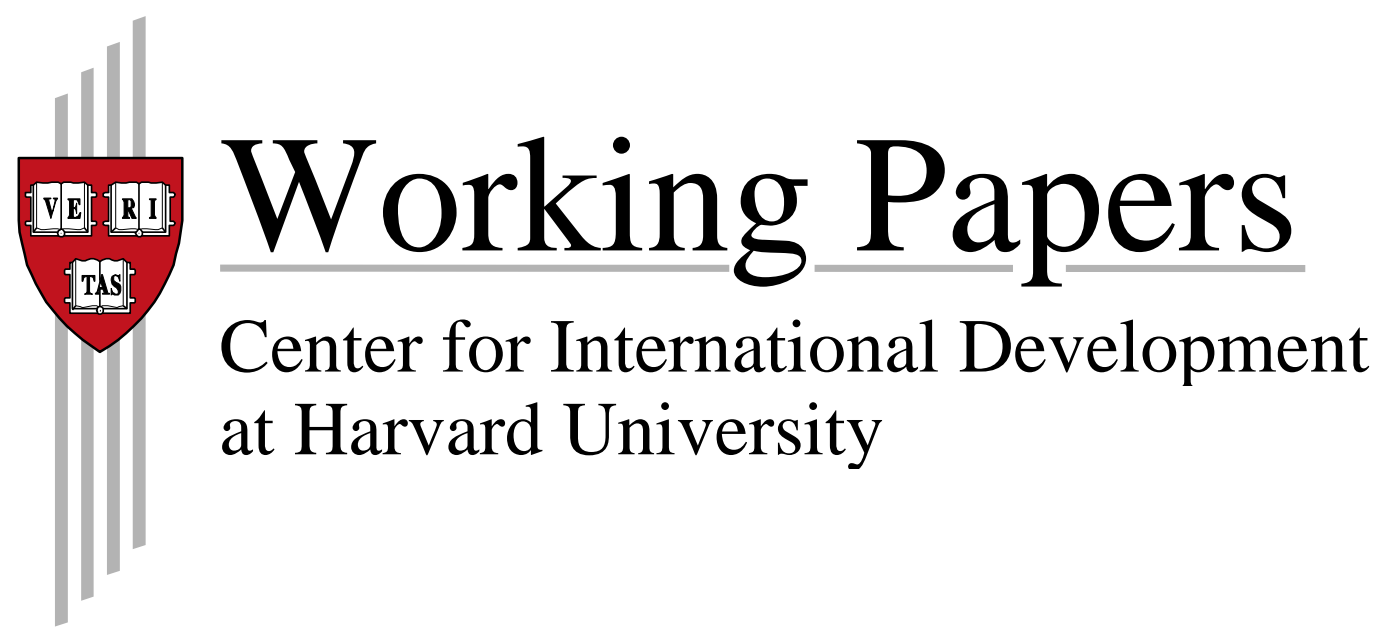
ESID Working Paper No. 26

ESID Methodological Paper No. 1

\section{Trillions Gained and Lost:}

Estimating the Magnitude of Growth Episodes.

Lant Pritchett ${ }^{1}$, Kunal Sen ${ }^{2}$, Sabyasachi Kar ${ }^{3}$ and Selim Raihan ${ }^{4}$

October, 2013

${ }^{1}$ Fellow, Center for Global Development and Professor of Practice, Harvard Kennedy School

2 IDPM and BWPI, University of Manchester and ESID Joint Research Director

${ }^{3}$ Institute of Economic Growth, Delhi

${ }^{4}$ Department of Economics, University of Dhaka and SANEM

Email correspondence: kunal.sen@manchester.ac.uk

ISBN: 978-1-908749-25-3 


\begin{abstract}
We propose and implement a new technique for measuring the total magnitude of a growth episode: the change in output per capita resulting from one structural break in the trend growth of output (acceleration or deceleration) to the next. The magnitude of the gain or loss from a growth episode combines (a) the difference between the post-break growth rate versus a counter-factual "no break" growth rate and (b) the duration of the episode to estimate the difference in output per capita at the end of an episode relative to what it would have been in the "no break" scenario. We use three "counter-factual" growth rates that allow for differing degrees of regression to global average growth: "no change" (zero regression to the mean), "world episode average" (full regression to the mean) and "unconditional predicted growth" (which uses a regression for each growth episode to predict future growth based only on past growth and episode initial level). We can also calculate the net present value at the start of an episode of the gain or loss in output comparing the actual evolution of output per capita versus a counter-factual. This method allows us to place dollar figures on growth episodes. The top 20 growth accelerations have Net Present Value (NPV) magnitude of 30 trillion dollars - twice US GDP. Conversely, the collapse in output in Iran between 1976 and 1988 produced an NPV loss of $\$ 143,000$ per person. The top 20 growth decelerations account for 35 trillion less in NPV of output. Paraphrasing Lucas, once one begins to think about what determines growth events that cause the appearance or disappearance of output value equal to the total US economy, it is hard to think about anything else.
\end{abstract}

\title{
Keywords:
}

Growth magnitude, growth episode, acceleration, deceleration, net present value.

JEL Classification: C18, O11, O47 


\section{Introduction}

Is there some action a government of India could take that would lead the Indian economy to grow like Indonesia's or Egypt's? If so, what, exactly? If not, what is it about the "nature of India" that makes it so? The consequences for human welfare involved in questions like these are simply staggering: Once one starts to think about them, it is hard to think about anything else.

(Lucas, 1988, p. 5; italics in original)

The importance of "institutions" in determining levels of national output per capita combined with the persistence of the long-run structural, historical and political factors that shape institutions suggests there may be no feasible "what, exactly" that will change economic outcomes. ${ }^{1}$ Yet, as we document here, there are cases in which identifiable accelerations and decelerations of economic growth cause spectacular gains and losses in output.

In 1988 when Lucas wrote many thought the "nature of India" condemned it to a modest "Hindu rate of growth." But, according to our estimates, GDP per capita growth in India accelerated in 1993 to 4.23 per cent per annum (ppa) versus a predicted rate of 2.34 ppa and then accelerated again in 2002 to 6.29 ppa versus a predicted rate of 2.91. The net present value (at a 5 percent discount rate) of the additional output from the 2002 growth acceleration was 2.65 trillion dollars (PPP) adding to the 1.05 trillion dollar Net Present Value (NPV) of output gain from the 1993 acceleration for a total NPV gain from growth accelerations 1993 of 3.7 trillion dollars.

Conversely, Brazil's was a "miracle" country from 1967 to 1980 growing at 5.16 ppa. But growth decelerated sharply in 1980 to essentially zero and stayed low until 2002. We estimate the Net Present Value (NPV) of the lost output from this slowing of growth relative to its prediction to be 7.3 trillion dollars.

We document 30 cases of NPV gains from growth accelerations that are more than triple initial GDP per capita and 32 cases where the NPV of losses from decelerations exceeded three times the initial GDP per capita. These changes in growth are much harder to explain as pre-determined - by history or institutions or otherwise - as often quite similarly situated countries launch into new paths, different from their own history and from their neighbours. That said, merely by documenting the magnitude of gains and losses only sets the stage for examining "what, exactly" can be done, which remain the most consequential research questions in development (indeed all of) economics.

\footnotetext{
${ }^{1}$ Acemoglu and Robinson (AR, 2012) and North et al. (NWW, 2009) both argue for the importance of institutions ("inclusive" for AR and "open access orders" for NWW) in determining levels of national output adding to the econometrics of "institutions rule" (Rodrik et al., 2004, Easterly and Levine 2003). Comin et al. (2010) take this to the extreme of showing that patterns of technological adoption in $1000 \mathrm{BC}$ affect levels of the GDP per capita today.
} 
Our estimation of the magnitude of countries' growth accelerations and decelerations builds from the identification of the structural breaks in the GDP per capita growth process using the latest version of the Penn World Tables (PWT7.1) using a combination of Bai-Perron (1998) and a magnitude filter for "true" breaks based on the difference in growth rates (Kar et al., 2013b). The existing literature on growth breaks (see Kar et al., 2013a and b for reviews of the literature) has been mostly concerned with the timing of the break in GDP per capita (e.g. Jones and Olken, 2008) or duration of the growth episode (e.g. Berg et al., 2012). In this paper, we build on the existing literature on growth breaks by proposing both a flow and a stock measure of the magnitude of a growth episode. The flow measure is the difference between the level of output at the end of the episode and the counter-factual of what the level of output would have been in the absence of the onset of the growth episode. The stock measure computes the total net present value of the difference between the actual trajectory of output during the episode and the predicted trajectory. These definitions of magnitude combine in an intuitive way the change in the growth rate due to the episode and the duration of the episode. An acceleration to a modest growth rate which is sustained over decades will have a larger magnitude than a large but short-lived burst.

Making these definitions operational requires an estimate of the "counter-factual" growth rate. For each growth episode we implement three counter-factuals: (a) the country's growth rate in its previous episode, (b) the world average growth rate and (c) an "unconditional predicted" growth rate. The "unconditional predicted" growth rate uses a regression for each country/episode to allow "predicted" growth to depend on a country's initial GDP per capita, the episode period specific world average growth and a flexibly specified regression to the mean. The definition of the magnitude of growth episodes allows us to decompose the total change in GDP per capita into the sum of the magnitude of the positive and negative contributions of each episode.

The rest of the paper is in six sections. The next section proposed our methodology and applies it to GDP per capita (GDPPC) data for 125 countries from Penn World Tables version 7.1 for 1950-2010. Section 3 decomposes country growth experiences into growth episodes using our approach. We extend this in Sections 4 and 5 with detailed analysis of growth accelerations and growth decelerations, respectively. Section 6 presents NPV estimates of the magnitude of growth episodes. Section 7 concludes.

\section{Estimating the magnitude of a growth episode}

It has long been recognized that differences in "steady state" growth rates must account for a relatively small part of the observed cross-national differences in medium to long-run economic growth among developing countries ${ }^{2}$. "Steady state" growth rates are bounded below by zero (as otherwise the economy reaches negative output in finite time) and

\footnotetext{
${ }^{2}$ In the first wave of growth theory Hicks (1965) pointed out that since, almost by definition, a steady state dynamic equilibrium had to have constant ratios (e.g. in sector composition of output and labour force, capital-output ratios, etc.) and the process of "development" was precisely about such transitions that growth theory was the domain of economics perhaps of least relevance to development.
} 
historical observation on the economically leading countries suggests 2 percent per annum (ppa) as an upper bound. Yet the variance in decadal growth rates in developing countries is much larger, with countries experiencing both very high growth rates and very sharp contractions. The combination of the large variance in medium to long term growth rates combined with the lack of growth persistence and strong regression to the mean (e.g. Easterly et al., 1993) suggests that developing country output growth is not well described by a "business cycle" around a "steady state" growth rate but rather is an "episodic" phenomena with countries undertaking discrete shifts from periods of low to periods of high growth and vice versa (Pritchett, 2000) or "the cycle is the trend" (Aguiar and Gopinath, 2007) or "startstop" growth (Jones and Olken, 2008).

Since Ben-David and Papell (1998), many papers have estimated the structural breaks in the growth process (and their correlates). Some of these papers focus on accelerations/takeoffs (Hausmann et al., 2005, Aizenmann and Spiegel, 2010), others on decelerations/depressions (Rodrik 1999, Hausmann et al., 2006, Arbache and Page, 2007, Breuer and McDermott, 2013). While most focus on the magnitude of growth rate differences, recently Berg et al., (2012) estimated the duration of growth episodes and its correlates as they recognized that cumulative impact combined both rates and durations.

In previous work we described a procedure for identifying structural breaks in economic growth that uses of the Bai-Perron (BP) (1998) procedure of maximizing the F-statistic to identify candidate years for structural breaks in growth with thresholds on the magnitude of the shift to determine which are actual breaks (Kar et al., 2013a). The magnitude filter was that the absolute value of the change in the growth rate after a BP potential break had to be (a) 2 percentage points if it was the first break, (b) 3 percentage points if the potential break was of the opposite sign of the previous break (an acceleration that followed a deceleration had to have accelerated growth by more than 3 ppa to qualify as a break) and (c) 1 percentage point if the BP potential break was of the same sign as the previous break, so if $\mathrm{BP}$ identified an acceleration that directly followed an acceleration (or deceleration that followed a previous deceleration) the magnitude had to be larger than 1 ppa to qualify as a break. Application of this procedure to the PWT7.1 data for 125 countries $^{3}$ identifies 316 structural breaks in growth, with some countries having no breaks (e.g. USA, France, Australia) and others having four breaks (e.g. Argentina, Zambia).

\subsection{The magnitude of growth accelerations and decelerations: flow}

Suppose we have a structural break in growth in year $t$ that ends a previous growth episode in which growth was $g_{\text {before }}$ that lasted $N_{b}$ years and growth in the episode is $g_{e p}$ and this episode lasts $N_{e p}$ years. We define the flow magnitude of the growth episode as the difference in GDP per capita (GDPPC) in year $t+N_{\text {ep }}$ between its actual and its counterfactual level. If natural log of GDPPC is $y$ then the equation is:

$$
\text { 1) Episode Magnitude }{ }_{F}=y_{t+N_{e p}}^{\text {Actual }}-y_{t+N_{e p}}^{\text {Counter factual }}
$$

\footnotetext{
${ }^{3}$ From the PWT7.1 data we eliminated all countries that had very small populations (less than 700,000 in 1980) and those that did not have data since 1970 (which eliminated many former Soviet sphere countries and some oil countries like Kuwait and Saudi Arabia).
} 
The three obvious counter-factual growth rates depend on what is assumed about regression to the mean.

"No change": Growth continues at pre-break levels. This assumes there is zero regression to the mean and the counter-factual for growth during the episode was the pre-break growth rate. In this case the magnitude of the total gain/loss from the episode is:

$$
\text { 2) Episode Magnitude }{ }_{F}^{\text {No Change }}=\left(g_{e p}-g_{\text {before }}\right) * N_{e p}
$$

"World Average": Growth during the episode is world average growth during the episode. Alternatively, complete regression to the mean assumes the growth rate during the episode would have been the world average growth during the same period.

$$
\text { 3) } \text { Episode Magnitude }_{F}^{\text {World Average }}=\left(g_{e p}-g_{\text {World Average }_{t, t+N_{e p}}}\right) * N_{e p}
$$

"Unconditional predicted": Growth during the episode is predicted from past growth. The awkward phrase "unconditional predicted" growth means that we want to "predict" the growth rate of a country during the period of the episode without using any information about the country - e.g. region, geography, institutions, policies - -other its own past output. We want a clean separation between the measurement of the magnitude of the growth episode and potential correlates or causal explanations of the growth episode.

The unconditional predicted growth is the prediction from a country/episode specific regression of growth for all countries $j$ other than the country with the break on a constant plus initial GDP per capita plus previous growth. We use a spline to allow the coefficient on previous growth to be different whether the country's growth rate before the episode was higher or lower than the world average.

$$
\text { 4) } g_{\text {ep }}^{j}=\alpha^{e p}+\beta_{\text {base }}^{e p} * g_{\text {before }}^{j}+\beta_{\text {above }}^{e p} * d^{j} *\left(g_{\text {before }}^{j}-g_{\text {before }}^{\text {world average }}\right)+\gamma * y_{t}^{j}+\varepsilon^{j}
$$

This functional form of the "unconditional predicted" growth allows for four things: (1) the constant allows the world average growth rate to vary over time and be specific to the period of the episode to accommodate a global "business cycle", (2) regression to the mean is period specific, (3) regression to the mean depends on previous growth (as recoveries from negative/slow growth make have different dynamics that the slowing of accelerations) and (4) growth to depend on the initial level of income (without conditioning variables this is not estimating "conditional convergence") ${ }^{4}$.

$$
\text { 5) Episode Magnitude }{ }_{F}^{U C P}=\left(g_{e p}-g_{U C P}\right) * N_{e p}
$$

Figure 1 illustrates the estimates of the episode magnitude for the three counter-factuals for the case of an acceleration from low growth to high growth. In this (hypothetical) case the "no change" counter-factual implies a very large magnitude, the "world average" (WA) counter-factual a small magnitude (as the post-acceleration growth is not much higher than the world average). The unconditional prediction (UCP) counter-factual will essentially be a

\footnotetext{
${ }^{4}$ For the period from the beginning of the data to the first growth break the UCP is just a regression of growth on the natural log level of output.
} 
regression determined weighted average of the two and hence will tend to be the two extremes. When using the WA or UCP counter-factual a growth acceleration could have a negative magnitude (or a growth deceleration a positive magnitude).

Figure 1: Illustration of the alternative definitions of the magnitude of an episode depending on the specification of the counter-factual growth rate (for an acceleration from stagnation)

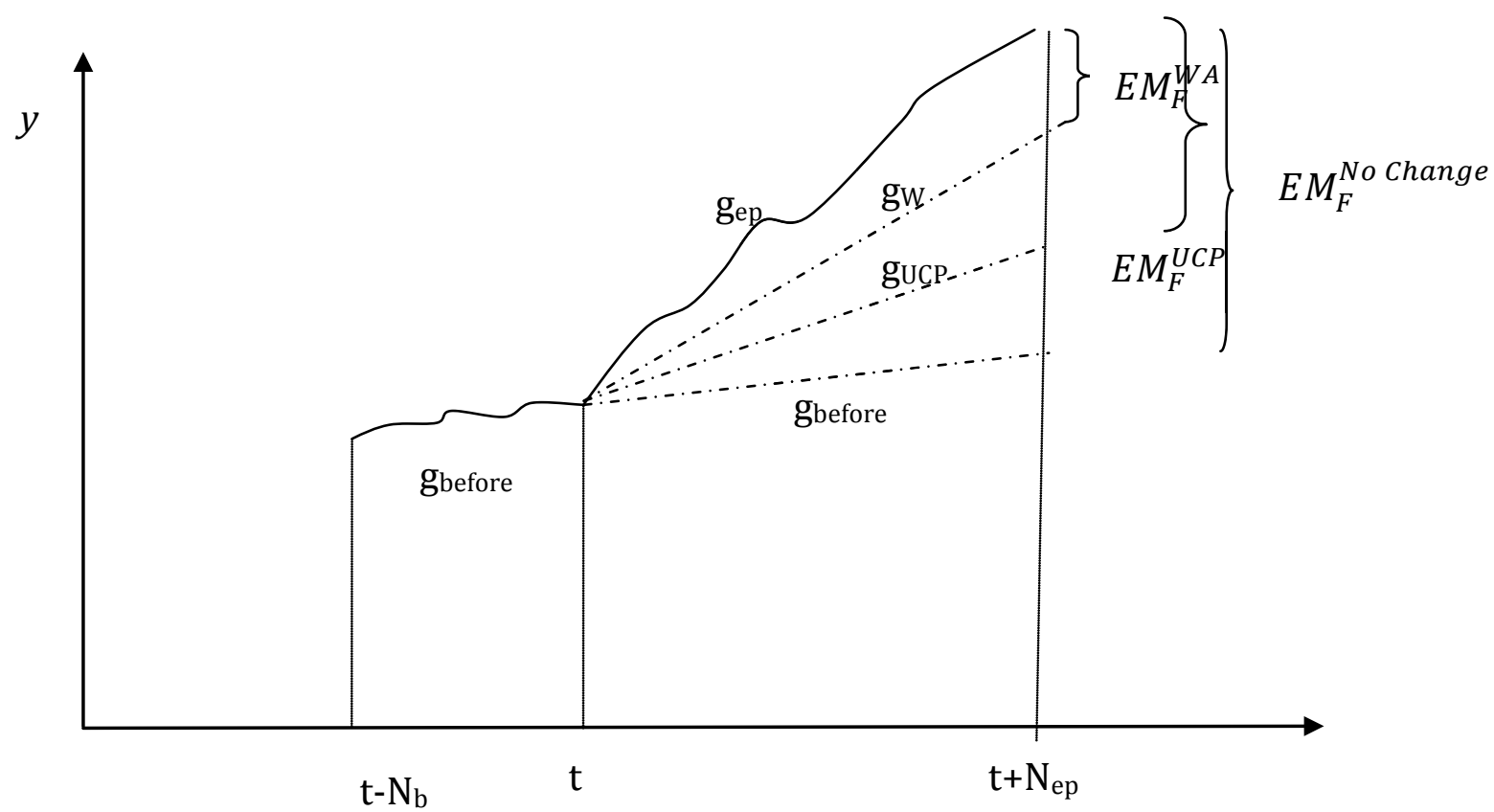

Our preferred specification uses the UCP counter-factual. Zero regression to the mean (No Change) or full regression to the mean (World Average), while easy to understand, impose strong and empirically unsupported assumptions about the actual dynamics of growth which is strongly, but not fully, mean reverting.

Table 1 summarizes the regressions for calculating the unconditional predicted growth rate (results for each episode Appendix 1). The regression constant, not surprisingly, shows substantial variability over time, as the "predicted" growth rate was positive from 1958 (the first possible growth break as spells have to be at least 8 years) to 1975, negative from 1975 to 1995 and then strongly positive from 1995 to 2002 (by construction the last growth break) as there was exceptionally strong growth.

The spline shows strong, and modestly asymmetric, regression to the mean. Countries with below world median growth show almost no persistence - the average coefficient on previous growth is only .175 while those with above average growth tended to have more persistence - but still show strong regression to the mean. Since each country/episode regression is for different periods of "before" and "after" we adjust to a "standard" of the 
persistence coefficient for an episode 10 years in duration, starting after an episode of 10 years duration in 1980. We see the asymmetry is, if anything, stronger with very near zero persistence of slow growth (.12) and substantial (but far from full) persistence of .388 for rapid growth.

\begin{tabular}{l}
\hline \multicolumn{2}{|l|}{ Table 1: Summary of the 314 countrylepisode specific regressions used to compute } \\
"unconditional predicted" growth rates \\
\hline
\end{tabular}

\subsection{The magnitude of growth accelerations/decelerations: total NPV}

Once the flow magnitude of a growth episode (acceleration or deceleration) is defined as above it is easy to define the net present value (NPV) magnitude of the episode. The "stock" estimate of the total gain, discounted to the beginning of the episode, is simply the sum of the discounted differences in annual output from the beginning to the end of the episode (equation 6). This NPV of additional GDP is expressed in the same units as GDP and hence in this instance in constant units of purchasing power. The counter-factual output series can be calculated from the beginning to end of the growth episode with any of the three counter-factual growth rates.

$$
\text { 6) Episode Magnitude }{ }_{N P V}^{N C, W A, \text { or UCP }}=\sum_{n=1}^{n=N_{e p}}\left(\left(\delta^{n}\right)\left(y_{t+n}^{\text {Actual }}-y_{t+n}^{\text {Counter factual }}\right)\right)
$$

Where the discount factor is the standard $\delta^{n}=1 /(1+r)^{n}$.

This is a "gross" not "net" concept of NPV. For instance, if growth is higher because people save and investments which raise the capital stock which raise output we do not deduct out the cost of the savings in assessing the NPV. This is therefore not (yet) directly comparable to NPVs as used in cost-benefit analysis of specific projects or policies.

This calculation of the total (NPV) magnitude of growth episodes is purely descriptive. We allow the data to say "something happened in year $t$ that changed the trend rate of growth of 
GDPPC that lasted for $\mathrm{N}$ years." We then calculate the total (NPV) of the difference in output between what happened over those years relative to a counter-factual series of output and this is the total (NPV) of the output that existed (or did not exist) because of what happened in year $t$. This does not prejudge in any way, shape, or form what it was that happened in year $\mathrm{t}$ - a terms of trade improvement, a shift in animal spirits, a policy shift, a shift in expectations due to a political regime shift, a transmission of a global shock, technological innovation - to cause this growth shift.

\subsection{Illustrative cases of estimates of the magnitudes of growth episodes}

Our method is easily understood graphically. Figure 2 shows the results for Brazil with UCP results in the top and bottom panels on the left side and World Average results in the top and bottom panels on the right side.

The upper panel shows the evolution of GDPPC and of the fitted values of the spline regression. Our method identifies three structural breaks in the GDPPC series: (i) an acceleration in 1967 in which growth increased from 4.16 to 5.16 ppa (accelerations are marked with a green vertical line and upward arrow), (ii) a deceleration in 1980 of 5.20 ppa from 5.16 to $-0.05 \mathrm{ppa}$ (decelerations are marked with a red vertical line and a downward arrow), (iii) an acceleration in 2002 of 3.20 ppa from -.05 to 3.15 ppa. These acceleration and deceleration years create four episodes of growth (1950-1967, 1967-1980, 1980-2002 and 2002-2010). The colour along the bottom indicates the range of the growth rate during each episode: bright green is rapid growth (above $4 \mathrm{ppa}$ ), light green for moderate growth (between 2 and $4 \mathrm{ppa}$ ), beige for slow growth (0 to $2 \mathrm{ppa}$ ) and red for negative growth ${ }^{5}$. The red line shows the counter-factual evolution of GDPPC had growth in each of the episodes been exactly the UCP growth.

The lower panel of Figure 2 shows the calculated flow magnitude of each growth acceleration and deceleration. For instance, growth from 1967 to 1980 was 5.16 ppa whereas UCP growth was 2.87 ppa so the excess of the growth during this episode was 2.29 ppa and the episode lasted for 13 years so the level of GDPPC in 1980 due to the acceleration of 1980 is $.30=(.0516-.0287)^{*} 13$. (Almost) equivalently, GDPPC in Brazil in 1967 was 3,166 and $3,166^{*}(1.0516)^{13}=6,086$ is the level of GDPPC had Brazil grown at exactly its least squares growth rate whereas $3,166^{*}(1.0287)^{13}=4,573$ is the level if had growth at exactly its UCP growth rate and $\ln (6,086)-\ln (4,573)=8.71-8.42=.29$.

The deceleration in 1980 slowed growth to -0.05 ppa whereas the UCP growth was 4.02 ppa. This implies the level of GDPPC in 2002 was lower by $(-.05-4.02)^{\star} 22=.89$ natural log

\footnotetext{
${ }^{5}$ Since the average growth rate is roughly 2 ppa and the standard deviation is roughly 2 ppa these categories are roughly one standard deviation above (light green) and below (brown) the mean and more than one standard deviation above (bright green) or below the mean (red). Our view is that the "focal point" advantage of rounding to 2 trumps the exactness of using exactly the mean and standard deviation.
} 
units. Rather than $\$ 6,885$ from the actual growth rate at the UCP counter-factual GDPPC would have been $\$ 16,653$ - 140 percent higher.

The bottom panel shows the magnitude of each episode and the cumulative gain/loss of the country over the entire period compared to growing at the UCP counter-factual in each episode. Brazil's GDPPC in 2010 was $\$ 8,324$ whereas its UCP output was $\$ 12,391$ so the cumulative total loss relative to the UCP counter-factuals is -.40 .

The right hand panels follow exactly the same format but use the WA growth rate. These differ in predictable ways. The UCP growth was 4.02 for the period 1980-2002 based on some predicted persistence of the rapid growth of 1967-1980 so the loss was larger. In contrast WA growth was only 1.3 ppa in the 1980 to 2002 period so loss from the growth deceleration in 1980 looks considerably smaller. Also, since the counter-factual of WA growth is lower in each period the WA assumptions show Brazil in 2010.30 In units above the cumulated WA counter-factual.

Figure 2: Illustrating the calculation of the magnitude of growth accelerations/ deceleration episodes, Brazil
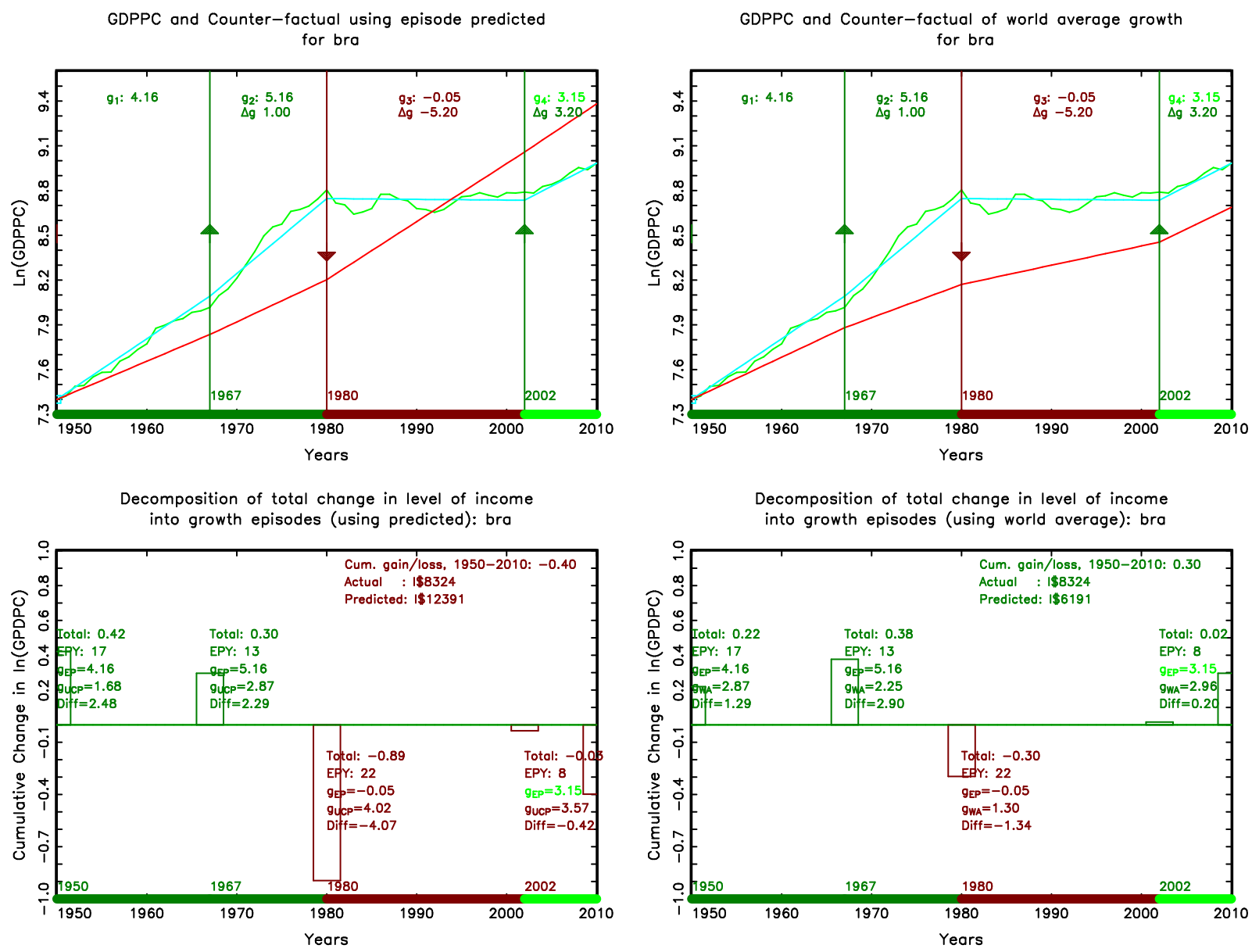

Source: Authors' calculations with PWT7.1 data.

The NPV calculations for the Brazilian episode illustrate the method and its variations. Our "base case" is the UCP counter-factual with a 5 percent discount rate. This gives a total loss of 7.5 trillion dollars. Intuitively, this loss is larger with a lower discount rate: 10 trillion at 3 
percent whereas it is only 3.9 trillion at 10 percent. As can be seen from the figure the UCP growth rate is in between the World Average of $1.3 \mathrm{ppa}$ and the No Change extrapolation of the previous period of 5.16 ppa. Obviously the loss (at 5 percent) using the World Average counter-factual is lower at "only" 2.1 trillion and is much larger using the No Change counterfactual, 10.46 trillion.

\begin{tabular}{|c|c|c|c|}
\hline \multirow[t]{2}{*}{ Discount rate: } & \multicolumn{3}{|c|}{ Counter-factual growth series (actual growth $=-0.05$ ) } \\
\hline & $\begin{array}{l}\text { Unconditional } \\
\text { Prediction }(\mathrm{g}=2.87)\end{array}$ & $\begin{array}{l}\text { World Average } \\
(\mathrm{g}=1.30)\end{array}$ & $\begin{array}{l}\text { No Change } \\
(g=5.16)\end{array}$ \\
\hline .05 & $-7,547$ & $-2,107$ & $-10,459$ \\
\hline .03 & $-10,062$ & $-2,786$ & $-13,991$ \\
\hline .10 & $-3,937$ & $-1,122$ & $-5,408$ \\
\hline
\end{tabular}

Figure 3 shows the same graphs for Ghana, which breaks Ghana's growth experience into five episodes (four breaks), 1955-1966 at .54 ppa, acceleration from 1966 to 1974 to 2.48 $\mathrm{ppa}^{6}$, a massive deceleration to $-3.81 \mathrm{ppa}$ from 1974 to 1983 , a recovery in 1983 but to growth of only $1.49 \mathrm{ppa}$, and finally an acceleration in 2002 to $4.07 \mathrm{ppa}$.

Ghana illustrates two aspects of our method. First, using the World Average counter-factual the growth acceleration in 1983 has a negative magnitude. The world average growth was 1.70 ppa from 1983 to 2002 so the growth acceleration in 1983, even though it is a massive acceleration in growth rates of $5.30 \mathrm{ppa}$ (from -3.81 to 1.49 ) is estimated to be of negative magnitude as the magnitude of growth of 1.49 is still below the world average growth of 1.70. Since the UCP allows for some persistence the UCP counter-factual is growth of only .10 ppa so the growth episode magnitude is positive.

\footnotetext{
${ }^{6}$ Ghana illustrates that our choice of a minimum 8 year period for growth episodes does force the timing of some breaks as visually it appears the recovery started in 1967 but our method cannot place breaks at 1967 and 1974.
} 


\begin{tabular}{|l|l|l|l|}
\hline $\begin{array}{l}\text { Table 3: NPV of the total magnitude of the gain/loss in output during the Ghanaian } \\
\text { growth episode, 1983-2002, in billions of dollars. }\end{array}$ \\
\hline \multirow{2}{*}{ Discount rate: } & \multicolumn{3}{|c|}{ Counter-factual growth series (actual growth=1.49) } \\
\cline { 2 - 4 } & $\begin{array}{l}\text { Unconditional } \\
\text { Prediction }(\mathrm{g}=0.10)\end{array}$ & $\begin{array}{l}\text { World Average } \\
(\mathrm{g}=1.70)\end{array}$ & $\begin{array}{l}\text { No Change } \\
(\mathrm{g}=-3.81)\end{array}$ \\
\hline .05 & 29.4 & -5.4 & 91.2 \\
\hline .03 & 37.7 & -6.95 & 115.9 \\
\hline .10 & 16.7 & -3.1 & 52.8 \\
\hline Source: Authors' calculations & \multicolumn{3}{l}{} \\
\hline
\end{tabular}

Figure 3: Illustrating the calculation of the magnitude of growth accelerations/ deceleration episodes, Ghana
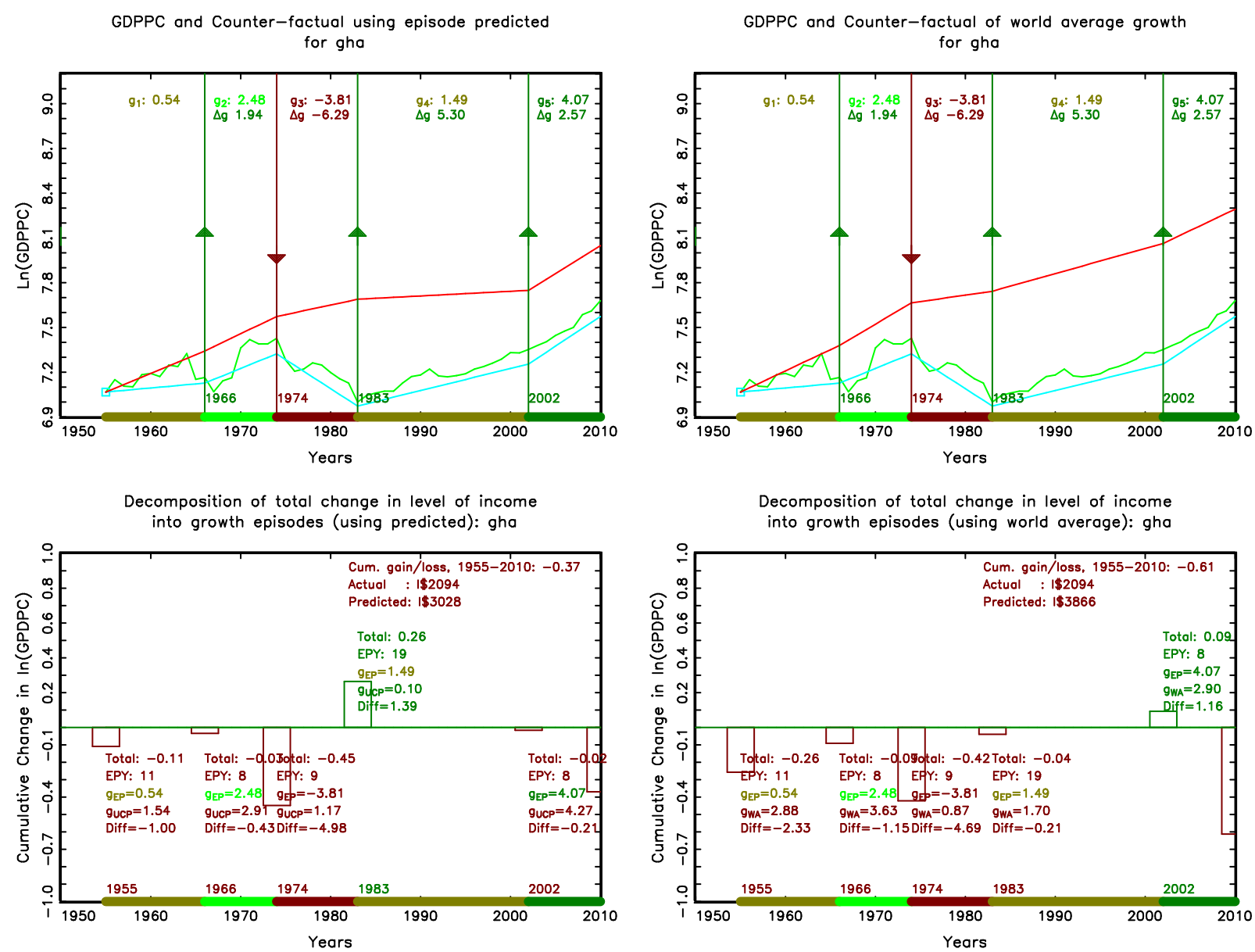

Source: Authors' calculations with PWT7.1 data.

The second aspect Ghana illustrates is that the No Change counter-factual tends to produce massive estimates of the gains from growth accelerations that are "recoveries" from negative growth. No Change extrapolates rapid decline into the future so the gain from the recovery even to slow or even less negative growth rates - produces large absolute estimates. Table 3 shows that using the same 5 percent discount rate the growth acceleration in 1983 either produced a 29 billion dollar gain with the UCP growth of .10, a 5.4 billion loss relative to the counter-factual with the World Average or a 91 billion dollar gain relative to the counterfactual that rapid decline continued. This is a major reason why we rarely use the No Change counter-factual as the data strongly reject that the projection of continued rapid decline is an empirically plausible counter-factual. 
The experience of Indonesia, a country that had a very large magnitude growth acceleration, is illustrated in Figure 4. The method produces three growth episodes with an acceleration in 1967 and a deceleration in 1996. In 1967 growth accelerated from 1.66 to 4.71 for the 1967 to 1996 period. Since the UCP growth over that period was 1.22 the growth episode flow magnitude is 1.01 (since the absolute magnitude of the vertical scale is constant across all countries this does slightly off the top of the figure, as indicated by the arrow). The very sharp recession during the East Asia Crisis followed by a modest recovery produces a deceleration to growth of 1.42 ppa from 1996 to 2010 of magnitude -.23 . The net result is that UCP predicted GDPPC was $\$ 1432$ whereas actual GDPPC in 2010 was $\$ 3966$.

Figure 4: Illustrating the calculation of the magnitude of growth accelerations/ deceleration episodes, Indonesia
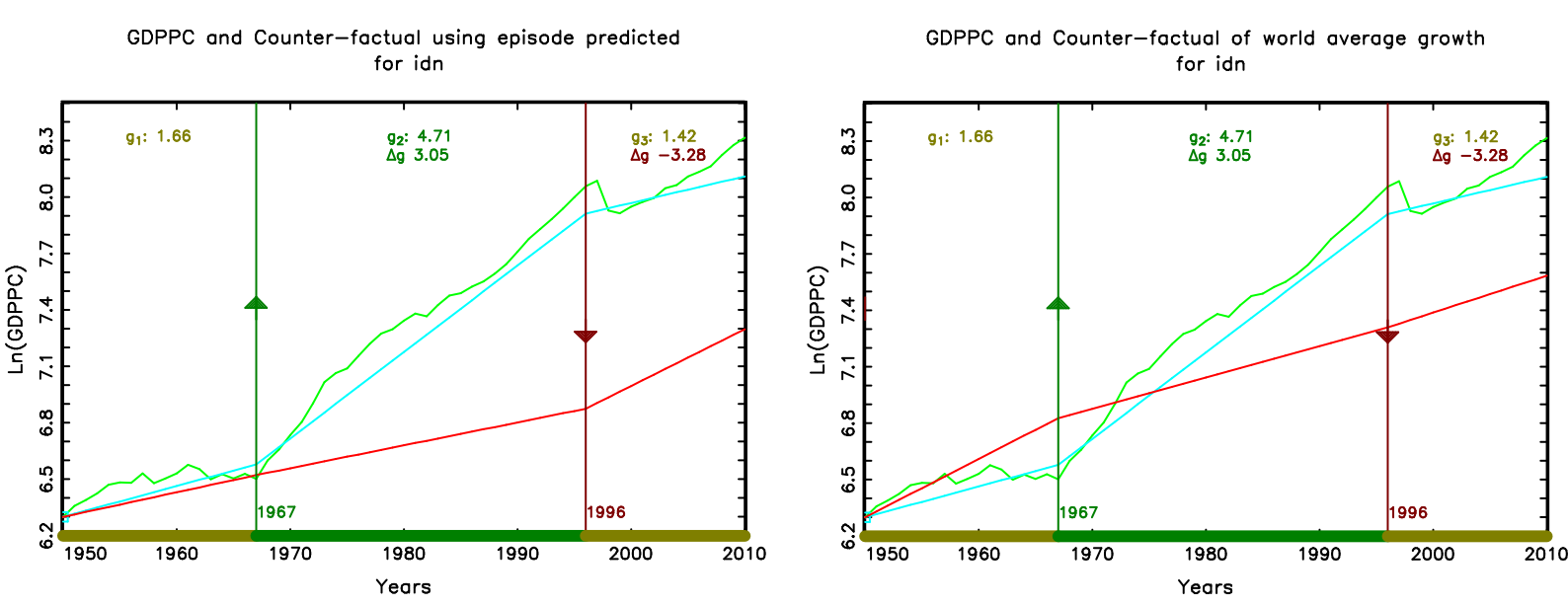

Decomposition of total change in level of income into growth episodes (using predicted): idn
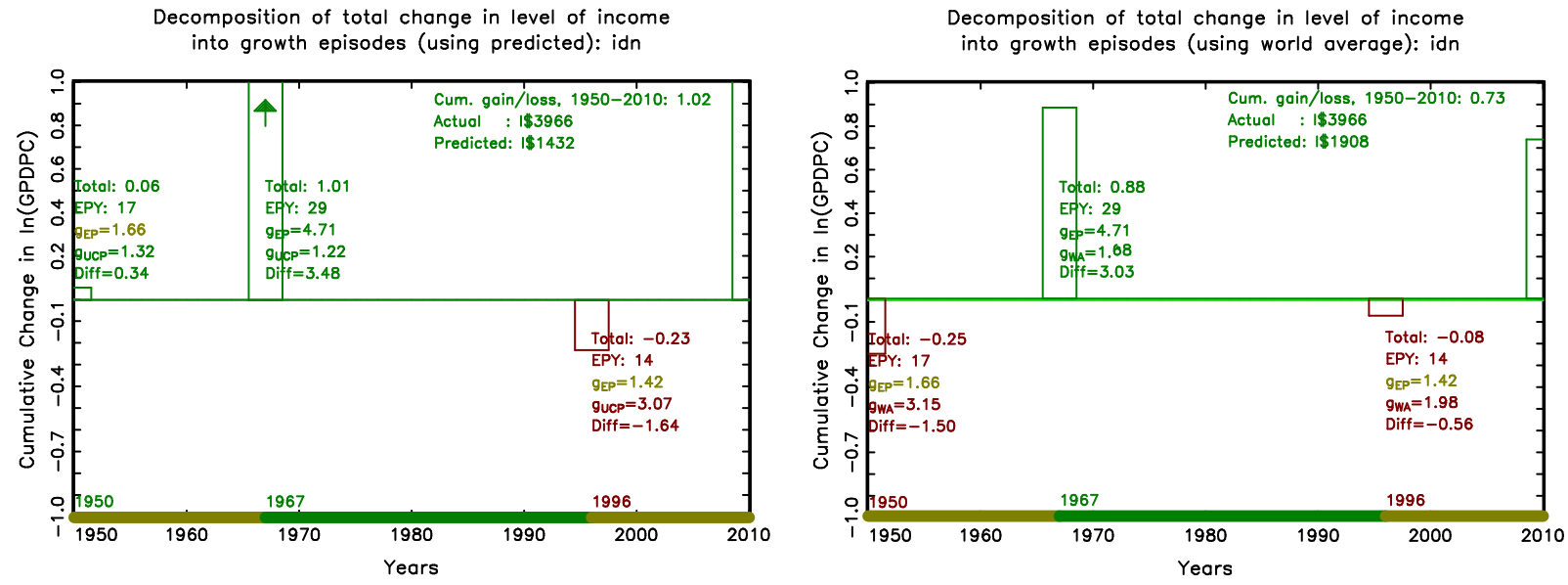

Source: Authors' calculations with PWT7.1 data.

Table 4 illustrates that the methods can agree as all three counter-factuals agree that the NPV of the gain from the growth acceleration in 1967 was around 1 trillion dollars. This is because over the long period of 29 years the unconditional predicted and world average growth are close (1.22 vs 1.68) so that the cumulative gain is 100 billion higher for the UCP and it just happens to have accelerated from previous growth of 1950 to 1967 also very near that magnitude. 
Table 4: NPV of the total magnitude of the gain in output during the Indonesian growth episode, 1967-1996, in billions of dollars.

\begin{tabular}{|l|l|l|l|}
\hline \multirow{2}{*}{ Discount rate: } & \multicolumn{3}{|c|}{ Counter-factual growth series (actual growth=1.49) } \\
\cline { 2 - 4 } & $\begin{array}{l}\text { Unconditional } \\
\text { Prediction }(\mathrm{g}=1.22)\end{array}$ & $\begin{array}{l}\text { World Average } \\
(\mathrm{g}=1.68)\end{array}$ & $\begin{array}{l}\text { No Change } \\
(\mathrm{g}=1.66)\end{array}$ \\
\hline .05 & 1,119 & 1,009 & 1,015 \\
\hline .03 & 1,648 & 1,489 & 1,498 \\
\hline .10 & 472 & 424 & 426 \\
\hline
\end{tabular}

\subsection{Comparing growth magnitude estimates across counter-factuals}

Figures 5 and 6 show the correlations of the different measures of episode magnitude (EM) using the different definitions, with each episode indicated by three letter country abbreviation and episode start date. The UCP and WA measures are highly correlated (.89) which is not surprising as the strong "regression to the mean" in the regression estimates of predicted growth implies that UCP as a weighted average of past growth and the period world average with more weight on world growth (see Table 1). The cluster of visual discrepancies which show small EM in UCP but large EM in WA, like the growth deceleration in Singapore in 1980 from a 7.94 ppa to $4.17 \mathrm{ppa}$, are illustrative. The UCP growth 1980 to 2010 was 4.50 ppa so the UCP magnitude of the growth deceleration to $4.17 \mathrm{ppa}$ is slightly negative (-.10) while the WA growth was 1.39 (as, by construction, it included no expectation of persistence) so the growth deceleration, even though it was slower than before, had large positive magnitude.

The lower correlation of the UCP and No Change method are illustrated in Figure $6 \mathrm{~b}$ which shows just positive UCP episodes. When growth accelerations are recoveries from highly negative growth rates the No Change counter-factual "predicts" the continuation of decline while the "unconditional prediction" usually predicts recovery to positive growth rates. So for instance, the growth acceleration in Iran in 1988 was from -7.20 ppa from 1976 to 1988 to 3.07 ppa from 1988 to 2010 . The No Change magnitude for the episode $1988-2010$ is 2.26 as it compares continuation of -7.20 versus 3.07 whereas UCP magnitude is only .314 as it compares the actual of 3.07 ppa to the UCP of 1.55 ppa (and WA is only .20 as it compares $3.07 \mathrm{ppa}$ to $2.15 \mathrm{ppa}$ ). Similarly, in Figure $6 \mathrm{c}$ growth accelerations to negative growth rates can appear as large positive magnitude in the No Change measure but are negative magnitude in UCP. For instance, Niger (NER) accelerated in 1987 from -5.16 ppa to -.48 ppa. This produces a large positive No Change magnitude (1.08) but a negative UCP magnitude (-.39) as UCP growth for Niger 1987-2010 was 1.30 ppa. 
Figure 50: UCP and WA episode magnitude, all

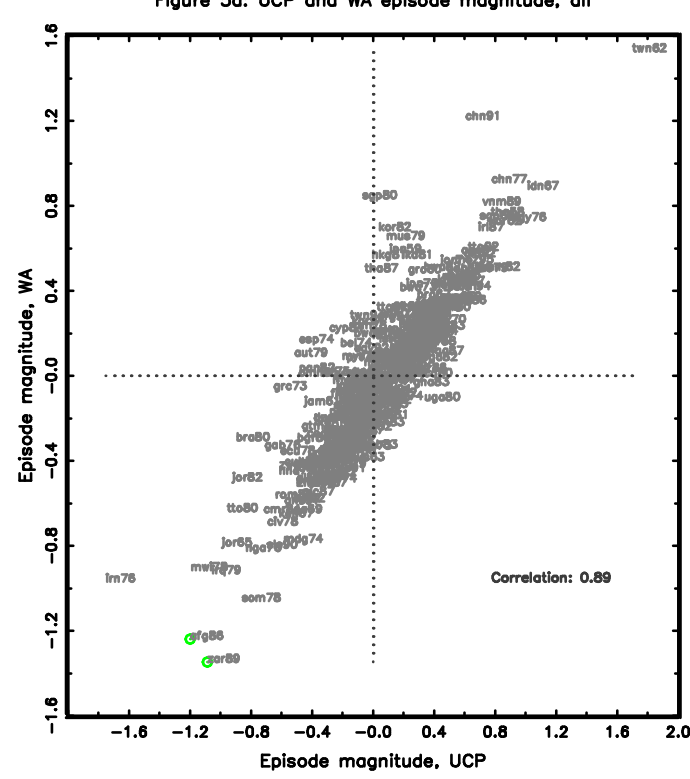

Figure 6a: UCP and NC episode magnitude, all

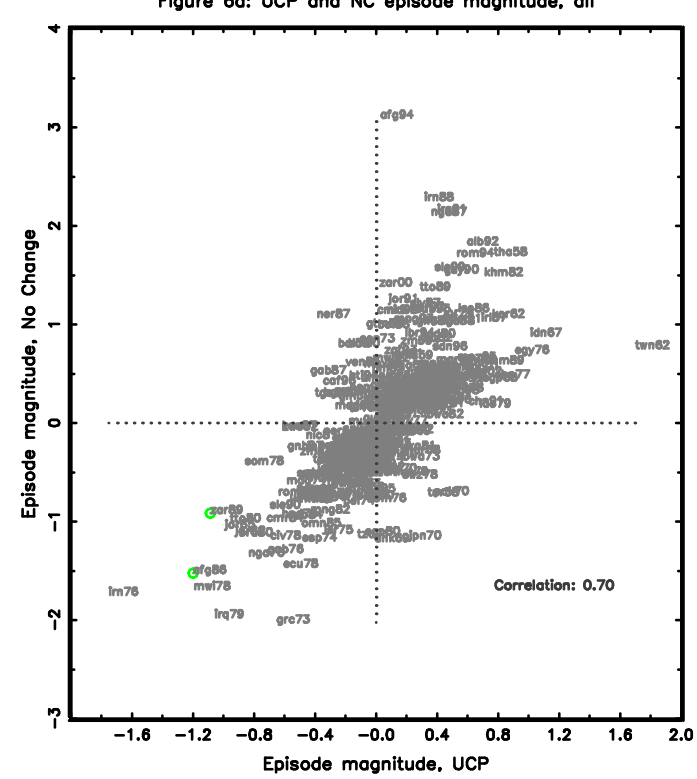

Figure 5b: UCP and WA episode magnitude, UCP occelerations

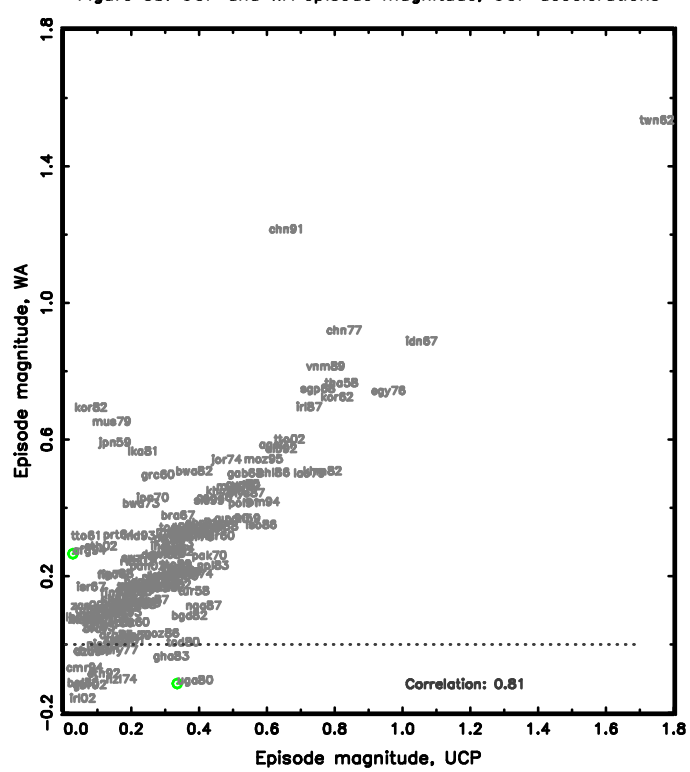

Figure 5c: UCP and WA episode magnitude, UCP decelerotions

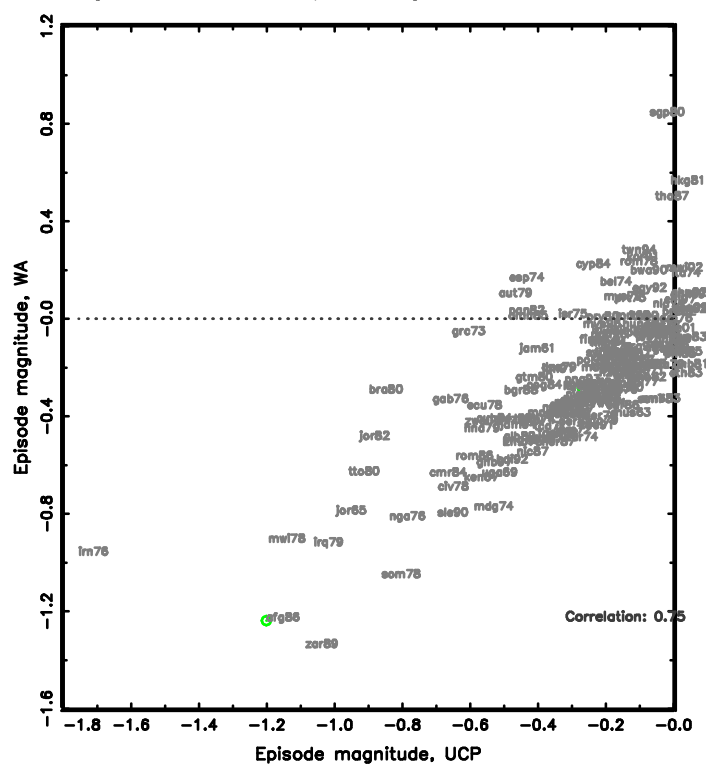

Figure 6b: UCP and NC episode magnitude, CP accelerations

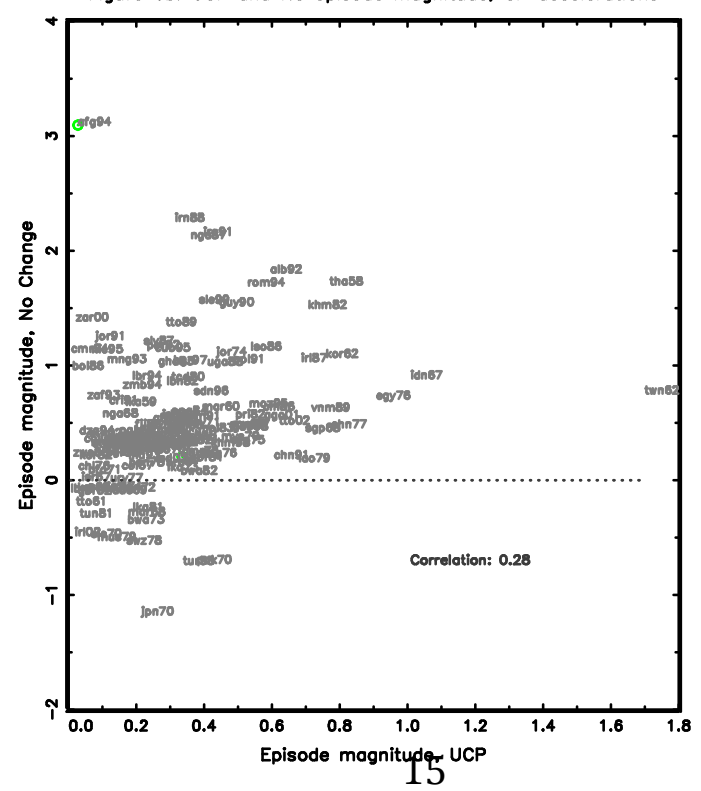

Figure 6c: UCP and NC episode magnitude, UCP decelerations

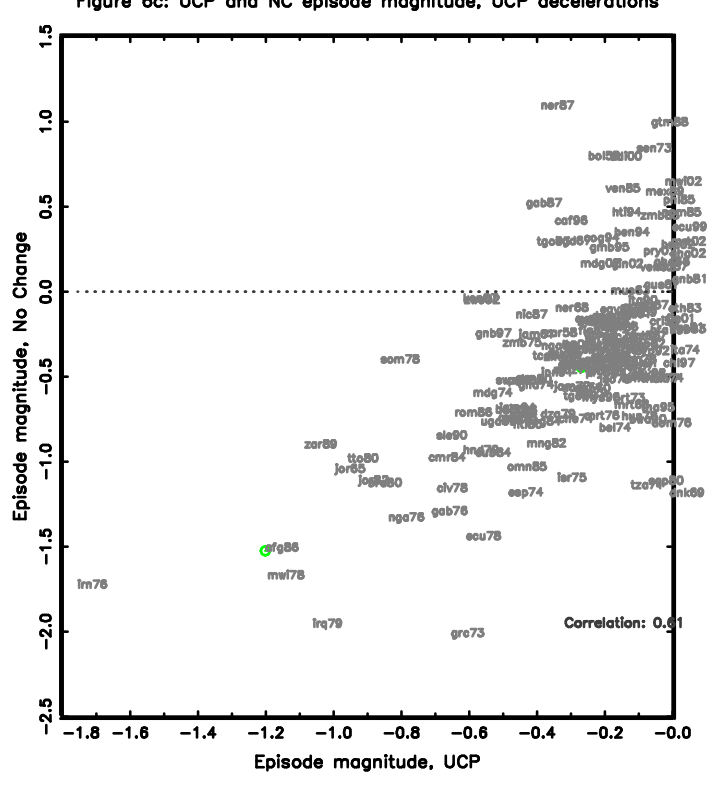




\subsection{Basic summary statistics on growth episode magnitudes}

Table 5 gives the summary statistics for each of the three counter-factuals, by all growth episodes (314) and accelerations and decelerations separately. The estimates of growth episode magnitude are differences in natural log units of changes in GDP per capita of end of episode actual versus counter-factual.

This table illustrates the importance of allowing for regression to the mean in the counterfactual. Our definition of an "acceleration" or "deceleration" is a Bai-Perron potential break that passes a threshold of magnitude in growth change. The median magnitude with the No Change counter-factual is .426 for accelerations and -.439 for decelerations as it presumes that, say, negative growth rates would stay negative rather than revert to, say, the world average. Once we allow for regression to the mean using either UCP or World Average the episode magnitudes are much smaller, UCP .206 and WA .187 for accelerations and UCP .245 and WA -.205 for decelerations.

\section{Table 5: Summary statistics of growth episode magnitude estimates (in units of natural log of GDP per capita)}

\begin{tabular}{|l|l|r|r|r|}
\hline \multirow{2}{*}{$\begin{array}{l}\text { Counter-factual } \\
\text { used }\end{array}$} & & \multicolumn{1}{l|}{ All } & Only accelerations & \multicolumn{1}{c|}{ Only decelerations } \\
\cline { 3 - 5 } & & 314 & 153 & 161 \\
\hline \multirow{2}{*}{$\begin{array}{l}\text { Unconditional } \\
\text { prediction }\end{array}$} & Median & -0.030 & 0.206 & -0.245 \\
\cline { 2 - 5 } & Std Dev & 0.394 & 0.291 & 0.310 \\
\hline \multirow{2}{*}{ World Average } & Median & 0.000 & 0.187 & -0.205 \\
\cline { 2 - 5 } & Std Dev & 0.380 & 0.310 & 0.332 \\
\hline \multirow{2}{*}{ No Change } & Median & -0.062 & 0.426 & -0.439 \\
\cline { 2 - 5 } & Std Dev & 0.709 & 0.486 & 0.390 \\
\hline
\end{tabular}

The second point evident in Table 5 is the large variability in the magnitude of growth episodes. Taking UCP estimates the median is .206 with a standard deviation of .291 so the "large" episodes are .497 or larger, implying gains in GDPPC of about 2/3 - larger than the gap between say Indonesia and an upper middle income country like Tunisia. Similarly, growth decelerations lead to some very large losses.

Figure 7 shows the histogram of the UCP estimates by magnitude into bins of size .2 . Within each column are shown all of the estimates (sorted from largest to smallest) with the country three letter abbreviation, year the episode began and the UCP magnitude estimate (where obviously the top of each column is near the upper threshold and bottom near the lower threshold). Growth accelerations are in green and decelerations in red.

Figure 8 shows the scatter-plot of UCP episode magnitude and initial GDP per capita (in absolute (8a) and natural log (8b)). 
Figure 7: Distribution of growth epsisode magnitudes, UCP

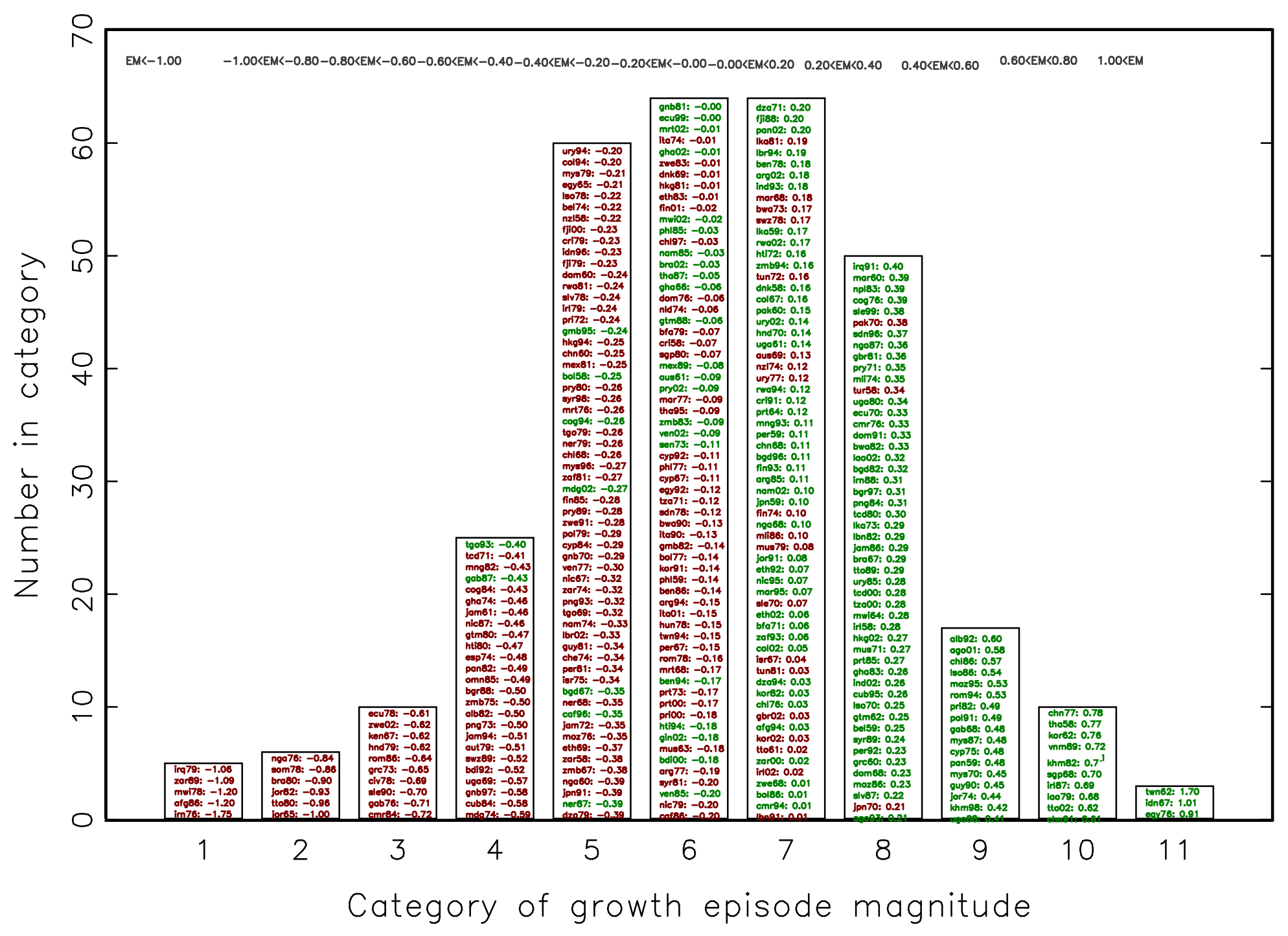


Figure 8a: Episode Magnitude (UCP) and initial per capita income

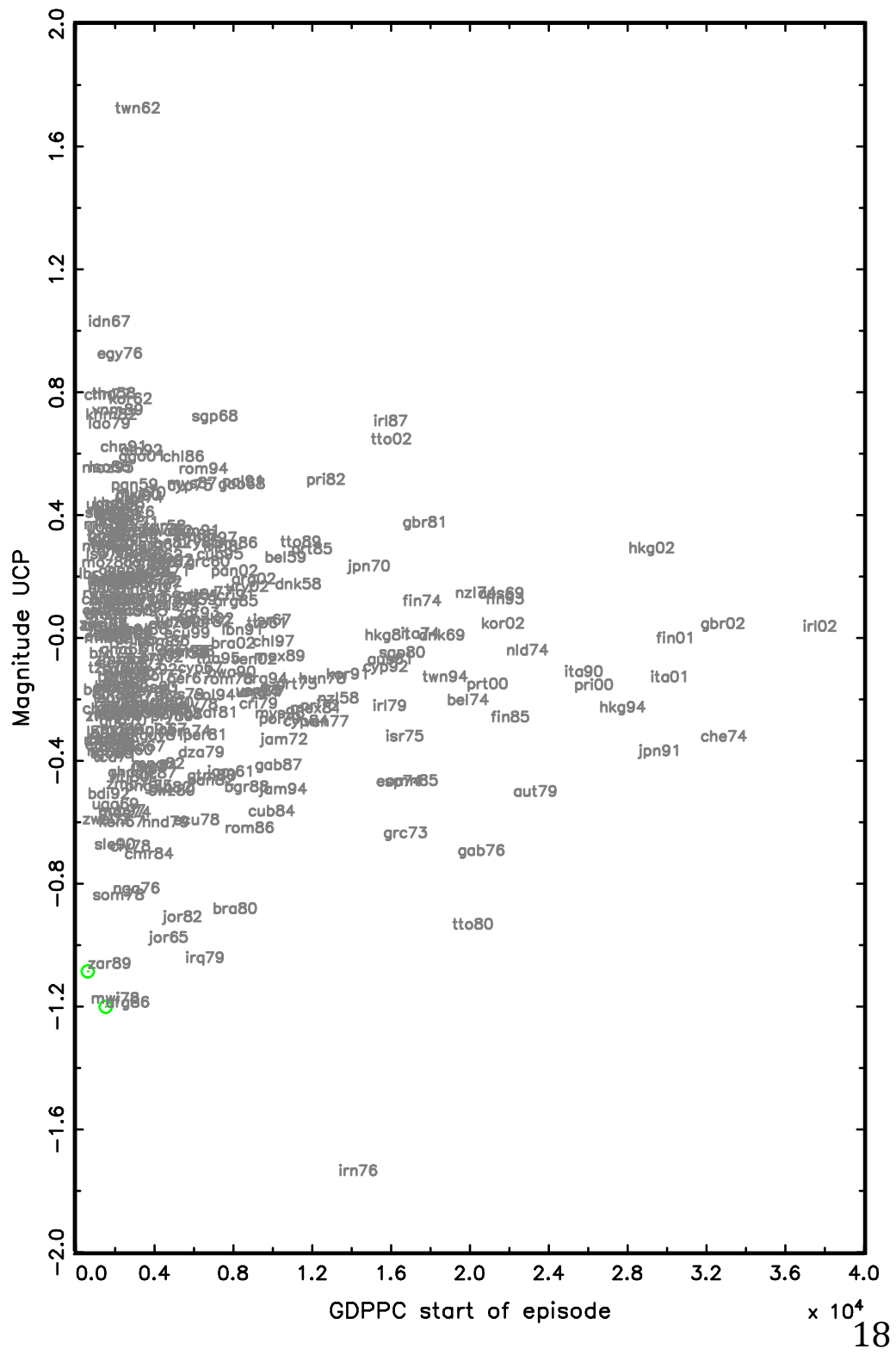

Figure 8b: Episode Magnitude (UCP) and initital per capita income

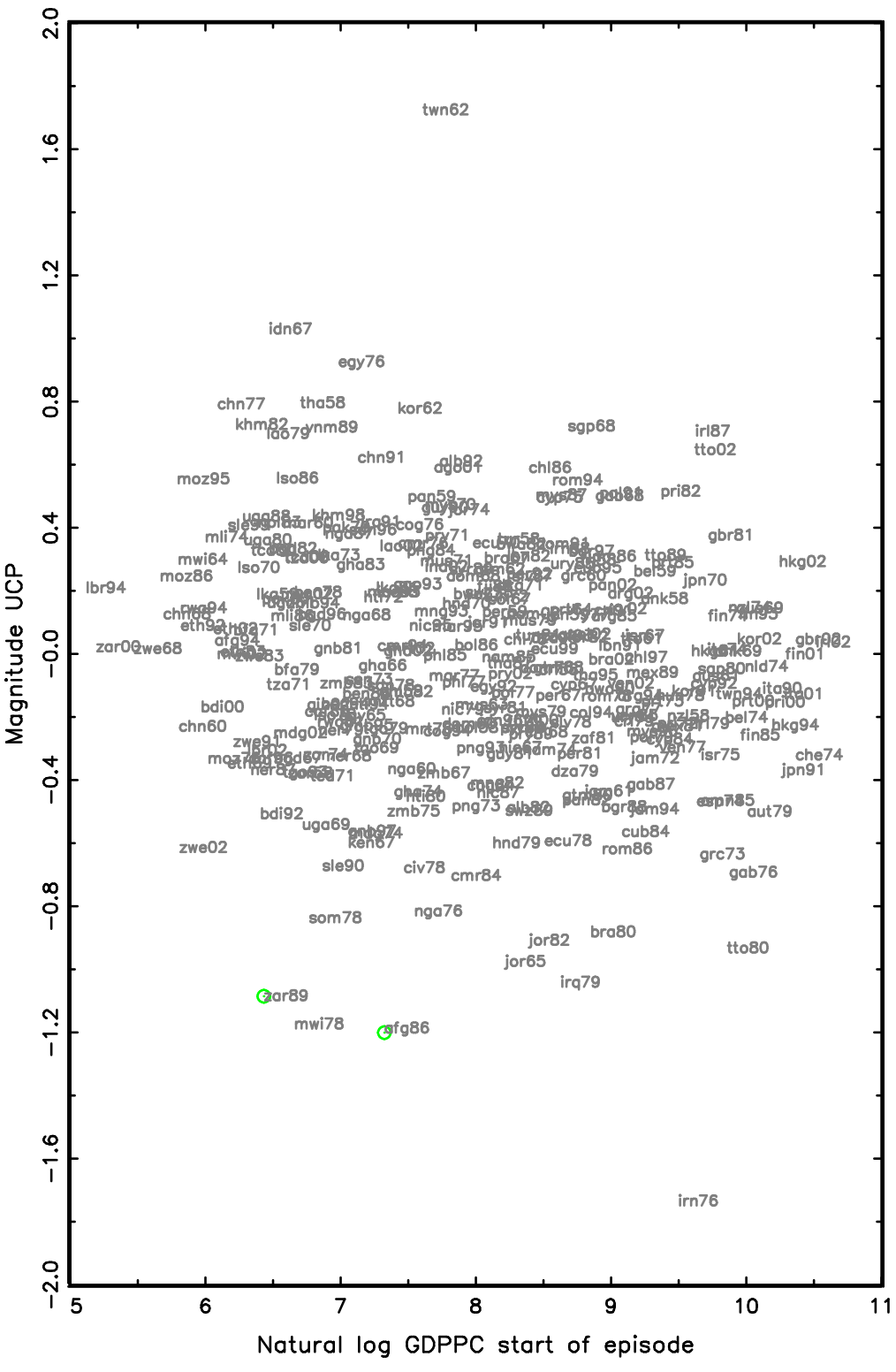




\section{Decomposing country growth experiences into episodes}

These estimates of the magnitude of growth episodes allow a different characterization of countries growth experiences. Appendix 2 provides a list of every country with any structural breaks with the timing and magnitude of each break.

The average growth rate is often inadequate as a representation of country's growth experience over an extended period. This is particularly true for countries with moderate growth. Rapid growth requires substantial time in episodes of rapid growth. Very slow growth requires substantial time in episodes of negative or slow growth. However there are two entirely different paths to "moderate" growth. Some countries with moderate growth spent most time in episodes of moderate growth. Other countries with moderate growth were "boom and bust" countries which had both large positive episodes and large negative episodes.

Table 6 classifies the 119 countries with at least one structural break into four categories based on the results of the calculations of the flow magnitude of episodes using the world average counter-factual.

There are 30 countries which are "high growth" defined as having their total gain in (In) GDPPC over their available data relative to world average growth of .4 units or higher. This implies a 2010 level of GDPPC 50 percent higher than had the country grown at the world average pace in each of its growth episodes. Strikingly, of these 29 all but six (Trinidad and Tobago, Panama, Dominican Republic, Oman, Egypt, and Botswana) are from the OECD/Eastern Europe or Asian regions. There are two clear regional concentrations of high growth, East/Southeast Asia (China, Taiwan, Singapore, Korea, Hong Kong, Japan, Vietnam, Malaysia, Laos, Thailand, Indonesia) and the periphery of Europe (Bulgaria, Spain, Greece, Ireland, Finland, Romania, Cyprus).

Table 6 divides the 46 countries with "middle growth" - which are countries than gained less than .4 but also did not lose relative to the world average more than -.4 - into "stable" and "boom and bust" countries. The 19 "boom and bust" countries are those whose largest single episode was bigger than .25 and whose smallest episode was loss of more than -.34. The rest are "stable." The average growth rate of the two categories of "middle growth" countries are exactly the same -2.0 ppa but the pattern of growth is entirely different.

The clear pattern is that nearly all of the "core" OECD countries fall into the "middle income, stable" category (Italy, Belgium, Denmark, Netherlands, Great Britain, Australia, New Zealand, Switzerland). Particularly if one includes the six countries with no structural breaks (USA, Canada, Sweden, Norway, France, Germany) it is clear that the (old) OECD countries were nearly all very stable growers and the periphery of Europe was mostly rapid or stable (Albania is the only exception). 


\begin{tabular}{|c|c|c|c|c|c|c|}
\hline & $\mathrm{N}$ & $\begin{array}{l}\text { Region/Cou } \\
\text { most to leas } \\
\text { Lanka is slo }\end{array}$ & $\begin{array}{l}\text { try (countries are listed within their region from } \\
\text { rapid growth within that category (e.g. so Sri } \\
\text { erer than Indonesia but faster than Pakistan) }\end{array}$ & $\begin{array}{l}\text { Median } \\
\text { size of } \\
\text { largest }\end{array}$ & $\begin{array}{r}\text { Median } \\
\text { size of } \\
\text { smallest }\end{array}$ & $\begin{array}{l}\text { Average } \\
\text { rate of } \\
\text { growth }\end{array}$ \\
\hline \multirow{5}{*}{$\begin{array}{l}\text { High growth } \\
\text { (total above } \\
\text {.40) }\end{array}$} & \multirow[t]{5}{*}{29} & OECD/EE & $\begin{array}{l}\text { BGR, ESP,GRC,AUT,IRL, ISR, FIN, ROM, } \\
\text { CYP, }\end{array}$ & \multirow[t]{5}{*}{0.621} & \multirow[t]{5}{*}{-0.104} & \multirow[t]{5}{*}{0.033} \\
\hline & & ASIA & $\begin{array}{l}\text { CHN,TWN,SGP,KOR,HKG,JPN,VNM,MYS, } \\
\text { LAO,THA, IND,IDN, LKA, }\end{array}$ & & & \\
\hline & & LAC & TTO, PAN, DOM, & & & \\
\hline & & MENA & OMN, EGY, & & & \\
\hline & & SSA & BWA & & & \\
\hline \multirow{5}{*}{$\begin{array}{l}\text { Middle } \\
\text { growth, not } \\
\text { boom and } \\
\text { bust }\end{array}$} & \multirow[t]{5}{*}{27} & OECD/EE & $\begin{array}{l}\text { ITA,POL,BEL, DNK, NLD, HUN,GBR,AUS, } \\
\text { NZL, CHE }\end{array}$ & \multirow[t]{5}{*}{0.175} & \multirow[t]{5}{*}{-0.194} & \multirow[t]{5}{*}{0.020} \\
\hline & & ASIA & PAK,NPL,PHL,FJI & & & \\
\hline & & LAC & MEX, CRI, COL, ARG & & & \\
\hline & & MENA & TUN, TUR, SYR, DZA & & & \\
\hline & & SSA & TZA, SDN, LSO, NAM, MLI & & & \\
\hline \multirow{5}{*}{$\begin{array}{l}\text { Middle } \\
\text { growth, boom } \\
\text { and bust } \\
\text { (max>.25, } \\
\min <-.34)\end{array}$} & \multirow[t]{5}{*}{19} & OECD/EE & ALB & \multirow[t]{5}{*}{0.492} & \multirow[t]{5}{*}{-0.424} & \multirow[t]{5}{*}{0.020} \\
\hline & & ASIA & MNG,KHM & & & \\
\hline & & LAC & BRA, CHL, GUY, ECU & & & \\
\hline & & MENA & MAR, IRN, IRQ & & & \\
\hline & & SSA & $\begin{array}{l}\text { MRT, SWZ,AGO, MUS, MOZ,COG, } \\
\text { GAB,SLE,TCD }\end{array}$ & & & \\
\hline \multirow{5}{*}{$\begin{array}{l}\text { Low growth } \\
\text { (total less } \\
\text { than }-.40 \text { ) }\end{array}$} & \multirow[t]{5}{*}{43} & OECD/EE & & \multirow[t]{5}{*}{0.127} & \multirow[t]{5}{*}{-0.544} & \multirow[t]{5}{*}{0.004} \\
\hline & & ASIA & PNG, BGD,AFG & & & \\
\hline & & LAC & $\begin{array}{l}\text { PER, SLV, GTM, URY, PRY, JAM, VEN, HND, } \\
\text { HTI,BOL, NIC }\end{array}$ & & & \\
\hline & & MENA & JOR, LBN, & & & \\
\hline & & SSA & $\begin{array}{l}\text { BFA,ZAF,RWA,MWI,BEN,ETH,CIV,CMR, BDI, } \\
\text { GHA,UGA, MB,NGA, GNB,SEN,TGO, } \\
\text { GIN,ZMB, KEN,ZWE,SOM,MDG,CAF, } \\
\text { NER,LBR,ZAR }\end{array}$ & & & \\
\hline
\end{tabular}

The "boom and bust" countries are an interesting collection. Some, like Brazil and Chile are middle income countries that experienced either a large slow down (Brazil 1980-2002) or had a sharp crisis (Chile's episode magnitude from 1968 to 1976 was -.308) but also extended booms with Chile's episode from 1986 to 1997 was a gain of .493. Others are natural resource countries like Ecuador, Congo, Gabon with booms and busts. Others conflict countries like Iraq, Sierra Leone, Mozambique, Cambodia with declines and recoveries. Finally others, like Guyana and Mauritius have extended periods of decline followed by sustained growth. 
Figure 9: The trajectories of output per capita of middle growth countries comparing steady growers (Colombia, Turkey) with "boom and bust" (Chile, Iran)

Middle Growth, Steady

GDPPC and Counter-factual of world average growth for col

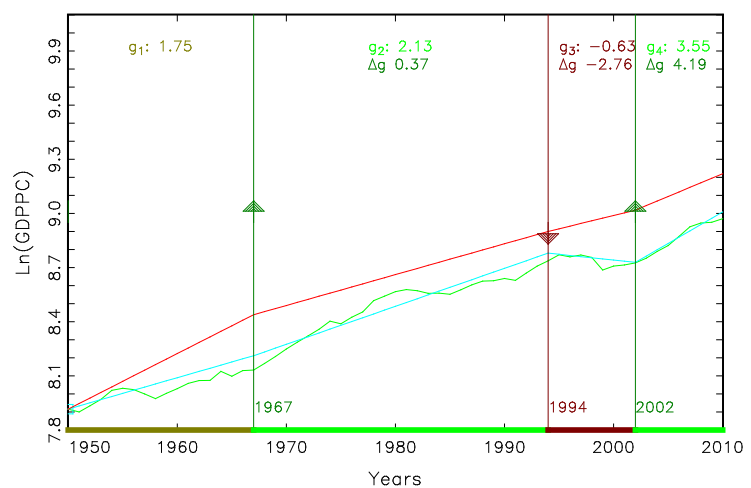

GDPPC and Counter-factual of world average growth for tur

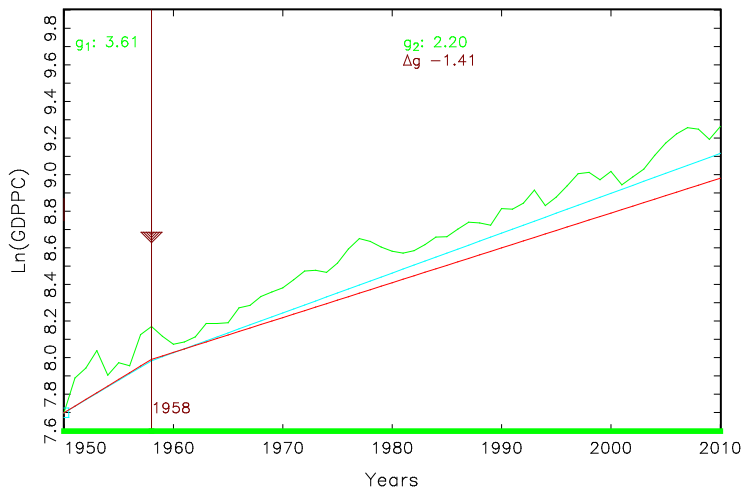

Middle Growth, Boom and Bust

GDPPC and Counter-factual of world average growth for chl

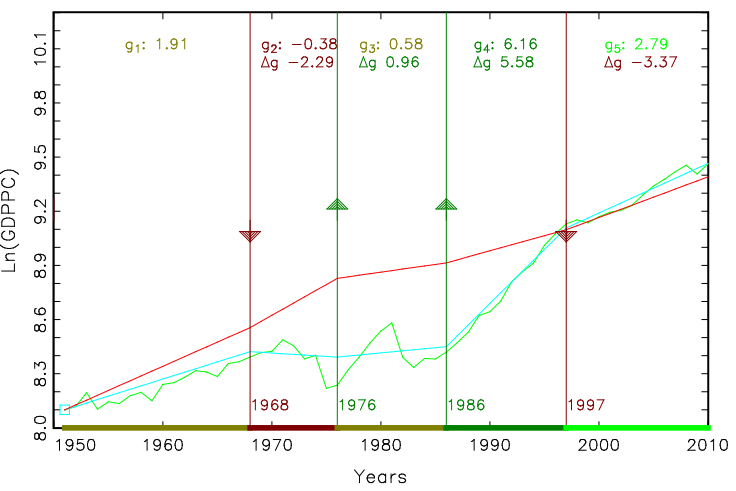

GDPPC and Counter-factual of world average growth for irn

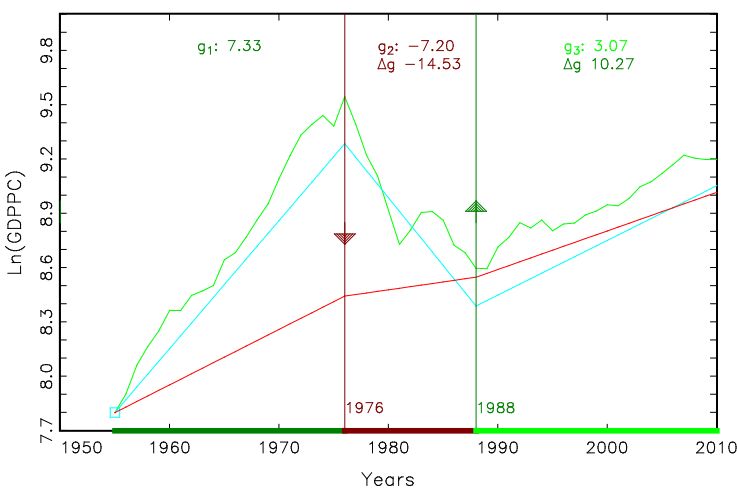

The "low growth" countries are dominated by Sub Saharan Africa (26 of 43) and LAC (11 of 43). One interesting feature of the growth episodes is that 11 of the 26 SSA countries in the "low growth" category have growth accelerations as their most recent episode. Figure 8 illustrates that some recoveries were starting from a very low base after a long period of decline and countries have yet to achieve the pre-growth peak. Zambia for instance had negative growth episodes from 1967-75, 1975-83, and 1983-94 (a growth acceleration to negative growth) and hence even growth of 3.57 ppa since 1994 has yet to being Zambia back to the 1967 peak. Ethiopia, in contrast, had less negative growth from 1969 to 1992 and then modest positive growth 1992 to 2002 so the post 2002 acceleration to rapid growth has brought it above the 1969 peak. 
Figure 10: Comparing growth accelerations that are recoveries that push past the previous all time peak GDPPC (e.g. Ethopia 2002-2010) versus episodes that recover from previous contractions but not (yet) past a previous peak (e.g. Zambia 1994-2010)

\section{Recovery growth, past previous} -..-

GDPPC and Counter-factual of world average growth for eth

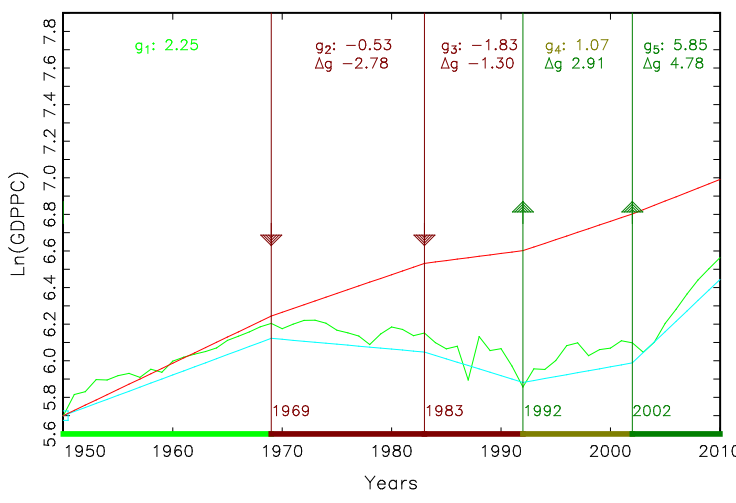

GDPPC and Counter-factual of world average growth

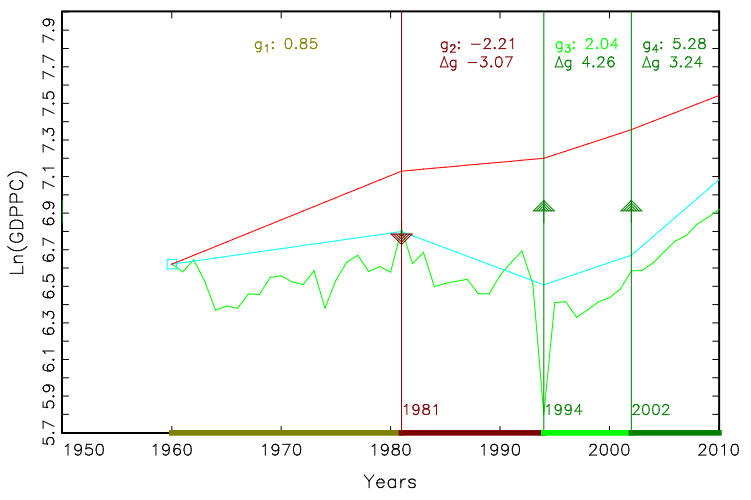

Recovery growth, not yet to peak

GDPPC and Counter-factual of world average growth for $z m b$

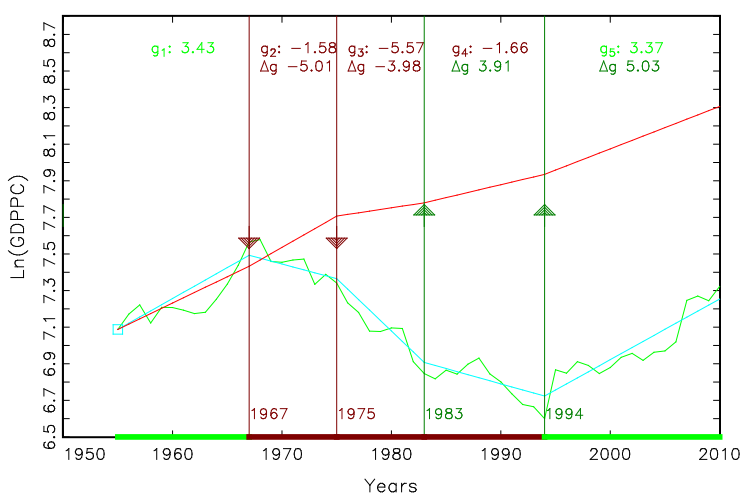

GDPPC and Counter-factual of world average growth for mwi

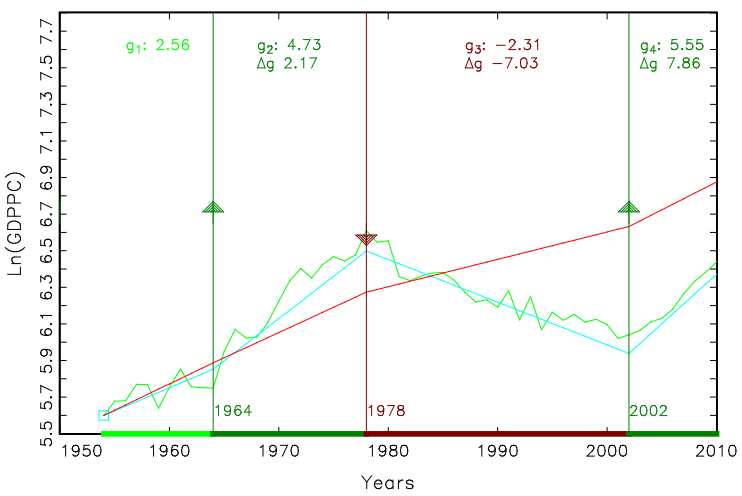

4. Accelerations: take-offs and recoveries

We are interested in the question of "what exactly" causes growth accelerations but before doing empirical investigation into the empirical correlates (and ultimately causes) we first want to classify the 153 identified growth accelerations in our 125 countries by two criteria: magnitude and whether the acceleration was a "recovery" from a previous fall and whether the recovery reached the previous peak or not.

The first distinction is that 31 of the growth acceleration episodes have negative episode magnitude, of which 22 are recoveries and of those 16 are recoveries that fail to reach the previous peak. These are often "accelerations" of the "even dead cats bounce" sort in which a sharp fall is followed by either a less sharp fall (e.g. Venezuela a fall of -3.39 ppa from 1977-85 was followed by an episode from 1985-2002 with growth of -.07) or a sharp fall is followed by a modest growth rate (e.g. Haiti's GDPPC fell from 1980-94 then had growth of .55 ppa from 1994 to 2010). While it is conceivable that the same causal factors stop output declines as cause output accelerations of already positive growth rates, this is a hypothesis to be tested, not assumed. 
The second distinction is between the 39 episodes which are "recoveries not reaching the peak" (including the 16 mentioned above that were of negative magnitude) and all others. These are often countries bouncing back from the end of an armed conflict (e.g. Cambodia 1982, Iraq 1991, Uganda 1980, Lebanon 1982, Liberia 1994, Rwanda 1994) or achieving political stability (not necessarily democratically) after political turmoil (Iran 1988, Ghana 1983, Zaire 2000, Chile 1976). Again, the causes of these "recovery accelerations" are unlikely to be the same as those of economies accelerating from already positive growth or already at a historic high GDPPC.

That leaves 99 growth accelerations in which the level of GDPPC was higher at the end than at the beginning of the episode. There are two possible divisions of these. 60 are not "recoveries" in that GDPPC was already more than $85 \%$ of its previous peak when the episode began whereas 39 are "recoveries" in which GDPPC at the beginning of the episode was less than $85 \%$ of the previous peak.

Alternatively, episodes classified by size produces 29 "large" UCP magnitude episodes more than 406 (implying GDPPC was more than 50 percent higher than predicted at the end of the episode), 33 episodes are "medium" in that GDPPC was more than 25 percent larger than predicted (but less than 50 percent), and 37 episodes are "small" in that the UCP episode magnitude was positive but less than a 25 percent gain in GDPPC.

Of 18 large episodes non-recovery episodes (the large, non-recovery plus Thailand 19581987) 10 are the well-studied and prominent East Asian growth episodes mostly with the common dating (e.g. Indonesia 1967, Korea 1962, Taiwan 1962, Vietnam 1989, Singapore 1968, Thailand 1958$)^{7}$ particularly when multiple episodes of accelerations are combined (China 1977-91, 1991-2010, Malaysia 1970-79, 1987-1996) ${ }^{8}$. The rest are a mix: Egypt 1976-992, Ireland 1987-2002, Chile 1986-1997, Puerto Rico 1982-2000, Panama 19591982, Gabon 1968-1976, Cambodia 1998-2010 and Laos 1979-2002.

\footnotetext{
${ }^{7}$ Hausmann et al. (2005) table 2.3 classifies their 69 growth accelerations by whether the accelerations are sustained with above average growth in the ten years after the seven years that defined the acceleration. Most of the 18 "large non-recoveries" in Table 6 dated before 1986 (the cut-off for having data episode plus 17 years in HPR) are identified with acceleration years either the same or within one year.

${ }^{8}$ For instance the Growth Commission headed by Michael Spence identified 13 country/periods of high growth including (alphabetically): Botswana, Brazil, China, Hong Kong, Indonesia, Japan, Korea, Malaysia, Malta, Oman, Singapore, Taiwan, Thailand. The countries not in our list are often because the rapid growth began with the data so is not an "acceleration" or "deceleration" (e.g. Botswana, Hong Kong, Japan, Oman) or excluded due to small size (Malta).
} 
Trillions Gained and Lost: Estimating the Magnitude of Growth Episodes Table 7: Classification of all growth accelerations by the episode UCP flow magnitude (large, medium, small, negative) and whether the acceleration was a recovery and whether the recovery surpassed previous peak GDPPC

\begin{tabular}{|c|c|c|c|c|c|c|c|c|c|c|c|c|c|c|c|}
\hline \multirow{2}{*}{$\begin{array}{l}\text { Total } \\
153\end{array}$} & \multicolumn{5}{|c|}{ Non-recoveries } & \multicolumn{5}{|c|}{ Recoveries passing the peak } & \multicolumn{5}{|c|}{ Recoveries not passing the peak } \\
\hline & \multicolumn{5}{|c|}{69} & \multicolumn{5}{|c|}{45} & \multicolumn{5}{|c|}{39} \\
\hline & Country & $\begin{array}{l}\text { Years of } \\
\text { episode }\end{array}$ & $\begin{array}{l}\text { Percent } \\
\text { gain in } \\
\text { GDPPC } \\
\text { during } \\
\text { episode } \\
\text { over } \\
\text { UCP gain }\end{array}$ & $\begin{array}{l}\text { Percent } \\
\text { gain in } \\
\text { GDPPC } \\
\text { during } \\
\text { episode } \\
\text { (absolute) }\end{array}$ & $\begin{array}{l}\text { Ratio of } \\
\text { episode } \\
\text { end to } \\
\text { previous } \\
\text { peak }\end{array}$ & Country & $\begin{array}{l}\text { Years of } \\
\text { episode }\end{array}$ & $\begin{array}{l}\text { Percent } \\
\text { gain in } \\
\text { GDPPC } \\
\text { during } \\
\text { episode } \\
\text { over } \\
\text { UCP gain }\end{array}$ & $\begin{array}{l}\text { Percent } \\
\text { gain in } \\
\text { GDPPC } \\
\text { during } \\
\text { episode } \\
\text { (absolute) }\end{array}$ & $\begin{array}{l}\text { Ratio of } \\
\text { episode } \\
\text { end to } \\
\text { previous } \\
\text { peak }\end{array}$ & Country & $\begin{array}{l}\text { Years of } \\
\text { episode }\end{array}$ & $\begin{array}{l}\text { Percent } \\
\text { gain in } \\
\text { GDPPC } \\
\text { during } \\
\text { episode } \\
\text { over } \\
\text { UCP gain }\end{array}$ & $\begin{array}{l}\text { Percent } \\
\text { gain in } \\
\text { GDPPC } \\
\text { during } \\
\text { episode } \\
\text { (absolute) }\end{array}$ & $\begin{array}{l}\text { Ratio of } \\
\text { episode } \\
\text { end to } \\
\text { previous } \\
\text { peak }\end{array}$ \\
\hline \multirow[t]{17}{*}{ Large } & TWN & $62-94$ & $447.1 \%$ & $776.1 \%$ & 8.8 & THA & $58-87$ & $116.2 \%$ & $299.1 \%$ & 3.22 & KHM & $82-98$ & $102.6 \%$ & $76.0 \%$ & 0.85 \\
\hline & IDN & $67-96$ & $174.5 \%$ & $374.1 \%$ & 4.4 & TTO & $02-10$ & $86.2 \%$ & $105.3 \%$ & 1.61 & & & & & \\
\hline & EGY & $76-92$ & $148.0 \%$ & $165.3 \%$ & 2.3 & ALB & $92-10$ & $81.3 \%$ & $190.6 \%$ & 1.73 & & & & & \\
\hline & $\mathrm{CHN}$ & $77-91$ & $117.2 \%$ & $181.9 \%$ & 2.8 & AGO & 01-10 & $78.1 \%$ & $133.2 \%$ & 1.96 & & & & & \\
\hline & KOR & $62-82$ & $113.4 \%$ & $241.0 \%$ & 3.3 & LSO & $86-10$ & $71.0 \%$ & $104.6 \%$ & 1.55 & & & & & \\
\hline & VNM & $89-10$ & $104.8 \%$ & $228.4 \%$ & 3.3 & $\mathrm{MOZ}$ & $95-10$ & $70.4 \%$ & $139.5 \%$ & 1.90 & & & & & \\
\hline & SGP & $68-80$ & $100.9 \%$ & $161.4 \%$ & 2.6 & ROM & $94-10$ & $69.4 \%$ & $79.2 \%$ & 1.24 & & & & & \\
\hline & IRL & $87-02$ & $98.6 \%$ & $144.0 \%$ & 2.4 & POL & $91-10$ & $62.6 \%$ & $124.5 \%$ & 1.80 & & & & & \\
\hline & LAO & $79-02$ & $97.0 \%$ & $130.8 \%$ & 2.2 & CYP & $75-84$ & $61.5 \%$ & $125.5 \%$ & 1.53 & & & & & \\
\hline & $\mathrm{CHN}$ & $91-10$ & $83.3 \%$ & $473.0 \%$ & 5.7 & GUY & $90-10$ & $56.1 \%$ & $124.5 \%$ & 1.33 & & & & & \\
\hline & $\mathrm{CHL}$ & $86-97$ & $77.4 \%$ & $103.4 \%$ & 1.7 & JOR & $74-82$ & $54.7 \%$ & $80.6 \%$ & 1.19 & & & & & \\
\hline & PRI & $82-00$ & $63.6 \%$ & $116.1 \%$ & 2.0 & UGA & $88-10$ & $50.7 \%$ & $108.2 \%$ & 1.34 & & & & & \\
\hline & GAB & $68-76$ & $62.0 \%$ & $168.5 \%$ & 2.7 & & & & & & & & & & \\
\hline & MYS & $87-96$ & $62.0 \%$ & $96.2 \%$ & 1.8 & & & & & & & & & & \\
\hline & PAN & $59-82$ & $60.9 \%$ & $214.4 \%$ & 2.8 & & & & & & & & & & \\
\hline & MYS & $70-79$ & $56.9 \%$ & $95.2 \%$ & 2.0 & & & & & & & & & & \\
\hline & KHM & $98-10$ & $52.1 \%$ & $113.3 \%$ & 1.8 & & & & & & & & & & \\
\hline 30 & 17 & & & & & 12 & & & & & 1 & & & & \\
\hline \multirow[t]{3}{*}{ Medium } & NPL & $83-10$ & $48.3 \%$ & $92.8 \%$ & 1.8 & MAR & $60-68$ & $48.3 \%$ & $86.7 \%$ & 1.59 & IRQ & $91-10$ & $49.0 \%$ & $255.6 \%$ & 0.81 \\
\hline & COG & $76-84$ & $48.0 \%$ & $69.7 \%$ & 1.5 & SDN & $96-10$ & $44.7 \%$ & $95.6 \%$ & 1.59 & SLE & $99-10$ & $46.9 \%$ & $96.2 \%$ & 0.92 \\
\hline & GBR & $81-02$ & $43.0 \%$ & $91.2 \%$ & 1.9 & MLI & $74-86$ & $41.7 \%$ & $62.7 \%$ & 1.24 & NGA & $87-10$ & $43.2 \%$ & $73.8 \%$ & 0.89 \\
\hline
\end{tabular}


Trillions Gained and Lost: Estimating the Magnitude of Growth Episodes

\begin{tabular}{|c|c|c|c|c|c|c|c|c|c|c|c|c|c|c|c|}
\hline & PRY & $71-80$ & $42.2 \%$ & $74.2 \%$ & 1.7 & BGR & $97-10$ & $36.3 \%$ & $78.5 \%$ & 1.40 & UGA & $80-88$ & $39.8 \%$ & $-1.2 \%$ & 0.64 \\
\hline & ECU & $70-78$ & $39.7 \%$ & $69.5 \%$ & 1.7 & PNG & $84-93$ & $35.7 \%$ & $44.7 \%$ & 1.03 & BGD & $82-96$ & $37.5 \%$ & $24.3 \%$ & 0.94 \\
\hline & CMR & $76-84$ & $39.7 \%$ & $47.6 \%$ & 1.4 & URY & $85-94$ & $32.9 \%$ & $56.8 \%$ & 1.15 & IRN & $88-10$ & $36.8 \%$ & $82.7 \%$ & 0.71 \\
\hline & DOM & $91-10$ & $39.4 \%$ & $125.9 \%$ & 2.1 & TCD & $00-10$ & $32.8 \%$ & $83.3 \%$ & 1.47 & TCD & $80-00$ & $35.6 \%$ & $28.3 \%$ & 0.80 \\
\hline & BWA & $82-90$ & $39.2 \%$ & $92.1 \%$ & 1.9 & MUS & $71-79$ & $31.3 \%$ & $85.5 \%$ & 1.27 & LBN & $82-91$ & $33.5 \%$ & $96.9 \%$ & 0.58 \\
\hline & LAO & $02-10$ & $37.8 \%$ & $79.0 \%$ & 1.8 & CUB & $95-10$ & $29.1 \%$ & $87.4 \%$ & 1.31 & JAM & $86-94$ & $33.5 \%$ & $36.8 \%$ & 1.00 \\
\hline & LKA & $73-81$ & $33.8 \%$ & $54.0 \%$ & 1.5 & SYR & $89-98$ & $27.7 \%$ & $46.7 \%$ & 1.14 & TTO & $89-02$ & $33.4 \%$ & $44.1 \%$ & 0.78 \\
\hline & BRA & $67-80$ & $33.4 \%$ & $119.9 \%$ & 2.2 & PER & $92-10$ & $26.0 \%$ & $98.1 \%$ & 1.34 & GHA & $83-02$ & $30.2 \%$ & $42.3 \%$ & 0.93 \\
\hline & TZA & $00-10$ & $32.2 \%$ & $62.6 \%$ & 1.6 & & & & & & $\mathrm{MOZ}$ & $86-95$ & $25.3 \%$ & $13.1 \%$ & 0.79 \\
\hline & $\mathrm{MWI}$ & $64-78$ & $31.9 \%$ & $136.6 \%$ & 2.1 & & & & & & & & & & \\
\hline & $\mathrm{IRL}$ & $58-79$ & $31.9 \%$ & $132.2 \%$ & 2.2 & & & & & & & & & & \\
\hline & HKG & $02-10$ & $31.4 \%$ & $38.0 \%$ & 1.4 & & & & & & & & & & \\
\hline & PRT & $85-00$ & $30.5 \%$ & $81.3 \%$ & 1.7 & & & & & & & & & & \\
\hline & IND & $02-10$ & $29.3 \%$ & $70.0 \%$ & 1.7 & & & & & & & & & & \\
\hline & LSO & $70-78$ & $28.8 \%$ & $75.4 \%$ & 1.7 & & & & & & & & & & \\
\hline & GTM & $62-80$ & $28.3 \%$ & $91.1 \%$ & 1.9 & & & & & & & & & & \\
\hline & BEL & $59-74$ & $27.9 \%$ & $96.7 \%$ & 2.0 & & & & & & & & & & \\
\hline & GRC & $60-73$ & $25.7 \%$ & $179.5 \%$ & 2.8 & & & & & & & & & & \\
\hline & DOM & 68-76 & $25.7 \%$ & $72.5 \%$ & 1.5 & & & & & & & & & & \\
\hline 45 & 22 & & & & & 11 & & & & & 12 & & & & \\
\hline \multirow[t]{12}{*}{ Small } & PAN & $02-10$ & $21.7 \%$ & $58.4 \%$ & 1.6 & SLV & $87-10$ & $24.8 \%$ & $58.2 \%$ & 1.19 & AGO & $93-01$ & $22.9 \%$ & $34.9 \%$ & 0.85 \\
\hline & IND & $93-02$ & $19.4 \%$ & $42.8 \%$ & 1.4 & DZA & 71-79 & $22.1 \%$ & $50.0 \%$ & 1.27 & LBR & $94-02$ & $20.7 \%$ & $229.5 \%$ & 0.38 \\
\hline & LKA & $59-73$ & $18.3 \%$ & $57.4 \%$ & 1.4 & FJI & $88-00$ & $21.7 \%$ & $40.2 \%$ & 1.13 & ZMB & $94-10$ & $17.3 \%$ & $106.0 \%$ & 0.77 \\
\hline & $\mathrm{HTI}$ & $72-80$ & $17.5 \%$ & $36.8 \%$ & 1.2 & BEN & $78-86$ & $19.6 \%$ & $42.9 \%$ & 1.19 & RWA & $94-02$ & $12.9 \%$ & $119.1 \%$ & 0.80 \\
\hline & DNK & $58-69$ & $17.1 \%$ & $72.3 \%$ & 1.7 & ARG & $02-10$ & $19.4 \%$ & $55.9 \%$ & 1.31 & ETH & $92-02$ & $7.4 \%$ & $27.3 \%$ & 0.88 \\
\hline & $\mathrm{COL}$ & $67-94$ & $16.9 \%$ & $83.2 \%$ & 1.8 & RWA & $02-10$ & $18.1 \%$ & $40.0 \%$ & 1.11 & $\mathrm{NIC}$ & $95-10$ & $7.0 \%$ & $25.6 \%$ & 0.55 \\
\hline & PAK & $60-70$ & $16.3 \%$ & $56.6 \%$ & 1.5 & URY & $02-10$ & $15.2 \%$ & $53.8 \%$ & 1.28 & $\mathrm{CHL}$ & $76-86$ & $3.0 \%$ & $20.2 \%$ & 0.93 \\
\hline & HND & $70-79$ & $15.1 \%$ & $44.4 \%$ & 1.4 & UGA & $61-69$ & $14.7 \%$ & $29.6 \%$ & 1.09 & AFG & $94-10$ & $2.8 \%$ & $142.5 \%$ & 0.69 \\
\hline & CRI & 91-10 & $12.8 \%$ & $61.2 \%$ & 1.4 & MNG & 93-10 & $12.1 \%$ & $86.5 \%$ & 1.18 & ZAR & $00-10$ & $2.1 \%$ & $33.8 \%$ & 0.29 \\
\hline & PRT & $64-73$ & $12.4 \%$ & $96.9 \%$ & 2.0 & FIN & 93-01 & $11.5 \%$ & $41.6 \%$ & 1.17 & CMR & $94-10$ & $0.8 \%$ & $21.5 \%$ & 0.71 \\
\hline & PER & $59-67$ & $11.7 \%$ & $48.4 \%$ & 1.3 & ARG & $85-94$ & $11.2 \%$ & $21.6 \%$ & 1.00 & & & & & \\
\hline & $\mathrm{CHN}$ & $68-77$ & $11.6 \%$ & $49.6 \%$ & 1.3 & NGA & $68-76$ & $10.6 \%$ & $70.0 \%$ & 1.19 & & & & & \\
\hline
\end{tabular}


Trillions Gained and Lost: Estimating the Magnitude of Growth Episodes

\begin{tabular}{|c|c|c|c|c|c|c|c|c|c|c|c|c|c|c|c|}
\hline & BGD & $96-10$ & $11.5 \%$ & $71.3 \%$ & 1.6 & JOR & $91-10$ & $8.2 \%$ & $59.5 \%$ & 1.02 & & & & & \\
\hline & NAM & $02-10$ & $11.0 \%$ & $28.3 \%$ & 1.1 & ZAF & $93-10$ & $5.7 \%$ & $46.9 \%$ & 1.24 & & & & & \\
\hline & JPN & $59-70$ & $10.9 \%$ & $176.3 \%$ & 2.8 & ZWE & $68-83$ & $1.4 \%$ & $112.0 \%$ & 1.70 & & & & & \\
\hline & MAR & $95-10$ & $6.8 \%$ & $67.9 \%$ & 1.5 & $\mathrm{BOL}$ & $86-10$ & $1.1 \%$ & $47.0 \%$ & 1.12 & & & & & \\
\hline & ETH & $02-10$ & $6.3 \%$ & $59.2 \%$ & 1.4 & & & & & & & & & & \\
\hline & BFA & 71-79 & $6.1 \%$ & $35.3 \%$ & 1.3 & & & & & & & & & & \\
\hline & $\mathrm{COL}$ & $02-10$ & $4.7 \%$ & $27.7 \%$ & 1.2 & & & & & & & & & & \\
\hline & DZA & $94-10$ & $3.3 \%$ & $39.6 \%$ & 1.2 & & & & & & & & & & \\
\hline & KOR & $82-91$ & $3.3 \%$ & $122.9 \%$ & 2.2 & & & & & & & & & & \\
\hline 47 & 21 & & & & & 16 & & & & & 10 & & & & \\
\hline Negative & ECU & 99-10 & $-0.2 \%$ & $38.8 \%$ & 1.2 & $\mathrm{PHL}$ & $85-10$ & $-2.7 \%$ & $57.8 \%$ & 1.28 & GNB & $81-97$ & $-0.1 \%$ & $28.5 \%$ & 0.96 \\
\hline & MRT & $02-10$ & $-0.5 \%$ & $25.0 \%$ & 1.1 & GTM & $88-10$ & $-6.1 \%$ & $33.7 \%$ & 1.08 & $\mathrm{MWI}$ & $02-10$ & $-2.2 \%$ & $49.1 \%$ & 0.84 \\
\hline & GHA & $02-10$ & $-0.8 \%$ & $38.6 \%$ & 1.3 & MEX & $89-10$ & $-7.7 \%$ & $31.9 \%$ & 1.10 & NAM & $85-02$ & $-3.1 \%$ & $20.4 \%$ & 0.88 \\
\hline & BRA & $02-10$ & $-3.3 \%$ & $21.4 \%$ & 1.2 & SEN & $73-10$ & $-10.0 \%$ & $29.3 \%$ & 1.04 & ZMB & $83-94$ & $-9.1 \%$ & $-21.8 \%$ & 0.38 \\
\hline & THA & $87-95$ & $-5.3 \%$ & $88.4 \%$ & 1.9 & BEN & $94-10$ & $-15.9 \%$ & $23.9 \%$ & 1.05 & VEN & $02-10$ & $-9.1 \%$ & $14.5 \%$ & 0.78 \\
\hline & GHA & 66-74 & $-5.4 \%$ & $30.0 \%$ & 1.1 & $\mathrm{BOL}$ & $58-77$ & $-22.1 \%$ & $30.4 \%$ & 1.01 & HTI & $94-10$ & $-16.4 \%$ & $20.7 \%$ & 0.79 \\
\hline & AUS & 61-69 & $-8.2 \%$ & $38.0 \%$ & 1.3 & & & & & & $\mathrm{BDI}$ & $00-10$ & $-16.8 \%$ & $1.7 \%$ & 0.65 \\
\hline & PRY & $02-10$ & $-8.3 \%$ & $24.6 \%$ & 1.1 & & & & & & VEN & $85-02$ & $-17.9 \%$ & $-2.7 \%$ & 0.68 \\
\hline & GIN & $02-10$ & $-16.4 \%$ & $-7.9 \%$ & 0.8 & & & & & & GMB & $95-10$ & $-21.7 \%$ & $16.7 \%$ & 0.87 \\
\hline & & & & & & & & & & & COG & $94-10$ & $-23.0 \%$ & $11.4 \%$ & 0.81 \\
\hline & & & & & & & & & & & MDG & $02-10$ & $-23.8 \%$ & $5.1 \%$ & 0.60 \\
\hline & & & & & & & & & & & BGD & $67-82$ & $-29.2 \%$ & $-3.9 \%$ & 0.76 \\
\hline & & & & & & & & & & & CAF & $96-10$ & $-29.4 \%$ & $5.9 \%$ & 0.56 \\
\hline & & & & & & & & & & & NER & $87-10$ & $-32.3 \%$ & $-7.4 \%$ & 0.50 \\
\hline & & & & & & & & & & & TGO & $93-10$ & $-33.0 \%$ & $2.4 \%$ & 0.57 \\
\hline & & & & & & & & & & & GAB & $87-10$ & $-35.1 \%$ & $9.0 \%$ & 0.51 \\
\hline 31 & 9 & & & & & 6 & & & & & 16 & & & & \\
\hline
\end{tabular}




\section{Decelerations: depressions to slow downs}

Growth decelerations similarly fall into very different magnitudes of growth episode (large, medium, small, and positive) and types. With decelerations we classify not into recoveries or non-recoveries based on the start of the episode but on the absolute level of GDPPC at the end of the episode relative to the start.

Some decelerations move countries into negative growth rates and hence produce losses in output, not just relative to a counter-factual, but in absolute terms. We follow Breuer and McDermott (2013) in defining "depressions" as episodes with losses in GDPPC from beginning to end larger than 20 percent. We find that 54 of the 161 growth decelerations were depressions. Of these, 30 had a "large" negative UCP magnitude (less than .405 or larger than 50 percent relative to UCP counter-factual) ${ }^{9}$. As with the "large non-recovery" growth accelerations, most of these are well known declines, often associated with political turmoil, conflict, and/or outright civil war (e.g. Iran 1976, Afghanistan 86-94, Zaire 19892000, Nicaragua 1987-1995, Sierra Leone 1990-99, Uganda 1969-80, Ghana 1974-83, Somalia 1978-2010) or transition from central planning (e.g. Romania, Bulgaria, Albania). Some were extended slides into poverty (Malawi 1978-2002, Cote d'Ivoire 1978-2010). Zambia has three periods of depression, a deceleration in 1967, another deceleration to even more negative growth in 1975 and the only depression which was the result of a growth acceleration - to growth of -1.66 ppa from 1983 to 1994.

Other growth decelerations are slow-downs where although the growth decelerates, it decelerates to positive levels so that GDPPC is higher at the end of the growth deceleration episode. 72 of the growth decelerations are slow-downs with positive GDP gains. Some of these are large UCP negative magnitude. Honduras decelerated in 1979 from 1970-79 growth of 3.19 ppa to $1979-2010$ growth of .13 ppa and hence had a UCP magnitude of -.62 ((1-exp(-.62)=46 percent loss) but GDPPC was 6.4\% higher in 2010 than 1979 . Some of these slow-down growth decelerations have positive UCP episode magnitude and large GCPPC gains. Turkey, for instance, experienced a growth deceleration in 1958 from 3.61 ppa to 2.20 ppa versus a UCP of 1.41 ppa so had a large positive episode magnitude (.339 or $\exp (.339)=46$ percent gain) and from 1958 to 2010 had a 200 percent gain in GDPPC (and no other structural growth breaks).

The decelerations reveal large discrepancies between the magnitudes of four possible hypothetical or counter-factual growth rates: No Change, World Average, UCP, and Zero growth. So Brazil in 1980-2002 shows a very large UCP magnitude deceleration of -.898 (-59 percent loss). The absolute loss, which implicitly uses zero growth as a hypothetical, was only 1.5 percent, which might make the magnitude of the growth break in 1980 seem inconsequential. Conversely, using the No Change scenario with the implicit counter-factual of continuation of the 51.6 ppa growth from 1967 to 1980 produces even larger estimates of the magnitude of the 1980 slow-down. We believe this shows the strength of our method as

\footnotetext{
${ }^{9}$ In spite of the different methodologies and filters 34 of our 54 "depressions" have the same dating (to within plus or minus 2 years) as in Breuer and McDermott, 2013 Table 1 and all but two countries with depressions in our Table 8 are not identified with some depression (Albania and Mongolia).
} 
the "magnitude" of the slow-down in Brazil in 1980 is neither the naïve extrapolation of past growth nor the comparison with the arbitrary standard of zero growth.

One stylized fact (as emphasized for instance by North et al., 2009) this method confirms is that "developed economies" (in ways that have to be defined) are at much, much less risk of large growth decelerations and especially of negative decelerations. If we examine the 89 growth decelerations with negative losses only two of these (Finland 1985 loss of $-1.3 \%$ and Italy 2001 loss of $-2.5 \%$ ) are rich industrial countries. Conversely, of the 90 "large" or "medium" magnitude decelerations (with UCP magnitude larger than -.223 hence loss larger than 25 percent) there are only six OECD episodes, nearly all slow-downs to moderate growth rates with large magnitude due to long duration (e.g. Greece 1973-2010, Spain 19742010, Austria 1979-2010, Switzerland 1974-2010). 
Trillions Gained and Lost: Estimating the Magnitude of Growth Episodes

\begin{tabular}{|c|c|c|c|c|c|c|c|c|c|c|c|c|c|c|c|}
\hline \multirow{2}{*}{$\begin{array}{l}\text { Total } \\
161\end{array}$} & \multicolumn{5}{|c|}{ Depression (GDPPC loss > 20 percent) } & \multicolumn{5}{|c|}{$\begin{array}{c}\text { Negative, not depression (GDPPC loss, less } \\
\text { than } 20 \text { percent) }\end{array}$} & \multicolumn{5}{|c|}{$\begin{array}{c}\text { Slow Down (Positive) } \\
\text { (GDPPC gain over episode) }\end{array}$} \\
\hline & Country & Period & $\begin{array}{l}\text { Percent } \\
\text { loss } \\
\text { relative } \\
\text { to UCP } \\
\text { predicted }\end{array}$ & $\begin{array}{l}\text { Percent } \\
\text { loss start } \\
\text { to finish, } \\
\text { actual }\end{array}$ & $\begin{array}{l}\text { Ratio } \\
\text { end } \\
\text { episod } \\
\text { e to all } \\
\text { time } \\
\text { low }\end{array}$ & Country & Period & $\begin{array}{l}\text { Percent } \\
\text { loss } \\
\text { relative } \\
\text { to UCP } \\
\text { predicted }\end{array}$ & $\begin{array}{l}\text { Percent } \\
\text { loss } \\
\text { start to } \\
\text { finish, } \\
\text { actual }\end{array}$ & $\begin{array}{l}\text { Ratio } \\
\text { end } \\
\text { episode } \\
\text { to all } \\
\text { time } \\
\text { low }\end{array}$ & Country & Period & $\begin{array}{l}\text { Percent } \\
\text { loss } \\
\text { relative } \\
\text { to UCP } \\
\text { predicted }\end{array}$ & $\begin{array}{l}\text { Percent } \\
\text { loss start } \\
\text { to finish, } \\
\text { actual }\end{array}$ & $\begin{array}{l}\text { Ratio } \\
\text { end } \\
\text { episode } \\
\text { to all } \\
\text { time } \\
\text { low }\end{array}$ \\
\hline \multirow[t]{23}{*}{ Large } & IRN & $76-88$ & $-82.7 \%$ & $-61.3 \%$ & 2.22 & BRA & $80-02$ & $-59.3 \%$ & $-1.5 \%$ & 4.01 & GRC & $73-10$ & $-48.0 \%$ & $61.5 \%$ & 6.60 \\
\hline & AFG & $86-94$ & $-69.9 \%$ & $-71.5 \%$ & 0.46 & ZWE & 02-10 & $-46.0 \%$ & $-3.9 \%$ & 1.34 & HND & $79-10$ & $-46.2 \%$ & $6.4 \%$ & 1.88 \\
\hline & MWI & $78-02$ & $-69.7 \%$ & $-43.4 \%$ & 1.55 & ECU & $78-99$ & $-45.7 \%$ & $-9.2 \%$ & 2.17 & KEN & $67-10$ & $-46.1 \%$ & $7.6 \%$ & 1.31 \\
\hline & ZAR & $89-00$ & $-66.2 \%$ & $-71.1 \%$ & 0.34 & SWZ & $89-10$ & $-40.6 \%$ & $-0.4 \%$ & 2.75 & AUT & $79-10$ & $-40.2 \%$ & $73.8 \%$ & 6.21 \\
\hline & IRQ & $79-91$ & $-65.4 \%$ & $-77.1 \%$ & 0.48 & JAM & $94-10$ & $-40.1 \%$ & $-8.2 \%$ & 2.02 & OMN & $85-10$ & $-38.6 \%$ & $42.4 \%$ & 4.45 \\
\hline & JOR & $65-74$ & $-63.1 \%$ & $-34.0 \%$ & 1.52 & GTM & $80-88$ & $-37.3 \%$ & $-19.3 \%$ & 1.72 & PAN & $82-02$ & $-38.5 \%$ & $21.1 \%$ & 4.14 \\
\hline & TTO & $80-89$ & $-61.6 \%$ & $-45.6 \%$ & 2.38 & & & & & & ESP & $74-10$ & $-38.4 \%$ & $79.3 \%$ & 7.19 \\
\hline & JOR & $82-91$ & $-60.5 \%$ & $-36.4 \%$ & 1.74 & & & & & & JAM & $61-72$ & $-36.6 \%$ & $41.0 \%$ & 2.21 \\
\hline & SOM & $78-10$ & $-57.7 \%$ & $-46.7 \%$ & 0.62 & & & & & & & & & & \\
\hline & NGA & 76-87 & $-56.7 \%$ & $-48.4 \%$ & 0.88 & & & & & & & & & & \\
\hline & CMR & $84-94$ & $-51.3 \%$ & $-41.9 \%$ & 1.06 & & & & & & & & & & \\
\hline & GAB & $76-87$ & $-50.9 \%$ & $-53.2 \%$ & 1.86 & & & & & & & & & & \\
\hline & SLE & $90-99$ & $-50.2 \%$ & $-50.3 \%$ & 1.10 & & & & & & & & & & \\
\hline & $\mathrm{CIV}$ & $78-10$ & $-50.1 \%$ & $-26.6 \%$ & 1.35 & & & & & & & & & & \\
\hline & ROM & $86-94$ & $-47.4 \%$ & $-30.8 \%$ & 3.82 & & & & & & & & & & \\
\hline & MDG & $74-02$ & $-44.5 \%$ & $-42.6 \%$ & 0.67 & & & & & & & & & & \\
\hline & CUB & $84-95$ & $-44.1 \%$ & $-29.9 \%$ & 1.37 & & & & & & & & & & \\
\hline & GNB & $97-10$ & $-44.1 \%$ & $-31.0 \%$ & 1.10 & & & & & & & & & & \\
\hline & UGA & $69-80$ & $-43.2 \%$ & $-35.0 \%$ & 0.84 & & & & & & & & & & \\
\hline & BDI & $92-00$ & $-40.7 \%$ & $-35.5 \%$ & 1.35 & & & & & & & & & & \\
\hline & PNG & $73-84$ & $-39.6 \%$ & $-28.3 \%$ & 1.23 & & & & & & & & & & \\
\hline & ALB & $82-92$ & $-39.4 \%$ & $-39.3 \%$ & 0.76 & & & & & & & & & & \\
\hline & ZMB & $75-83$ & $-39.4 \%$ & $-39.1 \%$ & 0.79 & & & & & & & & & & \\
\hline
\end{tabular}


Trillions Gained and Lost: Estimating the Magnitude of Growth Episodes

\begin{tabular}{|c|c|c|c|c|c|c|c|c|c|c|c|c|c|c|c|}
\hline & BGR & $88-97$ & $-39.4 \%$ & $-21.4 \%$ & 2.09 & & & & & & & & & & \\
\hline & $\mathrm{HTI}$ & $80-94$ & $-37.6 \%$ & $-34.2 \%$ & 0.90 & & & & & & & & & & \\
\hline & NIC & $87-95$ & $-37.1 \%$ & $-39.3 \%$ & 0.96 & & & & & & & & & & \\
\hline & GHA & $74-83$ & $-36.6 \%$ & $-34.8 \%$ & 0.94 & & & & & & & & & & \\
\hline & COG & $84-94$ & $-35.2 \%$ & $-27.6 \%$ & 2.07 & & & & & & & & & & \\
\hline & MNG & $82-93$ & $-35.0 \%$ & $-33.9 \%$ & 1.08 & & & & & & & & & & \\
\hline & TCD & $71-80$ & $-33.8 \%$ & $-35.4 \%$ & 0.72 & & & & & & & & & & \\
\hline 44 & 30 & & & & & 6 & & & & & 8 & & & & \\
\hline \multirow[t]{17}{*}{ Medium } & NGA & $60-68$ & $-32.1 \%$ & $-28.3 \%$ & 0.99 & DZA & $79-94$ & $-32.3 \%$ & $-13.8 \%$ & 1.79 & JPN & $91-10$ & $-32.2 \%$ & $10.2 \%$ & 11.29 \\
\hline & ZMB & $67-75$ & $-31.6 \%$ & $-20.1 \%$ & 1.29 & ETH & $69-83$ & $-30.6 \%$ & $-5.2 \%$ & 1.57 & ZAR & $58-74$ & $-31.5 \%$ & $11.8 \%$ & 1.57 \\
\hline & $\mathrm{MOZ}$ & $76-86$ & $-29.7 \%$ & $-29.7 \%$ & 0.94 & NER & $68-79$ & $-29.2 \%$ & $-5.6 \%$ & 1.08 & ISR & $75-10$ & $-28.9 \%$ & $65.6 \%$ & 5.81 \\
\hline & JAM & $72-86$ & $-29.6 \%$ & $-27.3 \%$ & 1.60 & LBR & $02-10$ & $-27.9 \%$ & $-16.4 \%$ & 2.85 & $\mathrm{CHE}$ & $74-10$ & $-28.6 \%$ & $26.1 \%$ & 2.69 \\
\hline & PER & $81-92$ & $-28.7 \%$ & $-31.3 \%$ & 1.39 & PRY & $89-02$ & $-24.3 \%$ & $-14.1 \%$ & 2.03 & TGO & $69-79$ & $-27.5 \%$ & $7.2 \%$ & 1.82 \\
\hline & GUY & $81-90$ & $-28.5 \%$ & $-38.1 \%$ & 0.77 & FIN & $85-93$ & $-24.1 \%$ & $-1.3 \%$ & 3.40 & PNG & $93-10$ & $-27.4 \%$ & $7.3 \%$ & 1.92 \\
\hline & NAM & $74-85$ & $-27.8 \%$ & $-26.1 \%$ & 1.15 & $\mathrm{ZAF}$ & $81-93$ & $-23.6 \%$ & $-15.6 \%$ & 1.59 & CYP & $84-92$ & $-25.0 \%$ & $38.6 \%$ & 5.49 \\
\hline & ZAR & 74-89 & $-27.4 \%$ & $-25.3 \%$ & 1.17 & $\mathrm{CHL}$ & $68-76$ & $-23.2 \%$ & $-14.4 \%$ & 1.15 & MYS & $96-10$ & $-23.5 \%$ & $31.5 \%$ & 9.44 \\
\hline & $\mathrm{NIC}$ & $67-79$ & $-27.3 \%$ & $-34.6 \%$ & 1.21 & MRT & $76-02$ & $-22.9 \%$ & $-12.2 \%$ & 2.80 & SYR & $98-10$ & $-22.8 \%$ & $5.3 \%$ & 2.50 \\
\hline & VEN & $77-85$ & $-25.8 \%$ & $-29.7 \%$ & 1.47 & MEX & $81-89$ & $-22.1 \%$ & $-16.8 \%$ & 2.50 & PRY & $80-89$ & $-22.6 \%$ & $6.5 \%$ & 2.37 \\
\hline & GNB & $70-81$ & $-25.1 \%$ & $-25.1 \%$ & 1.24 & $\mathrm{CHN}$ & $60-68$ & $-21.9 \%$ & $-10.8 \%$ & 1.36 & HKG & $94-02$ & $-21.7 \%$ & $5.6 \%$ & 8.55 \\
\hline & POL & $79-91$ & $-24.8 \%$ & $-20.0 \%$ & 1.24 & FJI & $79-88$ & $-20.8 \%$ & $-19.7 \%$ & 1.54 & PRI & $72-82$ & $-21.7 \%$ & $2.5 \%$ & 3.61 \\
\hline & ZWE & $91-02$ & $-24.4 \%$ & $-32.9 \%$ & 1.40 & CRI & $79-91$ & $-20.5 \%$ & $-14.1 \%$ & 2.09 & IRL & $79-87$ & $-21.5 \%$ & $0.4 \%$ & 2.50 \\
\hline & NER & $79-87$ & $-23.2 \%$ & $-39.4 \%$ & 0.73 & FJI & $00-10$ & $-20.5 \%$ & $-1.8 \%$ & 2.12 & DOM & $60-68$ & $-21.3 \%$ & $3.0 \%$ & 1.33 \\
\hline & TGO & $79-93$ & $-23.0 \%$ & $-44.8 \%$ & 1.00 & & & & & & IDN & $96-10$ & $-20.6 \%$ & $29.6 \%$ & 7.52 \\
\hline & SLV & $78-87$ & $-21.4 \%$ & $-24.9 \%$ & 1.38 & & & & & & & & & & \\
\hline & RWA & $81-94$ & $-21.3 \%$ & $-63.7 \%$ & 0.57 & & & & & & & & & & \\
\hline 46 & 17 & & & & & 14 & & & & & 15 & & & & \\
\hline \multirow[t]{6}{*}{ Small } & LSO & $78-86$ & $-19.4 \%$ & $-24.2 \%$ & 1.75 & $E G Y$ & $65-76$ & $-19.2 \%$ & $-0.6 \%$ & 1.39 & NZL & $58-74$ & $-19.7 \%$ & $56.8 \%$ & 1.75 \\
\hline & CAF & $86-96$ & $-18.0 \%$ & $-34.0 \%$ & 0.73 & $\mathrm{COL}$ & $94-02$ & $-18.3 \%$ & $-1.1 \%$ & 2.28 & BEL & $74-10$ & $-19.5 \%$ & $88.6 \%$ & 4.47 \\
\hline & SYR & $81-89$ & $-17.8 \%$ & $-22.3 \%$ & 1.62 & URY & $94-02$ & $-18.2 \%$ & $-6.1 \%$ & 1.68 & MYS & $79-87$ & $-18.6 \%$ & $16.0 \%$ & 3.66 \\
\hline & MUS & $63-71$ & $-16.7 \%$ & $-22.7 \%$ & 0.86 & ARG & $77-85$ & $-17.2 \%$ & $-16.7 \%$ & 1.39 & $\mathrm{NIC}$ & $79-87$ & $-18.0 \%$ & $30.1 \%$ & 1.58 \\
\hline & $\mathrm{BOL}$ & $77-86$ & $-12.9 \%$ & $-23.8 \%$ & 0.99 & PRI & $00-10$ & $-16.2 \%$ & $-9.8 \%$ & 7.04 & PRT & $73-85$ & $-15.9 \%$ & $7.7 \%$ & 4.07 \\
\hline & GMB & $82-95$ & $-12.9 \%$ & $-25.3 \%$ & 1.09 & PRT & $00-10$ & $-16.0 \%$ & $-0.2 \%$ & 7.37 & MRT & $68-76$ & $-15.9 \%$ & $32.2 \%$ & 3.19 \\
\hline
\end{tabular}


Trillions Gained and Lost: Estimating the Magnitude of Growth Episodes

\begin{tabular}{|c|c|c|c|c|c|c|c|c|c|c|c|c|c|c|c|}
\hline & ETH & $83-92$ & $-1.1 \%$ & $-25.6 \%$ & 1.17 & ITA & $01-10$ & $-13.7 \%$ & $-2.6 \%$ & 5.42 & ROM & $78-86$ & $-14.6 \%$ & $16.3 \%$ & 5.52 \\
\hline & & & & & & ARG & $94-02$ & $-13.7 \%$ & $-7.0 \%$ & 1.58 & PER & $67-81$ & $-14.3 \%$ & $17.3 \%$ & 2.02 \\
\hline & & & & & & BEN & $86-94$ & $-13.2 \%$ & $-14.6 \%$ & 1.37 & TWN & $94-10$ & $-14.1 \%$ & $82.6 \%$ & 26.00 \\
\hline & & & & & & SDN & $78-96$ & $-11.7 \%$ & $-12.4 \%$ & 1.21 & HUN & $78-10$ & $-14.1 \%$ & $46.2 \%$ & 2.13 \\
\hline & & & & & & CYP & $67-75$ & $-10.7 \%$ & $-10.2 \%$ & 1.76 & $\mathrm{PHL}$ & $59-77$ & $-13.1 \%$ & $58.7 \%$ & 2.32 \\
\hline & & & & & & $\mathrm{PHL}$ & $77-85$ & $-10.6 \%$ & $-12.9 \%$ & 2.02 & KOR & 91-02 & $-12.9 \%$ & $61.7 \%$ & 13.89 \\
\hline & & & & & & ZWE & $83-91$ & $-0.8 \%$ & $-1.8 \%$ & 2.08 & ITA & $90-01$ & $-12.2 \%$ & $17.6 \%$ & 5.56 \\
\hline & & & & & & & & & & & BWA & $90-10$ & $-12.0 \%$ & $45.0 \%$ & 14.35 \\
\hline & & & & & & & & & & & TZA & $71-00$ & $-11.6 \%$ & $14.1 \%$ & 1.89 \\
\hline & & & & & & & & & & & EGY & $92-10$ & $-11.4 \%$ & $69.5 \%$ & 6.27 \\
\hline & & & & & & & & & & & CYP & $92-10$ & $-10.4 \%$ & $28.7 \%$ & 7.06 \\
\hline & & & & & & & & & & & THA & $95-10$ & $-8.8 \%$ & $32.1 \%$ & 10.99 \\
\hline & & & & & & & & & & & MAR & $77-95$ & $-8.7 \%$ & $2.5 \%$ & 3.29 \\
\hline & & & & & & & & & & & SGP & $80-10$ & $-6.9 \%$ & $262.9 \%$ & 12.75 \\
\hline & & & & & & & & & & & CRI & $58-79$ & $-6.5 \%$ & $74.8 \%$ & 2.44 \\
\hline & & & & & & & & & & & BFA & $79-10$ & $-6.4 \%$ & $38.6 \%$ & 2.08 \\
\hline & & & & & & & & & & & NLD & $74-10$ & $-6.0 \%$ & $74.9 \%$ & 3.92 \\
\hline & & & & & & & & & & & DOM & $76-91$ & $-5.9 \%$ & $12.4 \%$ & 2.59 \\
\hline & & & & & & & & & & & $\mathrm{CHL}$ & $97-10$ & $-2.8 \%$ & $39.5 \%$ & 3.91 \\
\hline & & & & & & & & & & & FIN & $01-10$ & $-1.8 \%$ & $12.0 \%$ & 5.39 \\
\hline & & & & & & & & & & & HKG & $81-94$ & $-1.0 \%$ & $81.2 \%$ & 8.10 \\
\hline & & & & & & & & & & & DNK & $69-10$ & $-0.9 \%$ & $93.5 \%$ & 3.92 \\
\hline & & & & & & & & & & & ITA & $74-90$ & $-0.6 \%$ & $50.2 \%$ & 4.73 \\
\hline 49 & 7 & & & & & 13 & & & & & 29 & & & & \\
\hline \multirow[t]{9}{*}{ Positive } & & & & & & IRL & $02-10$ & $1.8 \%$ & $-5.4 \%$ & 5.77 & LBN & $91-10$ & $0.6 \%$ & $71.5 \%$ & 3.38 \\
\hline & & & & & & URY & $77-85$ & $13.1 \%$ & $-10.8 \%$ & 1.14 & TTO & $61-80$ & $2.4 \%$ & $119.9 \%$ & 4.37 \\
\hline & & & & & & & & & & & KOR & $02-10$ & $2.7 \%$ & $29.4 \%$ & 17.97 \\
\hline & & & & & & & & & & & GBR & $02-10$ & $2.8 \%$ & $8.1 \%$ & 3.81 \\
\hline & & & & & & & & & & & TUN & $81-10$ & $3.4 \%$ & $52.5 \%$ & 3.37 \\
\hline & & & & & & & & & & & ISR & $67-75$ & $3.9 \%$ & $74.6 \%$ & 3.51 \\
\hline & & & & & & & & & & & SLE & $70-90$ & $6.8 \%$ & $28.0 \%$ & 2.22 \\
\hline & & & & & & & & & & & MUS & $79-10$ & $8.8 \%$ & $177.4 \%$ & 5.15 \\
\hline & & & & & & & & & & & $\mathrm{MLI}$ & $86-10$ & $10.4 \%$ & $52.4 \%$ & 2.48 \\
\hline
\end{tabular}


Trillions Gained and Lost: Estimating the Magnitude of Growth Episodes

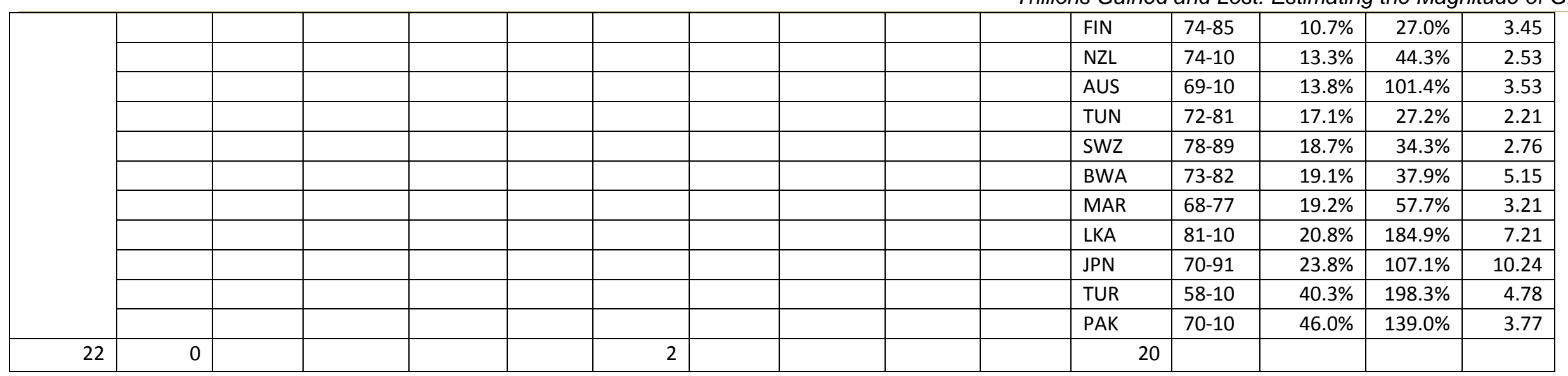




\section{Cumulative estimates of the magnitude of growth episodes: NPV estimates}

Table 9 shows the NPV of growth episodes using the UCP counter-factual for the 10 largest growth episodes, defined in two different ways. The first four columns of Table 9 show the absolute gain which is a product of total GDP and hence is affected by the size of country population. There are 8 growth episodes with more than a trillion dollars in NPV gain. Obviously a number of these are the world's largest countries with China's accelerations in 1977 and 1991 on the list plus India's growth acceleration in 2002. Countries with high levels of output per person such as Great Britain in 1981 and Australia 1969 also make the list as total GDP is large.

To adjust for population and initial income we also sort the largest gains by the ratio of NPV of the episode to initial GDPPC. This brings the smaller East Asian Dragons to the fore. The accelerations in Taiwan 1962, Indonesia 1967, Thailand in 1958, Korea 1962 and Vietnam 1989 plus Egypt 1976 and China 1991 all have NPV/GDPPC over eight. Interestingly, the growth accelerations in Uganda in 1988 and Mozambique in 1995 make the list of the top 21.

\begin{tabular}{|c|c|c|c|c|c|c|c|c|c|}
\hline \multicolumn{5}{|c|}{ Sorted by absolute dollar size } & \multicolumn{5}{|c|}{ Sorted by ratio of end to beginning GDPPC } \\
\hline $\begin{array}{l}\text { Coun } \\
\text { try }\end{array}$ & Year & $\begin{array}{l}\text { Size } \\
\text { (billions } \\
\text { of PPP\$) }\end{array}$ & \begin{tabular}{|l} 
Ratio \\
NPV \\
gain to \\
initial \\
GDPPC \\
\end{tabular} & $\begin{array}{l}\text { NPV gain } \\
\text { per } \\
\text { person }\end{array}$ & $\begin{array}{l}\text { Coun } \\
\text { try }\end{array}$ & Year & $\begin{array}{l}\text { Ratio NPV } \\
\text { gain to } \\
\text { beginning } \\
\text { GDPPC }\end{array}$ & $\begin{array}{l}\text { Size } \\
\text { (billions } \\
\text { of PPP\$) }\end{array}$ & $\begin{array}{l}\text { NPV } \\
\text { gain per } \\
\text { person }\end{array}$ \\
\hline $\mathrm{CHN}$ & 1991 & $\begin{array}{r}11,786.5 \\
2 \\
\end{array}$ & 8.14 & $10,129.3$ & TWN & 1962 & 36.67 & 877.15 & $73,593.2$ \\
\hline JPN & 1970 & $2,815.56$ & 1.96 & $26,983.2$ & IDN & 1967 & 15.05 & $1,119.03$ & $9,711.9$ \\
\hline $\mathrm{CHN}$ & 1977 & $2,655.71$ & 6.36 & $2,807.0$ & THA & 1958 & 14.73 & 309.17 & $11,962.2$ \\
\hline IND & 2002 & $2,523.38$ & 1.19 & $2,425.7$ & KOR & 1962 & 9.53 & 421.17 & $15,941.3$ \\
\hline GBR & 1981 & $2,498.77$ & 2.67 & $44,318.2$ & VNM & 1989 & 8.17 & 455.44 & $6,914.4$ \\
\hline IDN & 1967 & $1,119.03$ & 15.05 & $9,711.9$ & EGY & 1976 & 8.15 & 332.25 & $8,804.2$ \\
\hline IND & 1993 & $1,097.62$ & 0.86 & $1,237.8$ & $\mathrm{CHN}$ & 1991 & 8.14 & $11,786.52$ & $10,129.3$ \\
\hline $\mathrm{POL}$ & 1991 & $1,048.22$ & 3.68 & $27,402.1$ & LAO & 1979 & 7.02 & 14.56 & $4,455.5$ \\
\hline IRN & 1988 & 881.76 & 3.15 & $16,275.1$ & TUR & 1958 & 6.80 & 630.97 & $23,805.0$ \\
\hline TWN & 1962 & 877.15 & 36.67 & $73,593.2$ & PAK & 1970 & 6.80 & 441.11 & $6,535.8$ \\
\hline BRA & 1967 & 631.80 & 2.27 & $7,175.5$ & $\mathrm{CHN}$ & 1977 & 6.36 & $2,655.71$ & $2,807.0$ \\
\hline TUR & 1958 & 630.97 & 6.80 & $23,805.0$ & PAN & 1959 & 6.33 & 12.71 & $11,396.7$ \\
\hline VNM & 1989 & 455.44 & 8.17 & $6,914.4$ & KHM & 1982 & 5.92 & 21.76 & $2,982.1$ \\
\hline PAK & 1970 & 441.11 & 6.80 & $6,535.8$ & UGA & 1988 & 5.36 & 45.85 & $2,834.5$ \\
\hline AUS & 1969 & 425.93 & 1.69 & $34,406.8$ & IRL & 1987 & 5.12 & 273.88 & $77,368.4$ \\
\hline KOR & 1962 & 421.17 & 9.53 & $15,941.3$ & SGP & 1968 & 4.98 & 59.04 & $29,344.2$ \\
\hline ROM & 1994 & 408.57 & 3.43 & $17,972.7$ & LSO & 1986 & 4.97 & 5.38 & $3,390.6$ \\
\hline JPN & 1959 & 371.56 & 0.80 & $3,982.6$ & $\mathrm{MOZ}$ & 1995 & 4.68 & 24.25 & $1,526.2$ \\
\hline EGY & 1976 & 332.25 & 8.15 & $8,804.2$ & ALB & 1992 & 4.64 & 32.45 & $10,562.0$ \\
\hline NGA & 1987 & 323.54 & 3.71 & $3,618.8$ & NPL & 1983 & 4.58 & 42.84 & $2,718.6$ \\
\hline
\end{tabular}


Table 10 shows the biggest growth episode NPV losses sorted in the same two ways. The NPV of losses is in this case dominated by countries that started with high income per capita and had long-lasting slow downs (e.g. Japan 1991, Greece 1973, Spain 1974, Austria 1979, Switzerland 1974) including Italy in 2001 and 1990.

The list of NPV loss to initial GDPPC finds overlap and some new countries. The growth slowdown in Brazil, a big deceleration (5 percentage points) that was long (22 years) in a country of upper middle income and large population is high on both lists the magnitude of the loss was 7.5 trillion dollars or 61,353 dollars per person for a ratio of loss to GDPPC over 8. The growth deceleration in Iran that lasted from 1976 to 1988 is particularly striking as it cost each citizen $\$ 146,643$, a loss 11 times initial GDPPC and over 5 trillion dollars.

Using the ratio also emphasizes the losses for smaller and poorer countries. The growth decelerations in the 1970s/early 1980s were costly in Africa (Malawi 1978, Cote d'Ivoire 1978, Somalia 1978, Madagascar 1974) and Latin America (Brazil 1980, Honduras 1979, Ecuador 1978). When starting from a low base these are particularly tragic. The growth deceleration in Malawi that began in 1978 cost each person cumulatively almost 10,000 dollars.

Table 10: Biggest growth episode gains in NPV using UCP magnitude

\begin{tabular}{|l|r|l|l|l|l|l|r|r|r|}
\hline \multicolumn{4}{|c|}{ Sorted by absolute dollar size } & \multicolumn{3}{c|}{ Sorted by ratio of NPV loss to beginning GDPPC } \\
\hline $\begin{array}{l}\text { Cou } \\
\text { ntry }\end{array}$ & Year & $\begin{array}{l}\text { Size } \\
\text { (billions of } \\
\text { PPP\$) }\end{array}$ & $\begin{array}{l}\text { Ratio } \\
\text { NPV loss } \\
\text { to initial } \\
\text { GDPPC }\end{array}$ & $\begin{array}{l}\text { NPV loss } \\
\text { per } \\
\text { person }\end{array}$ & $\begin{array}{l}\text { Coun } \\
\text { try }\end{array}$ & Year & $\begin{array}{l}\text { Ratio NPV } \\
\text { loss to } \\
\text { beginning } \\
\text { GDPPC }\end{array}$ & $\begin{array}{l}\text { Size } \\
\text { (billions } \\
\text { of PPP\$) }\end{array}$ & $\begin{array}{l}\text { NPV loss } \\
\text { per } \\
\text { person }\end{array}$ \\
\hline Jpn & 1991 & $-9,379.01$ & -2.65 & -75670 & mwi & 1978 & -12.36 & -56.50 & -9608 \\
\hline Bra & 1980 & $-7,547.67$ & -8.82 & -61353 & ken & 1967 & -11.48 & -135.49 & -13294 \\
\hline Irn & 1976 & $-5,055.57$ & -11.00 & -146643 & irn & 1976 & -11.00 & $-5,055.57$ & -146643 \\
\hline Esp & 1974 & $-3,274.15$ & -6.11 & -93057 & bra & 1980 & -8.82 & $-7,547.67$ & -61353 \\
\hline Grc & 1973 & $-1,078.03$ & -7.73 & -120733 & civ & 1978 & -8.71 & -121.05 & -15218 \\
\hline Ita & 2001 & -994.50 & -0.59 & -17167 & hnd & 1979 & -8.59 & -94.72 & -28886 \\
\hline Idn & 1996 & -922.53 & -1.50 & -4587 & grc & 1973 & -7.73 & $-1,078.03$ & -120733 \\
\hline Aut & 1979 & -906.28 & -5.41 & -120046 & som & 1978 & -7.57 & -30.69 & -6559 \\
\hline Ita & 1990 & -898.18 & -0.64 & -15837 & omn & 1985 & -6.89 & -162.17 & -108314 \\
\hline mex & 1981 & -749.44 & -0.98 & -10711 & esp & 1974 & -6.11 & $-3,274.15$ & -93057 \\
\hline Che & 1974 & -581.51 & -2.84 & -90017 & ecu & 1978 & -5.51 & -204.00 & -27239 \\
\hline mex & 1989 & -521.25 & -0.69 & -6253 & jor & 1965 & -5.50 & -21.52 & -20275 \\
\hline Kor & 1991 & -468.41 & -0.85 & -10808 & aut & 1979 & -5.41 & -906.28 & -120046 \\
\hline nga & 1976 & -449.57 & -3.58 & -6771 & mdg & 1974 & -5.34 & -46.13 & -6214 \\
\hline twn & 1994 & -443.19 & -1.20 & -21011 & isr & 1975 & -5.30 & -279.51 & -83330 \\
\hline Pol & 1979 & -434.73 & -1.33 & -12330 & irq & 1979 & -4.89 & -348.06 & -27260 \\
\hline Bel & 1974 & -405.51 & -2.20 & -41515 & pan & 1982 & -4.74 & -54.69 & -26816 \\
\hline mys & 1996 & -386.74 & -2.04 & -18543 & swz & 1989 & -4.72 & -14.86 & -17497 \\
\hline rom & 1986 & -348.54 & -2.04 & -15422 & jor & 1982 & -4.67 & -48.20 & -20533 \\
\hline Irq & 1979 & -348.06 & -4.89 & -27260 & zar & 1989 & -4.03 & -94.79 & -2503 \\
\hline
\end{tabular}


The calculation of the total gain in constant PPP dollar terms is mainly a mechanism for converting our estimates of the gains and losses from growth accelerations and decelerations into figures that are comparable with estimates of the gains from other proposed interventions in development. For instance, in deciding on research priorities there is a balance between what it might cost to find the right answer, how hard it might be to be sure the answers found are right and the value of the right answer. It may well be that precision and rigour can be had using certain techniques at relatively low cost for certain questions, but that these questions also have low total potential benefit. In contrast, we argue it may be difficult to have precision and rigour on questions of what might promote economic growth but the consequences of getting it right (or avoiding getting it wrong) as so massive that, as Lucas says, it is hard to think about anything else.

\section{Conclusion}

In this paper, we estimate the magnitude of countries' growth accelerations and decelerations. We propose a flow and stock measure of the magnitude of a growth episode. The flow measure is the difference between the level of output at the end of the episode and the counter-factual of what the level of output would have been in the absence of the onset of the growth episode. The stock measure computes the total net present value of the difference between the actual trajectory of output during the episode and the predicted trajectory. To calculate the "counter-factual" growth rate, we use three options: (a) the country's growth rate in its previous episode, (b) the world average growth rate and (c) an "unconditional predicted" growth rate. The "unconditional predicted" growth rate uses a regression for each country/episode to allow "predicted" growth to depend on a country's initial GDP per capita, the episode period specific world average growth and a flexibly specified regression to the mean.

"What, exactly" can countries do to initiate an episode of sustained (and not subsequently reversed) growth? "What, exactly" can countries do to avoid a period of sustained stagnation? "What, exactly" can countries do to avoid a depression? We are obviously not answering any of these questions here, much less "exactly." But we do hope to lay an empirical foundation of the magnitude of growth changes and a classification that clarifies and measures of what it is to be explained. 
Appendix 1: Estimates of the cumulative magnitude of the gain/loss from each of $\mathbf{3 1 4}$ growth transitions using three counter-factual growth rates: Continuation of previous trend, world period average, and regression predicted growth

\begin{tabular}{|c|c|c|c|c|}
\hline \multirow[t]{2}{*}{ Country } & \multirow{2}{*}{$\begin{array}{c}\text { Beginning } \\
\text { of } \\
\text { episode }\end{array}$} & \multicolumn{3}{|c|}{ Counter-factual } \\
\hline & & No change & World average & $\begin{array}{l}\text { Unconditional } \\
\text { Prediction }\end{array}$ \\
\hline afg & 1986 & -1.525 & -1.238 & -1.201 \\
\hline afg & 1994 & 3.095 & 0.266 & 0.027 \\
\hline ago & 1993 & 0.358 & 0.156 & 0.206 \\
\hline ago & 2001 & 0.540 & 0.576 & 0.577 \\
\hline alb & 1982 & -0.761 & -0.496 & -0.502 \\
\hline alb & 1992 & 1.809 & 0.563 & 0.595 \\
\hline $\arg$ & 1977 & -0.323 & -0.222 & -0.189 \\
\hline $\arg$ & 1985 & 0.336 & 0.018 & 0.106 \\
\hline $\arg$ & 1994 & -0.107 & -0.127 & -0.147 \\
\hline $\arg$ & 2002 & 0.331 & 0.166 & 0.177 \\
\hline aus & 1961 & 0.020 & -0.129 & -0.085 \\
\hline aus & 1969 & -0.112 & 0.112 & 0.129 \\
\hline aut & 1979 & -0.761 & 0.093 & -0.515 \\
\hline bdi & 1992 & -0.712 & -0.591 & -0.522 \\
\hline bdi & 2000 & 0.776 & -0.157 & -0.184 \\
\hline bel & 1959 & 0.310 & 0.189 & 0.246 \\
\hline bel & 1974 & -0.819 & 0.139 & -0.217 \\
\hline ben & 1978 & 0.127 & 0.175 & 0.179 \\
\hline ben & 1986 & -0.278 & -0.202 & -0.141 \\
\hline ben & 1994 & 0.333 & -0.169 & -0.173 \\
\hline bfa & 1971 & 0.065 & 0.037 & 0.059 \\
\hline bfa & 1979 & -0.247 & -0.200 & -0.066 \\
\hline bgd & 1967 & 0.279 & -0.398 & -0.346 \\
\hline bgd & 1982 & 0.324 & 0.074 & 0.319 \\
\hline bgd & 1996 & 0.222 & 0.114 & 0.109 \\
\hline bgr & 1988 & -0.716 & -0.306 & -0.501 \\
\hline bgr & 1997 & 1.019 & 0.315 & 0.310 \\
\hline bol & 1958 & 0.780 & -0.338 & -0.250 \\
\hline bol & 1977 & -0.347 & -0.271 & -0.138 \\
\hline bol & 1986 & 0.966 & -0.122 & 0.011 \\
\hline bra & 1967 & 0.130 & 0.368 & 0.288 \\
\hline bra & 1980 & -1.145 & -0.304 & -0.898 \\
\hline bra & 2002 & 0.256 & 0.017 & -0.034 \\
\hline bwa & 1973 & -0.372 & 0.403 & 0.174 \\
\hline bwa & 1982 & 0.057 & 0.498 & 0.331 \\
\hline bwa & 1990 & -0.769 & 0.186 & -0.127 \\
\hline caf & 1986 & -0.226 & -0.367 & -0.199 \\
\hline caf & 1996 & 0.399 & -0.374 & -0.347 \\
\hline
\end{tabular}




\begin{tabular}{|c|c|c|c|c|}
\hline che & 1974 & -0.766 & -0.350 & -0.337 \\
\hline chl & 1968 & -0.183 & -0.308 & -0.264 \\
\hline $\mathrm{chl}$ & 1976 & 0.096 & -0.028 & 0.030 \\
\hline chl & 1986 & 0.614 & 0.493 & 0.573 \\
\hline $\mathrm{chl}$ & 1997 & -0.439 & 0.066 & -0.028 \\
\hline chn & 1960 & -0.198 & -0.205 & -0.247 \\
\hline chn & 1968 & 0.322 & 0.123 & 0.110 \\
\hline chn & 1977 & 0.460 & 0.909 & 0.776 \\
\hline chn & 1991 & 0.193 & 1.207 & 0.606 \\
\hline civ & 1978 & -1.176 & -0.702 & -0.695 \\
\hline $\mathrm{cmr}$ & 1976 & 0.229 & 0.306 & 0.334 \\
\hline $\mathrm{cmr}$ & 1984 & -0.995 & -0.643 & -0.719 \\
\hline $\mathrm{cmr}$ & 1994 & 1.119 & -0.078 & 0.008 \\
\hline $\operatorname{cog}$ & 1976 & 0.208 & 0.422 & 0.392 \\
\hline $\operatorname{cog}$ & 1984 & -0.782 & -0.285 & -0.434 \\
\hline $\operatorname{cog}$ & 1994 & 0.298 & -0.326 & -0.261 \\
\hline $\mathrm{col}$ & 1967 & 0.100 & 0.109 & 0.157 \\
\hline $\mathrm{col}$ & 1994 & -0.221 & -0.170 & -0.202 \\
\hline col & 2002 & 0.335 & 0.080 & 0.045 \\
\hline cri & 1958 & -0.193 & -0.062 & -0.067 \\
\hline cri & 1979 & -0.415 & -0.189 & -0.230 \\
\hline cri & 1991 & 0.670 & 0.087 & 0.121 \\
\hline cub & 1984 & -0.965 & -0.421 & -0.581 \\
\hline cub & 1995 & 1.126 & 0.257 & 0.255 \\
\hline cyp & 1967 & -0.097 & -0.079 & -0.114 \\
\hline cyp & 1975 & 0.324 & 0.460 & 0.479 \\
\hline cyp & 1984 & -0.179 & 0.211 & -0.287 \\
\hline cyp & 1992 & -0.368 & -0.062 & -0.110 \\
\hline dnk & 1958 & 0.274 & 0.144 & 0.158 \\
\hline dnk & 1969 & -1.203 & 0.089 & -0.009 \\
\hline dom & 1960 & -0.162 & -0.173 & -0.239 \\
\hline dom & 1968 & 0.411 & 0.254 & 0.228 \\
\hline dom & 1976 & -0.792 & -0.010 & -0.061 \\
\hline dom & 1991 & 0.533 & 0.316 & 0.332 \\
\hline dza & 1971 & 0.260 & 0.175 & 0.200 \\
\hline dza & 1979 & -0.738 & -0.212 & -0.390 \\
\hline dza & 1994 & 0.406 & -0.031 & 0.033 \\
\hline ecu & 1970 & 0.396 & 0.312 & 0.334 \\
\hline ecu & 1978 & -1.458 & -0.368 & -0.610 \\
\hline ecu & 1999 & 0.361 & 0.031 & -0.002 \\
\hline egy & 1965 & -0.122 & -0.219 & -0.213 \\
\hline egy & 1976 & 0.707 & 0.732 & 0.908 \\
\hline egy & 1992 & -0.500 & 0.114 & -0.121 \\
\hline esp & 1974 & -1.198 & 0.157 & -0.485 \\
\hline eth & 1969 & -0.389 & -0.366 & -0.365 \\
\hline eth & 1983 & -0.117 & -0.234 & -0.012 \\
\hline
\end{tabular}




\begin{tabular}{|c|c|c|c|c|}
\hline eth & 1992 & 0.291 & -0.095 & 0.071 \\
\hline eth & 2002 & 0.382 & 0.278 & 0.062 \\
\hline fin & 1974 & -0.085 & 0.193 & 0.102 \\
\hline fin & 1985 & -0.250 & -0.098 & -0.276 \\
\hline fin & 1993 & 0.301 & 0.142 & 0.109 \\
\hline fin & 2001 & -0.177 & -0.051 & -0.019 \\
\hline$f j i$ & 1979 & -0.453 & -0.153 & -0.233 \\
\hline $\mathrm{fji}$ & 1988 & 0.461 & 0.106 & 0.196 \\
\hline $\mathrm{fji}$ & 2000 & -0.202 & -0.194 & -0.229 \\
\hline gab & 1968 & 0.442 & 0.492 & 0.483 \\
\hline gab & 1976 & -1.311 & -0.342 & -0.710 \\
\hline gab & 1987 & 0.505 & -0.504 & -0.432 \\
\hline gbr & 1981 & 0.171 & 0.346 & 0.358 \\
\hline gbr & 2002 & -0.116 & -0.129 & 0.028 \\
\hline gha & 1966 & 0.155 & -0.096 & -0.055 \\
\hline gha & 1974 & -0.566 & -0.427 & -0.456 \\
\hline gha & 1983 & 1.008 & -0.044 & 0.264 \\
\hline gha & 2002 & 0.206 & 0.094 & -0.008 \\
\hline $\operatorname{gin}$ & 2002 & 0.144 & -0.060 & -0.179 \\
\hline gmb & 1982 & -0.324 & -0.252 & -0.138 \\
\hline gmb & 1995 & 0.244 & -0.297 & -0.245 \\
\hline gnb & 1970 & -0.590 & -0.275 & -0.289 \\
\hline gnb & 1981 & 0.055 & -0.198 & -0.001 \\
\hline gnb & 1997 & -0.263 & -0.602 & -0.581 \\
\hline grc & 1960 & 0.285 & 0.487 & 0.229 \\
\hline grc & 1973 & -2.027 & -0.064 & -0.653 \\
\hline gtm & 1962 & 0.512 & 0.158 & 0.250 \\
\hline gtm & 1980 & -0.535 & -0.251 & -0.467 \\
\hline gtm & 1988 & 0.980 & -0.134 & -0.063 \\
\hline guy & 1981 & -0.437 & -0.348 & -0.336 \\
\hline guy & 1990 & 1.522 & 0.359 & 0.445 \\
\hline hkg & 1981 & -0.229 & 0.555 & -0.010 \\
\hline hkg & 1994 & -0.337 & -0.110 & -0.245 \\
\hline hkg & 2002 & 0.305 & 0.165 & 0.273 \\
\hline hnd & 1970 & 0.244 & 0.112 & 0.141 \\
\hline hnd & 1979 & -0.951 & -0.462 & -0.619 \\
\hline hti & 1972 & 0.379 & 0.134 & 0.161 \\
\hline hti & 1980 & -0.800 & -0.423 & -0.471 \\
\hline hti & 1994 & 0.449 & -0.244 & -0.179 \\
\hline hun & 1978 & -0.753 & -0.035 & -0.151 \\
\hline idn & 1967 & 0.885 & 0.878 & 1.010 \\
\hline idn & 1996 & -0.460 & -0.078 & -0.230 \\
\hline ind & 1993 & 0.193 & 0.309 & 0.177 \\
\hline ind & 2002 & 0.165 & 0.278 & 0.257 \\
\hline irl & 1958 & 0.548 & 0.188 & 0.277 \\
\hline irl & 1979 & -0.343 & -0.060 & -0.241 \\
\hline
\end{tabular}




\begin{tabular}{|c|c|c|c|c|}
\hline irl & 1987 & 1.036 & 0.686 & 0.686 \\
\hline irl & 2002 & -0.482 & -0.168 & 0.018 \\
\hline irn & 1976 & -1.744 & -0.969 & -1.755 \\
\hline irn & 1988 & 2.260 & 0.201 & 0.314 \\
\hline irq & 1979 & -1.972 & -0.931 & -1.061 \\
\hline irq & 1991 & 2.136 & 0.329 & 0.399 \\
\hline isr & 1967 & -0.001 & 0.159 & 0.038 \\
\hline isr & 1975 & -1.115 & 0.006 & -0.340 \\
\hline ita & 1974 & -0.363 & 0.176 & -0.006 \\
\hline ita & 1990 & -0.071 & -0.001 & -0.131 \\
\hline ita & 2001 & -0.149 & -0.212 & -0.148 \\
\hline jam & 1961 & -0.269 & -0.134 & -0.456 \\
\hline jam & 1972 & -0.578 & -0.468 & -0.350 \\
\hline jam & 1986 & 0.451 & 0.191 & 0.289 \\
\hline jam & 1994 & -0.703 & -0.448 & -0.512 \\
\hline jor & 1965 & -1.061 & -0.800 & -0.996 \\
\hline jor & 1974 & 1.089 & 0.531 & 0.436 \\
\hline jor & 1982 & -1.128 & -0.494 & -0.928 \\
\hline jor & 1991 & 1.229 & -0.022 & 0.079 \\
\hline jpn & 1959 & 0.303 & 0.582 & 0.103 \\
\hline jpn & 1970 & -1.173 & 0.419 & 0.213 \\
\hline jpn & 1991 & -0.494 & -0.219 & -0.389 \\
\hline ken & 1967 & -0.057 & -0.664 & -0.619 \\
\hline $\mathrm{khm}$ & 1982 & 1.499 & 0.497 & 0.706 \\
\hline khm & 1998 & 0.301 & 0.439 & 0.420 \\
\hline kor & 1962 & 1.074 & 0.714 & 0.758 \\
\hline kor & 1982 & 0.193 & 0.684 & 0.033 \\
\hline kor & 1991 & -0.439 & 0.242 & -0.139 \\
\hline kor & 2002 & -0.090 & 0.063 & 0.026 \\
\hline lao & 1979 & 0.166 & 0.492 & 0.678 \\
\hline lao & 2002 & 0.358 & 0.332 & 0.321 \\
\hline Ibn & 1982 & 0.837 & 0.262 & 0.289 \\
\hline Ibn & 1991 & -0.102 & 0.070 & 0.006 \\
\hline $\mathrm{Ibr}$ & 1994 & 0.883 & 0.159 & 0.188 \\
\hline $\mathrm{Ibr}$ & 2002 & -0.332 & -0.288 & -0.327 \\
\hline Ika & 1959 & 0.656 & 0.017 & 0.168 \\
\hline Ika & 1973 & 0.088 & 0.285 & 0.291 \\
\hline Ika & 1981 & -0.265 & 0.555 & 0.189 \\
\hline Iso & 1970 & 0.242 & 0.193 & 0.253 \\
\hline Iso & 1978 & -0.532 & -0.130 & -0.215 \\
\hline Iso & 1986 & 1.134 & 0.340 & 0.536 \\
\hline mar & 1960 & 0.616 & 0.308 & 0.394 \\
\hline mar & 1968 & -0.306 & 0.112 & 0.176 \\
\hline mar & 1977 & -0.530 & -0.040 & -0.091 \\
\hline mar & 1995 & 0.306 & 0.098 & 0.066 \\
\hline $\mathrm{mdg}$ & 1974 & -0.612 & -0.783 & -0.589 \\
\hline
\end{tabular}




\begin{tabular}{|c|c|c|c|c|}
\hline mdg & 2002 & 0.147 & -0.213 & -0.272 \\
\hline mex & 1981 & -0.362 & -0.108 & -0.249 \\
\hline mex & 1989 & 0.572 & -0.115 & -0.081 \\
\hline $\mathrm{mli}$ & 1974 & 0.326 & 0.196 & 0.348 \\
\hline $\mathrm{mli}$ & 1986 & -0.105 & 0.069 & 0.099 \\
\hline $\mathrm{mng}$ & 1982 & -0.912 & -0.398 & -0.431 \\
\hline $\mathrm{mng}$ & 1993 & 1.029 & 0.084 & 0.115 \\
\hline $\mathrm{moz}$ & 1976 & -0.479 & -0.355 & -0.353 \\
\hline $\mathrm{moz}$ & 1986 & 0.378 & 0.023 & 0.225 \\
\hline $\mathrm{moz}$ & 1995 & 0.639 & 0.533 & 0.533 \\
\hline $\mathrm{mrt}$ & 1968 & -0.684 & 0.001 & -0.173 \\
\hline $\mathrm{mrt}$ & 1976 & -0.747 & -0.344 & -0.260 \\
\hline mrt & 2002 & 0.277 & 0.027 & -0.005 \\
\hline mus & 1963 & -0.013 & -0.399 & -0.183 \\
\hline mus & 1971 & 0.536 & 0.321 & 0.273 \\
\hline mus & 1979 & -0.525 & 0.643 & 0.084 \\
\hline mwi & 1964 & 0.304 & 0.270 & 0.277 \\
\hline mwi & 1978 & -1.688 & -0.915 & -1.195 \\
\hline mwi & 2002 & 0.629 & 0.197 & -0.022 \\
\hline mys & 1970 & 0.354 & 0.454 & 0.450 \\
\hline mys & 1979 & -0.492 & 0.079 & -0.206 \\
\hline mys & 1987 & 0.466 & 0.433 & 0.482 \\
\hline mys & 1996 & -0.642 & -0.033 & -0.268 \\
\hline nam & 1974 & -0.583 & -0.339 & -0.326 \\
\hline nam & 1985 & 0.448 & -0.148 & -0.032 \\
\hline nam & 2002 & 0.276 & 0.099 & 0.105 \\
\hline ner & 1968 & -0.114 & -0.405 & -0.346 \\
\hline ner & 1979 & -0.324 & -0.411 & -0.264 \\
\hline ner & 1987 & 1.076 & -0.519 & -0.390 \\
\hline nga & 1960 & -0.337 & -0.377 & -0.388 \\
\hline nga & 1968 & 0.553 & 0.197 & 0.101 \\
\hline nga & 1976 & -1.347 & -0.824 & -0.838 \\
\hline nga & 1987 & 2.109 & 0.104 & 0.359 \\
\hline nic & 1967 & -0.359 & -0.322 & -0.319 \\
\hline nic & 1979 & -0.281 & -0.304 & -0.198 \\
\hline nic & 1987 & -0.154 & -0.559 & -0.463 \\
\hline nic & 1995 & 1.115 & -0.009 & 0.068 \\
\hline nld & 1974 & -0.529 & 0.049 & -0.062 \\
\hline $\mathrm{npl}$ & 1983 & 0.427 & 0.222 & 0.394 \\
\hline $\mathrm{nzl}$ & 1958 & -0.209 & -0.233 & -0.220 \\
\hline $\mathrm{nzl}$ & 1974 & -0.083 & -0.111 & 0.125 \\
\hline omn & 1985 & -1.048 & 0.000 & -0.487 \\
\hline pak & 1960 & 0.407 & 0.054 & 0.151 \\
\hline pak & 1970 & -0.723 & 0.250 & 0.379 \\
\hline pan & 1959 & 0.459 & 0.359 & 0.476 \\
\hline pan & 1982 & -0.538 & 0.021 & -0.486 \\
\hline
\end{tabular}




\begin{tabular}{|c|c|c|c|c|}
\hline pan & 2002 & 0.354 & 0.219 & 0.196 \\
\hline per & 1959 & 0.212 & 0.053 & 0.110 \\
\hline per & 1967 & -0.459 & -0.181 & -0.155 \\
\hline per & 1981 & -0.455 & -0.434 & -0.338 \\
\hline per & 1992 & 1.150 & 0.187 & 0.231 \\
\hline phl & 1959 & -0.141 & -0.067 & -0.140 \\
\hline $\mathrm{phl}$ & 1977 & -0.280 & -0.085 & -0.112 \\
\hline $\mathrm{phl}$ & 1985 & 0.522 & -0.156 & -0.028 \\
\hline png & 1973 & -0.763 & -0.508 & -0.505 \\
\hline png & 1984 & 0.575 & 0.205 & 0.305 \\
\hline png & 1993 & -0.433 & -0.262 & -0.321 \\
\hline pol & 1979 & -0.614 & -0.182 & -0.286 \\
\hline pol & 1991 & 1.025 & 0.405 & 0.486 \\
\hline pri & 1972 & -0.484 & -0.078 & -0.244 \\
\hline pri & 1982 & 0.546 & 0.455 & 0.492 \\
\hline pri & 2000 & -0.431 & -0.294 & -0.177 \\
\hline prt & 1964 & 0.245 & 0.312 & 0.117 \\
\hline prt & 1973 & -0.643 & 0.073 & -0.174 \\
\hline prt & 1985 & 0.275 & 0.301 & 0.266 \\
\hline prt & 2000 & -0.360 & -0.247 & -0.174 \\
\hline pry & 1971 & 0.479 & 0.325 & 0.352 \\
\hline pry & 1980 & -0.495 & -0.005 & -0.257 \\
\hline pry & 1989 & -0.182 & -0.352 & -0.278 \\
\hline pry & 2002 & 0.222 & -0.036 & -0.086 \\
\hline rom & 1978 & -0.418 & 0.223 & -0.158 \\
\hline rom & 1986 & -0.730 & -0.574 & -0.642 \\
\hline rom & 1994 & 1.696 & 0.407 & 0.527 \\
\hline rwa & 1981 & -0.399 & -0.358 & -0.239 \\
\hline rwa & 1994 & 0.341 & 0.005 & 0.121 \\
\hline rwa & 2002 & 0.259 & 0.234 & 0.166 \\
\hline sdn & 1978 & -0.518 & -0.200 & -0.125 \\
\hline sdn & 1996 & 0.748 & 0.341 & 0.369 \\
\hline sen & 1973 & 0.825 & -0.342 & -0.106 \\
\hline sgp & 1968 & 0.426 & 0.739 & 0.698 \\
\hline sgp & 1980 & -1.133 & 0.834 & -0.071 \\
\hline sle & 1970 & -0.494 & 0.062 & 0.066 \\
\hline sle & 1990 & -0.864 & -0.810 & -0.697 \\
\hline sle & 1999 & 1.548 & 0.413 & 0.384 \\
\hline slv & 1978 & -0.403 & -0.282 & -0.241 \\
\hline slv & 1987 & 1.185 & 0.120 & 0.222 \\
\hline som & 1978 & -0.418 & -1.061 & -0.862 \\
\hline swz & 1978 & -0.556 & 0.244 & 0.171 \\
\hline swz & 1989 & -0.541 & -0.424 & -0.521 \\
\hline syr & 1981 & -0.394 & -0.146 & -0.196 \\
\hline syr & 1989 & 0.461 & 0.163 & 0.244 \\
\hline syr & 1998 & -0.295 & -0.153 & -0.259 \\
\hline
\end{tabular}




\begin{tabular}{|c|c|c|c|c|}
\hline tcd & 1971 & -0.395 & -0.454 & -0.412 \\
\hline tcd & 1980 & 0.873 & -0.003 & 0.304 \\
\hline tcd & 2000 & 0.486 & 0.333 & 0.284 \\
\hline tgo & 1969 & -0.633 & -0.283 & -0.322 \\
\hline tgo & 1979 & -0.268 & -0.430 & -0.262 \\
\hline tgo & 1993 & 0.276 & -0.480 & -0.400 \\
\hline tha & 1958 & 1.702 & 0.755 & 0.771 \\
\hline tha & 1987 & 0.128 & 0.490 & -0.054 \\
\hline tha & 1995 & -0.698 & -0.070 & -0.092 \\
\hline tto & 1961 & -0.214 & 0.308 & 0.023 \\
\hline tto & 1980 & -1.001 & -0.639 & -0.958 \\
\hline tto & 1989 & 1.350 & 0.225 & 0.288 \\
\hline tto & 2002 & 0.491 & 0.590 & 0.622 \\
\hline tun & 1972 & -0.093 & 0.159 & 0.158 \\
\hline tun & 1981 & -0.320 & 0.092 & 0.033 \\
\hline tur & 1958 & -0.733 & 0.146 & 0.339 \\
\hline twn & 1962 & 0.756 & 1.526 & 1.699 \\
\hline twn & 1994 & -0.526 & 0.270 & -0.152 \\
\hline tza & 1971 & -1.158 & -0.230 & -0.123 \\
\hline tza & 2000 & 0.499 & 0.305 & 0.279 \\
\hline uga & 1961 & 0.358 & 0.001 & 0.137 \\
\hline uga & 1969 & -0.784 & -0.643 & -0.566 \\
\hline uga & 1980 & 0.203 & -0.114 & 0.335 \\
\hline uga & 1988 & 1.004 & 0.336 & 0.410 \\
\hline ury & 1977 & -0.007 & -0.026 & 0.123 \\
\hline ury & 1985 & 0.316 & 0.219 & 0.284 \\
\hline ury & 1994 & -0.308 & -0.150 & -0.201 \\
\hline ury & 2002 & 0.319 & 0.131 & 0.142 \\
\hline ven & 1977 & -0.459 & -0.321 & -0.298 \\
\hline ven & 1985 & 0.588 & -0.276 & -0.197 \\
\hline ven & 2002 & 0.125 & -0.074 & -0.095 \\
\hline vnm & 1989 & 0.602 & 0.805 & 0.717 \\
\hline zaf & 1981 & -0.444 & -0.285 & -0.269 \\
\hline zaf & 1993 & 0.712 & 0.041 & 0.055 \\
\hline zar & 1958 & -0.260 & -0.486 & -0.379 \\
\hline zar & 1974 & -0.353 & -0.498 & -0.321 \\
\hline zar & 1989 & -0.917 & -1.347 & -1.086 \\
\hline zar & 2000 & 1.391 & 0.103 & 0.021 \\
\hline $\mathrm{zmb}$ & 1967 & -0.401 & -0.405 & -0.380 \\
\hline $\mathrm{zmb}$ & 1975 & -0.319 & -0.518 & -0.501 \\
\hline $\mathrm{zmb}$ & 1983 & 0.430 & -0.339 & -0.095 \\
\hline $\mathrm{zmb}$ & 1994 & 0.805 & 0.164 & 0.159 \\
\hline zwe & 1968 & 0.215 & 0.065 & 0.014 \\
\hline zwe & 1983 & -0.239 & -0.087 & -0.008 \\
\hline zwe & 1991 & -0.195 & -0.450 & -0.280 \\
\hline zwe & 2002 & -0.066 & -0.432 & -0.616 \\
\hline
\end{tabular}


Appendix 2: Regression estimates used to calculate "unconditional predicted" growth rates for each episode (sorted by start of episode, duration of episode and start of previous)

\begin{tabular}{|c|c|c|c|c|c|c|c|}
\hline Ctry & $\begin{array}{l}\text { Start of } \\
\text { Episode }\end{array}$ & $\begin{array}{l}\text { Duration } \\
\text { of } \\
\text { Episode }\end{array}$ & $\begin{array}{l}\text { Start of } \\
\text { previous } \\
\text { episode }\end{array}$ & $\begin{array}{l}\text { Regression } \\
\text { constant } \\
\text { (in ppa) }\end{array}$ & $\begin{array}{l}\text { Coefficient } \\
\text { on (In) } \\
\text { initial } \\
\text { income }\end{array}$ & $\begin{array}{l}\text { Coefficient } \\
\text { on } \\
\text { previous } \\
\text { growth } \\
\text { (below } \\
\text { median) }\end{array}$ & $\begin{array}{l}\text { Coefficient } \\
\text { on } \\
\text { previous } \\
\text { group } \\
\text { (above } \\
\text { median) }\end{array}$ \\
\hline dnk & 1958 & 11 & 1950 & 0.006 & 0.003 & -0.043 & 0.970 \\
\hline $\mathrm{nzl}$ & 1958 & 16 & 1950 & 0.004 & 0.003 & -0.079 & 0.705 \\
\hline zar & 1958 & 16 & 1950 & 0.017 & 0.001 & 0.028 & 0.732 \\
\hline bol & 1958 & 19 & 1950 & 0.017 & 0.001 & -0.014 & 0.655 \\
\hline cri & 1958 & 21 & 1950 & 0.015 & 0.001 & -0.042 & 0.571 \\
\hline irl & 1958 & 21 & 1950 & 0.012 & 0.001 & -0.062 & 0.608 \\
\hline tha & 1958 & 29 & 1950 & 0.002 & 0.003 & -0.179 & 0.398 \\
\hline tur & 1958 & 52 & 1950 & -0.003 & 0.003 & -0.179 & 0.096 \\
\hline per & 1959 & 8 & 1950 & 0.018 & 0.001 & 0.020 & 0.798 \\
\hline jpn & 1959 & 11 & 1950 & 0.034 & -0.001 & 0.238 & 0.897 \\
\hline Ika & 1959 & 14 & 1950 & 0.025 & 0.000 & 0.226 & 0.714 \\
\hline bel & 1959 & 15 & 1950 & 0.008 & 0.002 & -0.015 & 0.725 \\
\hline phl & 1959 & 18 & 1950 & 0.020 & 0.001 & 0.066 & 0.643 \\
\hline pan & 1959 & 23 & 1950 & 0.008 & 0.002 & -0.134 & 0.486 \\
\hline mar & 1960 & 8 & 1950 & 0.024 & 0.000 & 0.257 & 0.684 \\
\hline nga & 1960 & 8 & 1950 & 0.024 & 0.000 & 0.274 & 0.640 \\
\hline dom & 1960 & 8 & 1951 & 0.026 & 0.000 & 0.382 & 0.686 \\
\hline chn & 1960 & 8 & 1952 & 0.015 & 0.001 & 0.358 & 0.558 \\
\hline pak & 1960 & 10 & 1950 & 0.019 & 0.001 & 0.198 & 0.972 \\
\hline grc & 1960 & 13 & 1951 & 0.028 & -0.001 & 0.225 & 0.757 \\
\hline aus & 1961 & 8 & 1950 & 0.024 & 0.000 & 0.363 & 1.098 \\
\hline uga & 1961 & 8 & 1950 & 0.028 & -0.001 & 0.533 & 0.712 \\
\hline jam & 1961 & 11 & 1953 & 0.026 & 0.000 & 0.560 & 0.587 \\
\hline tto & 1961 & 19 & 1950 & 0.015 & 0.001 & 0.126 & 0.520 \\
\hline gtm & 1962 & 18 & 1950 & 0.018 & 0.000 & 0.186 & 0.507 \\
\hline kor & 1962 & 20 & 1953 & 0.033 & -0.001 & 0.005 & 0.401 \\
\hline twn & 1962 & 32 & 1951 & 0.003 & 0.002 & -0.185 & 0.253 \\
\hline mus & 1963 & 8 & 1950 & 0.034 & -0.002 & 0.825 & 0.703 \\
\hline prt & 1964 & 9 & 1950 & 0.023 & 0.000 & 0.498 & 0.739 \\
\hline mwi & 1964 & 14 & 1954 & 0.039 & -0.002 & -0.106 & 0.562 \\
\hline jor & 1965 & 9 & 1954 & 0.023 & 0.000 & 0.356 & 0.366 \\
\hline egy & 1965 & 11 & 1950 & 0.025 & -0.001 & 0.373 & 0.565 \\
\hline gha & 1966 & 8 & 1955 & 0.022 & 0.001 & 0.125 & 0.568 \\
\hline cyp & 1967 & 8 & 1950 & 0.021 & 0.001 & 0.159 & 0.684 \\
\hline isr & 1967 & 8 & 1950 & 0.011 & 0.001 & 0.182 & 0.877 \\
\hline $\mathrm{zmb}$ & 1967 & 8 & 1955 & 0.027 & 0.000 & -0.049 & 0.669 \\
\hline nic & 1967 & 12 & 1950 & 0.016 & 0.001 & 0.149 & 0.514 \\
\hline bra & 1967 & 13 & 1950 & 0.017 & 0.000 & 0.130 & 0.546 \\
\hline
\end{tabular}




\begin{tabular}{|c|c|c|c|c|c|c|c|}
\hline per & 1967 & 14 & 1959 & 0.002 & 0.002 & -0.015 & 0.334 \\
\hline bgd & 1967 & 15 & 1959 & 0.014 & 0.000 & 0.083 & 0.073 \\
\hline $\mathrm{col}$ & 1967 & 27 & 1950 & -0.001 & 0.002 & -0.160 & 0.331 \\
\hline ken & 1967 & 43 & 1950 & 0.003 & 0.002 & -0.172 & 0.278 \\
\hline chl & 1968 & 8 & 1951 & 0.034 & -0.001 & -0.044 & 0.739 \\
\hline dom & 1968 & 8 & 1960 & 0.010 & 0.004 & -0.594 & 0.504 \\
\hline gab & 1968 & 8 & 1960 & 0.007 & 0.003 & -0.036 & 0.371 \\
\hline $\mathrm{mrt}$ & 1968 & 8 & 1960 & 0.007 & 0.002 & 0.013 & 0.309 \\
\hline nga & 1968 & 8 & 1960 & -0.001 & 0.005 & -0.411 & 0.328 \\
\hline chn & 1968 & 9 & 1960 & 0.017 & 0.003 & -0.528 & 0.490 \\
\hline mar & 1968 & 9 & 1960 & 0.001 & 0.003 & -0.253 & 0.377 \\
\hline ner & 1968 & 11 & 1960 & 0.005 & 0.002 & -0.001 & 0.291 \\
\hline sgp & 1968 & 12 & 1960 & -0.009 & 0.003 & 0.072 & 0.089 \\
\hline zwe & 1968 & 15 & 1954 & 0.034 & -0.002 & 0.120 & 0.482 \\
\hline idn & 1968 & 28 & 1960 & -0.011 & 0.003 & 0.017 & 0.060 \\
\hline tgo & 1969 & 10 & 1960 & 0.008 & 0.002 & 0.003 & 0.322 \\
\hline uga & 1969 & 11 & 1961 & 0.001 & 0.003 & -0.214 & 0.328 \\
\hline eth & 1969 & 14 & 1950 & 0.012 & 0.000 & 0.213 & 0.433 \\
\hline dnk & 1969 & 41 & 1958 & 0.000 & 0.002 & -0.087 & 0.275 \\
\hline aus & 1969 & 41 & 1961 & -0.004 & 0.003 & -0.203 & 0.271 \\
\hline ecu & 1970 & 8 & 1951 & 0.045 & -0.003 & -0.068 & 0.690 \\
\hline Iso & 1970 & 8 & 1960 & 0.010 & 0.002 & -0.068 & 0.473 \\
\hline hnd & 1970 & 9 & 1950 & 0.001 & 0.002 & -0.032 & 0.673 \\
\hline mys & 1970 & 9 & 1955 & 0.028 & -0.001 & -0.017 & 0.345 \\
\hline gnb & 1970 & 11 & 1960 & 0.007 & 0.001 & 0.036 & 0.316 \\
\hline sle & 1970 & 20 & 1961 & -0.002 & 0.001 & 0.175 & 0.167 \\
\hline jpn & 1970 & 21 & 1959 & -0.015 & 0.004 & -0.197 & 0.381 \\
\hline pak & 1970 & 40 & 1960 & -0.002 & 0.002 & -0.155 & 0.304 \\
\hline bfa & 1971 & 8 & 1959 & -0.001 & 0.002 & -0.045 & 0.223 \\
\hline dza & 1971 & 8 & 1960 & 0.011 & 0.001 & -0.051 & 0.420 \\
\hline mus & 1971 & 8 & 1963 & -0.021 & 0.005 & -0.476 & 0.867 \\
\hline pry & 1971 & 9 & 1951 & 0.035 & -0.002 & 0.125 & 0.468 \\
\hline tcd & 1971 & 9 & 1960 & 0.009 & 0.001 & 0.031 & 0.389 \\
\hline tza & 1971 & 29 & 1960 & -0.012 & 0.003 & 0.044 & 0.222 \\
\hline hti & 1972 & 8 & 1960 & 0.010 & 0.001 & -0.019 & 0.382 \\
\hline tun & 1972 & 9 & 1961 & -0.013 & 0.002 & 0.113 & 0.327 \\
\hline pri & 1972 & 10 & 1950 & 0.018 & -0.001 & 0.135 & 0.466 \\
\hline jam & 1972 & 14 & 1961 & 0.035 & -0.004 & 0.261 & 0.563 \\
\hline Ika & 1973 & 8 & 1959 & -0.018 & 0.003 & -0.003 & 0.699 \\
\hline bwa & 1973 & 9 & 1960 & 0.006 & 0.000 & 0.088 & 0.313 \\
\hline png & 1973 & 11 & 1960 & 0.005 & 0.000 & 0.151 & 0.353 \\
\hline prt & 1973 & 12 & 1964 & -0.003 & 0.001 & 0.032 & 0.485 \\
\hline grc & 1973 & 37 & 1960 & 0.006 & 0.001 & 0.061 & 0.353 \\
\hline sen & 1973 & 37 & 1960 & -0.002 & 0.001 & 0.043 & 0.288 \\
\hline jor & 1974 & 8 & 1965 & 0.037 & -0.002 & -0.174 & 0.391 \\
\hline gha & 1974 & 9 & 1966 & 0.020 & -0.002 & 0.171 & -0.151 \\
\hline
\end{tabular}




\begin{tabular}{|c|c|c|c|c|c|c|c|}
\hline fin & 1974 & 11 & 1950 & 0.012 & -0.001 & 0.433 & 0.310 \\
\hline nam & 1974 & 11 & 1960 & 0.005 & -0.001 & 0.279 & 0.397 \\
\hline $\mathrm{mli}$ & 1974 & 12 & 1960 & -0.010 & 0.001 & 0.286 & 0.355 \\
\hline zar & 1974 & 15 & 1958 & 0.002 & 0.000 & 0.355 & 0.439 \\
\hline ita & 1974 & 16 & 1950 & 0.008 & 0.000 & 0.197 & 0.407 \\
\hline $\mathrm{mdg}$ & 1974 & 28 & 1960 & -0.009 & 0.002 & 0.103 & 0.336 \\
\hline che & 1974 & 36 & 1950 & 0.011 & -0.001 & 0.375 & 0.210 \\
\hline esp & 1974 & 36 & 1950 & 0.011 & -0.001 & 0.375 & 0.210 \\
\hline nld & 1974 & 36 & 1950 & 0.011 & -0.001 & 0.375 & 0.210 \\
\hline $\mathrm{nzl}$ & 1974 & 36 & 1958 & 0.010 & -0.001 & 0.452 & 0.217 \\
\hline bel & 1974 & 36 & 1959 & 0.009 & -0.001 & 0.420 & 0.216 \\
\hline $\mathrm{zmb}$ & 1975 & 8 & 1967 & 0.025 & -0.002 & 0.147 & -0.168 \\
\hline cyp & 1975 & 9 & 1967 & 0.000 & 0.000 & 0.303 & 0.071 \\
\hline isr & 1975 & 35 & 1967 & 0.006 & 0.000 & 0.260 & 0.173 \\
\hline $\mathrm{cmr}$ & 1976 & 8 & 1960 & 0.012 & -0.002 & 0.326 & 0.380 \\
\hline $\operatorname{cog}$ & 1976 & 8 & 1960 & 0.012 & -0.002 & 0.326 & 0.380 \\
\hline $\mathrm{moz}$ & 1976 & 10 & 1960 & 0.010 & -0.002 & 0.410 & 0.396 \\
\hline chl & 1976 & 10 & 1968 & -0.004 & 0.001 & 0.093 & 0.308 \\
\hline gab & 1976 & 11 & 1968 & -0.020 & 0.002 & 0.391 & 0.040 \\
\hline nga & 1976 & 11 & 1968 & -0.023 & 0.003 & 0.422 & -1.002 \\
\hline irn & 1976 & 12 & 1955 & 0.002 & -0.003 & 1.328 & -0.045 \\
\hline dom & 1976 & 15 & 1968 & -0.018 & 0.003 & 0.132 & -0.180 \\
\hline egy & 1976 & 16 & 1965 & -0.021 & 0.002 & 0.507 & 0.194 \\
\hline $\mathrm{mrt}$ & 1976 & 26 & 1968 & -0.016 & 0.003 & 0.112 & 0.239 \\
\hline $\arg$ & 1977 & 8 & 1950 & 0.009 & -0.003 & 0.867 & 0.121 \\
\hline ury & 1977 & 8 & 1950 & 0.009 & -0.003 & 0.867 & 0.121 \\
\hline ven & 1977 & 8 & 1950 & 0.012 & -0.003 & 0.680 & 0.270 \\
\hline phl & 1977 & 8 & 1959 & -0.024 & 0.000 & 1.025 & 0.408 \\
\hline bol & 1977 & 9 & 1958 & -0.021 & 0.000 & 0.971 & 0.384 \\
\hline chn & 1977 & 14 & 1968 & 0.004 & 0.000 & 0.408 & -0.185 \\
\hline mar & 1977 & 18 & 1968 & -0.022 & 0.003 & 0.299 & -0.147 \\
\hline ben & 1978 & 8 & 1959 & 0.029 & -0.005 & 0.965 & -0.025 \\
\hline rom & 1978 & 8 & 1960 & 0.006 & -0.002 & 0.433 & 0.466 \\
\hline Iso & 1978 & 8 & 1970 & -0.034 & 0.003 & 0.405 & 0.091 \\
\hline slv & 1978 & 9 & 1950 & -0.020 & 0.001 & 0.694 & 0.269 \\
\hline swz & 1978 & 11 & 1970 & -0.040 & 0.005 & 0.154 & -0.049 \\
\hline sdn & 1978 & 18 & 1970 & -0.035 & 0.005 & 0.055 & 0.014 \\
\hline ecu & 1978 & 21 & 1970 & -0.034 & 0.005 & -0.012 & 0.402 \\
\hline $\mathrm{mwi}$ & 1978 & 24 & 1964 & -0.005 & 0.001 & 0.263 & 0.580 \\
\hline civ & 1978 & 32 & 1960 & 0.001 & 0.001 & 0.194 & 0.400 \\
\hline hun & 1978 & 32 & 1970 & -0.008 & 0.002 & -0.011 & 0.240 \\
\hline som & 1978 & 32 & 1970 & -0.008 & 0.002 & -0.011 & 0.240 \\
\hline irl & 1979 & 8 & 1958 & -0.005 & -0.003 & 1.428 & 0.180 \\
\hline nic & 1979 & 8 & 1967 & -0.010 & 0.000 & 0.623 & 0.039 \\
\hline ner & 1979 & 8 & 1968 & -0.034 & 0.003 & 0.410 & 0.340 \\
\hline mys & 1979 & 8 & 1970 & 0.002 & -0.001 & 0.453 & 0.198 \\
\hline
\end{tabular}




\begin{tabular}{|c|c|c|c|c|c|c|c|}
\hline $\mathrm{fji}$ & 1979 & 9 & 1960 & 0.000 & -0.001 & 0.529 & 0.579 \\
\hline cri & 1979 & 12 & 1958 & -0.024 & 0.000 & 1.274 & 0.283 \\
\hline irq & 1979 & 12 & 1970 & -0.042 & 0.005 & 0.124 & -0.026 \\
\hline pol & 1979 & 12 & 1970 & -0.042 & 0.005 & 0.124 & -0.026 \\
\hline tgo & 1979 & 14 & 1969 & -0.028 & 0.003 & 0.305 & 0.290 \\
\hline dza & 1979 & 15 & 1971 & -0.030 & 0.004 & 0.247 & 0.197 \\
\hline lao & 1979 & 23 & 1970 & -0.027 & 0.004 & 0.022 & 0.198 \\
\hline aut & 1979 & 31 & 1950 & 0.010 & -0.001 & 0.824 & 0.072 \\
\hline hnd & 1979 & 31 & 1970 & 0.002 & 0.001 & 0.243 & 0.336 \\
\hline bfa & 1979 & 31 & 1971 & 0.007 & 0.001 & 0.097 & 0.470 \\
\hline mus & 1979 & 31 & 1971 & -0.001 & 0.001 & 0.150 & 0.436 \\
\hline gtm & 1980 & 8 & 1962 & -0.027 & -0.001 & 1.788 & -0.006 \\
\hline uga & 1980 & 8 & 1969 & -0.026 & 0.002 & 1.184 & -1.009 \\
\hline tto & 1980 & 9 & 1961 & 0.000 & -0.004 & 1.697 & 0.090 \\
\hline pry & 1980 & 9 & 1971 & -0.009 & 0.001 & 0.652 & -0.123 \\
\hline hti & 1980 & 14 & 1972 & -0.032 & 0.004 & 0.192 & 0.250 \\
\hline tcd & 1980 & 20 & 1971 & -0.026 & 0.004 & 0.094 & 0.402 \\
\hline bra & 1980 & 22 & 1967 & -0.014 & 0.002 & 0.530 & 0.392 \\
\hline sgp & 1980 & 30 & 1968 & -0.003 & 0.001 & 0.104 & 0.411 \\
\hline mex & 1981 & 8 & 1950 & -0.024 & 0.000 & 1.217 & 0.110 \\
\hline syr & 1981 & 8 & 1960 & 0.001 & -0.002 & 0.496 & 0.716 \\
\hline guy & 1981 & 9 & 1970 & -0.048 & 0.006 & 0.107 & 0.099 \\
\hline per & 1981 & 11 & 1967 & -0.022 & 0.001 & 1.155 & -0.266 \\
\hline zaf & 1981 & 12 & 1950 & -0.017 & 0.000 & 1.063 & 0.180 \\
\hline hkg & 1981 & 13 & 1960 & -0.009 & 0.000 & 0.427 & 0.657 \\
\hline rwa & 1981 & 13 & 1960 & -0.009 & 0.000 & 0.427 & 0.657 \\
\hline gnb & 1981 & 16 & 1970 & -0.029 & 0.004 & 0.147 & 0.474 \\
\hline gbr & 1981 & 21 & 1950 & -0.005 & 0.000 & 0.988 & 0.129 \\
\hline tun & 1981 & 29 & 1972 & -0.010 & 0.002 & 0.002 & 0.445 \\
\hline Ika & 1981 & 29 & 1973 & -0.001 & 0.002 & 0.129 & 0.438 \\
\hline bwa & 1982 & 8 & 1973 & -0.045 & 0.006 & 0.235 & 0.252 \\
\hline kor & 1982 & 9 & 1962 & 0.018 & -0.004 & 0.960 & 1.098 \\
\hline Ibn & 1982 & 9 & 1970 & -0.053 & 0.006 & 0.024 & 0.185 \\
\hline jor & 1982 & 9 & 1974 & -0.044 & 0.006 & 0.330 & 0.377 \\
\hline alb & 1982 & 10 & 1970 & -0.051 & 0.006 & 0.004 & 0.197 \\
\hline $\mathrm{mng}$ & 1982 & 11 & 1970 & -0.050 & 0.006 & -0.011 & 0.219 \\
\hline gmb & 1982 & 13 & 1960 & -0.022 & 0.002 & 0.352 & 0.662 \\
\hline bgd & 1982 & 14 & 1967 & -0.022 & 0.003 & 0.215 & 1.077 \\
\hline khm & 1982 & 16 & 1970 & -0.038 & 0.005 & 0.000 & 0.311 \\
\hline pri & 1982 & 18 & 1972 & -0.042 & 0.006 & 0.154 & 0.746 \\
\hline pan & 1982 & 20 & 1959 & -0.005 & -0.001 & 1.069 & 0.163 \\
\hline zwe & 1983 & 8 & 1968 & -0.031 & 0.003 & 0.312 & 1.468 \\
\hline eth & 1983 & 9 & 1969 & -0.016 & 0.001 & 0.929 & 0.745 \\
\hline $\mathrm{zmb}$ & 1983 & 11 & 1975 & -0.056 & 0.007 & 0.034 & 0.732 \\
\hline gha & 1983 & 19 & 1974 & -0.034 & 0.005 & 0.022 & 0.699 \\
\hline $\mathrm{npl}$ & 1983 & 27 & 1960 & 0.004 & 0.000 & 0.213 & 0.515 \\
\hline
\end{tabular}




\begin{tabular}{|c|c|c|c|c|c|c|c|}
\hline сур & 1984 & 8 & 1975 & -0.072 & 0.009 & 0.091 & 1.170 \\
\hline png & 1984 & 9 & 1973 & -0.050 & 0.006 & 0.017 & 0.626 \\
\hline $\mathrm{cmr}$ & 1984 & 10 & 1976 & -0.052 & 0.007 & -0.052 & 0.495 \\
\hline $\operatorname{cog}$ & 1984 & 10 & 1976 & -0.052 & 0.007 & -0.052 & 0.495 \\
\hline cub & 1984 & 11 & 1970 & -0.053 & 0.007 & -0.072 & 0.422 \\
\hline fin & 1985 & 8 & 1974 & -0.037 & 0.004 & 0.362 & 1.108 \\
\hline arg & 1985 & 9 & 1977 & -0.040 & 0.005 & 0.165 & 0.756 \\
\hline ury & 1985 & 9 & 1977 & -0.040 & 0.005 & 0.165 & 0.756 \\
\hline prt & 1985 & 15 & 1973 & -0.039 & 0.006 & 0.170 & 0.849 \\
\hline nam & 1985 & 17 & 1974 & -0.029 & 0.004 & -0.008 & 0.540 \\
\hline ven & 1985 & 17 & 1977 & -0.041 & 0.006 & 0.036 & 0.499 \\
\hline omn & 1985 & 25 & 1970 & -0.001 & 0.001 & -0.008 & 0.495 \\
\hline phl & 1985 & 25 & 1977 & 0.002 & 0.002 & 0.048 & 0.305 \\
\hline afg & 1986 & 8 & 1970 & -0.071 & 0.008 & -0.167 & 0.607 \\
\hline jam & 1986 & 8 & 1972 & -0.068 & 0.008 & 0.071 & 1.395 \\
\hline ben & 1986 & 8 & 1978 & -0.067 & 0.009 & -0.069 & 0.763 \\
\hline rom & 1986 & 8 & 1978 & -0.064 & 0.008 & -0.184 & 0.637 \\
\hline $\mathrm{moz}$ & 1986 & 9 & 1976 & -0.056 & 0.007 & -0.127 & 0.683 \\
\hline caf & 1986 & 10 & 1960 & -0.031 & 0.003 & 0.279 & 0.781 \\
\hline chl & 1986 & 11 & 1976 & -0.043 & 0.006 & 0.132 & 0.624 \\
\hline mli & 1986 & 24 & 1974 & -0.004 & 0.002 & -0.014 & 0.515 \\
\hline bol & 1986 & 24 & 1977 & 0.005 & 0.001 & 0.064 & 0.304 \\
\hline Iso & 1986 & 24 & 1978 & -0.003 & 0.002 & -0.075 & 0.429 \\
\hline tha & 1987 & 8 & 1958 & -0.023 & -0.001 & 1.688 & 0.428 \\
\hline nic & 1987 & 8 & 1979 & -0.063 & 0.008 & -0.075 & 0.766 \\
\hline mys & 1987 & 9 & 1979 & -0.053 & 0.007 & -0.042 & 0.794 \\
\hline irl & 1987 & 15 & 1979 & -0.038 & 0.006 & -0.027 & 0.456 \\
\hline gab & 1987 & 23 & 1976 & -0.001 & 0.002 & -0.062 & 0.473 \\
\hline nga & 1987 & 23 & 1976 & 0.013 & 0.000 & 0.116 & 0.240 \\
\hline slv & 1987 & 23 & 1978 & 0.005 & 0.001 & 0.049 & 0.277 \\
\hline ner & 1987 & 23 & 1979 & -0.002 & 0.002 & -0.074 & 0.442 \\
\hline bgr & 1988 & 9 & 1970 & -0.056 & 0.007 & -0.025 & 0.611 \\
\hline $\mathrm{fji}$ & 1988 & 12 & 1979 & -0.039 & 0.006 & -0.070 & 0.534 \\
\hline irn & 1988 & 22 & 1976 & 0.010 & 0.001 & -0.003 & 0.492 \\
\hline $\mathrm{gtm}$ & 1988 & 22 & 1980 & 0.011 & 0.001 & 0.033 & 0.212 \\
\hline uga & 1988 & 22 & 1980 & 0.012 & 0.001 & 0.032 & 0.170 \\
\hline syr & 1989 & 9 & 1981 & -0.049 & 0.007 & -0.049 & 0.523 \\
\hline zar & 1989 & 11 & 1974 & -0.031 & 0.005 & 0.307 & 0.538 \\
\hline pry & 1989 & 13 & 1980 & -0.026 & 0.005 & 0.072 & 0.372 \\
\hline tto & 1989 & 13 & 1980 & -0.029 & 0.005 & 0.061 & 0.338 \\
\hline vnm & 1989 & 21 & 1970 & 0.009 & 0.001 & 0.063 & 0.492 \\
\hline sWZ & 1989 & 21 & 1978 & 0.010 & 0.000 & 0.020 & 0.403 \\
\hline mex & 1989 & 21 & 1981 & 0.009 & 0.001 & -0.001 & 0.202 \\
\hline sle & 1990 & 9 & 1970 & -0.048 & 0.006 & -0.034 & 0.637 \\
\hline ita & 1990 & 11 & 1974 & -0.033 & 0.005 & 0.283 & 0.407 \\
\hline guy & 1990 & 20 & 1981 & 0.010 & 0.001 & -0.018 & 0.364 \\
\hline
\end{tabular}




\begin{tabular}{|c|c|c|c|c|c|c|c|}
\hline bwa & 1990 & 20 & 1982 & 0.008 & 0.001 & -0.024 & 0.353 \\
\hline kor & 1991 & 11 & 1982 & -0.023 & 0.005 & 0.070 & 0.417 \\
\hline zwe & 1991 & 11 & 1983 & -0.020 & 0.004 & 0.108 & 0.391 \\
\hline jpn & 1991 & 19 & 1970 & 0.025 & -0.001 & 0.328 & 0.243 \\
\hline dom & 1991 & 19 & 1976 & 0.019 & 0.000 & 0.123 & 0.218 \\
\hline chn & 1991 & 19 & 1977 & 0.027 & -0.001 & 0.093 & 0.448 \\
\hline cri & 1991 & 19 & 1979 & 0.018 & 0.000 & 0.068 & 0.176 \\
\hline irq & 1991 & 19 & 1979 & 0.015 & 0.000 & -0.013 & 0.403 \\
\hline pol & 1991 & 19 & 1979 & 0.015 & 0.000 & -0.013 & 0.403 \\
\hline jor & 1991 & 19 & 1982 & 0.030 & -0.001 & 0.061 & 0.330 \\
\hline Ibn & 1991 & 19 & 1982 & 0.013 & 0.000 & -0.046 & 0.354 \\
\hline bdi & 1992 & 8 & 1960 & -0.038 & 0.005 & 0.160 & 0.468 \\
\hline eth & 1992 & 10 & 1983 & -0.018 & 0.004 & 0.153 & 0.089 \\
\hline egy & 1992 & 18 & 1976 & 0.027 & -0.001 & 0.168 & 0.116 \\
\hline per & 1992 & 18 & 1981 & 0.024 & 0.000 & 0.063 & 0.081 \\
\hline alb & 1992 & 18 & 1982 & 0.015 & 0.000 & -0.070 & 0.359 \\
\hline сур & 1992 & 18 & 1984 & 0.028 & -0.001 & 0.080 & 0.055 \\
\hline ago & 1993 & 8 & 1970 & -0.042 & 0.006 & -0.178 & 0.438 \\
\hline fin & 1993 & 8 & 1985 & -0.024 & 0.005 & 0.212 & 0.036 \\
\hline ind & 1993 & 9 & 1950 & -0.010 & -0.001 & 1.910 & -0.708 \\
\hline tgo & 1993 & 17 & 1979 & 0.014 & 0.000 & 0.001 & 0.392 \\
\hline zaf & 1993 & 17 & 1981 & 0.020 & 0.000 & -0.008 & 0.118 \\
\hline $\mathrm{mng}$ & 1993 & 17 & 1982 & 0.017 & 0.000 & -0.097 & 0.364 \\
\hline png & 1993 & 17 & 1984 & 0.015 & 0.000 & 0.012 & 0.313 \\
\hline $\mathrm{col}$ & 1994 & 8 & 1967 & -0.026 & 0.004 & 0.546 & 0.071 \\
\hline lbr & 1994 & 8 & 1970 & -0.032 & 0.005 & -0.210 & 0.360 \\
\hline hkg & 1994 & 8 & 1981 & -0.022 & 0.005 & -0.006 & 0.250 \\
\hline rwa & 1994 & 8 & 1981 & -0.022 & 0.005 & -0.006 & 0.250 \\
\hline arg & 1994 & 8 & 1985 & -0.020 & 0.004 & 0.201 & 0.033 \\
\hline ury & 1994 & 8 & 1985 & -0.020 & 0.004 & 0.201 & 0.033 \\
\hline twn & 1994 & 16 & 1962 & 0.027 & -0.002 & 0.493 & 0.082 \\
\hline dza & 1994 & 16 & 1979 & 0.018 & 0.000 & 0.022 & 0.371 \\
\hline hti & 1994 & 16 & 1980 & 0.018 & 0.000 & 0.017 & 0.364 \\
\hline $\mathrm{zmb}$ & 1994 & 16 & 1983 & 0.042 & -0.002 & 0.083 & 0.306 \\
\hline $\mathrm{cmr}$ & 1994 & 16 & 1984 & 0.019 & 0.000 & 0.041 & 0.316 \\
\hline $\operatorname{cog}$ & 1994 & 16 & 1984 & 0.019 & 0.000 & 0.041 & 0.316 \\
\hline afg & 1994 & 16 & 1986 & 0.019 & 0.000 & -0.130 & 0.301 \\
\hline ben & 1994 & 16 & 1986 & 0.042 & -0.003 & 0.133 & 0.216 \\
\hline jam & 1994 & 16 & 1986 & 0.042 & -0.002 & 0.067 & 0.272 \\
\hline rom & 1994 & 16 & 1986 & 0.021 & 0.000 & 0.075 & 0.252 \\
\hline mar & 1995 & 15 & 1977 & 0.035 & -0.001 & 0.097 & -0.016 \\
\hline gmb & 1995 & 15 & 1982 & 0.017 & 0.000 & -0.041 & 0.328 \\
\hline cub & 1995 & 15 & 1984 & 0.023 & 0.000 & -0.153 & 0.331 \\
\hline $\mathrm{moz}$ & 1995 & 15 & 1986 & 0.023 & -0.001 & 0.067 & 0.277 \\
\hline nic & 1995 & 15 & 1987 & 0.046 & -0.003 & 0.153 & 0.001 \\
\hline tha & 1995 & 15 & 1987 & 0.032 & -0.001 & -0.025 & 0.082 \\
\hline
\end{tabular}




\begin{tabular}{|c|c|c|c|c|c|c|c|}
\hline idn & 1996 & 14 & 1968 & 0.020 & -0.001 & 0.082 & 0.377 \\
\hline sdn & 1996 & 14 & 1978 & 0.029 & -0.001 & -0.090 & 0.326 \\
\hline bgd & 1996 & 14 & 1982 & 0.037 & -0.002 & -0.065 & 0.341 \\
\hline caf & 1996 & 14 & 1986 & 0.021 & 0.000 & -0.028 & 0.284 \\
\hline mys & 1996 & 14 & 1987 & 0.058 & -0.004 & 0.170 & 0.237 \\
\hline gnb & 1997 & 13 & 1981 & 0.030 & -0.001 & 0.049 & 0.296 \\
\hline chl & 1997 & 13 & 1986 & 0.053 & -0.003 & 0.142 & 0.027 \\
\hline bgr & 1997 & 13 & 1988 & 0.030 & -0.001 & -0.184 & 0.329 \\
\hline $\mathrm{khm}$ & 1998 & 12 & 1982 & 0.037 & -0.002 & -0.177 & 0.307 \\
\hline syr & 1998 & 12 & 1989 & 0.043 & -0.003 & 0.200 & 0.356 \\
\hline ecu & 1999 & 11 & 1978 & 0.057 & -0.003 & -0.015 & -0.103 \\
\hline sle & 1999 & 11 & 1990 & 0.042 & -0.002 & 0.005 & 0.306 \\
\hline tza & 2000 & 10 & 1971 & 0.041 & -0.002 & 0.021 & 0.205 \\
\hline tcd & 2000 & 10 & 1980 & 0.049 & -0.003 & 0.112 & 0.195 \\
\hline pri & 2000 & 10 & 1982 & 0.073 & -0.005 & -0.035 & -0.302 \\
\hline prt & 2000 & 10 & 1985 & 0.077 & -0.006 & 0.035 & -0.277 \\
\hline$f j i$ & 2000 & 10 & 1988 & 0.055 & -0.004 & 0.216 & 0.362 \\
\hline zar & 2000 & 10 & 1989 & 0.087 & -0.007 & 0.182 & -0.272 \\
\hline bdi & 2000 & 10 & 1992 & 0.044 & -0.002 & 0.019 & 0.206 \\
\hline ita & 2001 & 9 & 1990 & 0.102 & -0.009 & 0.216 & -0.380 \\
\hline ago & 2001 & 9 & 1993 & 0.054 & -0.003 & -0.184 & 0.402 \\
\hline fin & 2001 & 9 & 1993 & 0.096 & -0.008 & 0.178 & 0.240 \\
\hline gin & 2002 & 8 & 1959 & 0.093 & -0.008 & 0.005 & 0.257 \\
\hline $\mathrm{mdg}$ & 2002 & 8 & 1974 & 0.060 & -0.004 & -0.024 & 0.046 \\
\hline $\mathrm{mrt}$ & 2002 & 8 & 1976 & 0.065 & -0.004 & 0.100 & 0.037 \\
\hline mwi & 2002 & 8 & 1978 & 0.100 & -0.008 & -0.220 & 0.160 \\
\hline lao & 2002 & 8 & 1979 & 0.074 & -0.005 & -0.165 & 0.081 \\
\hline bra & 2002 & 8 & 1980 & 0.102 & -0.008 & -0.130 & -0.604 \\
\hline gbr & 2002 & 8 & 1981 & 0.092 & -0.006 & -0.324 & -0.495 \\
\hline pan & 2002 & 8 & 1982 & 0.100 & -0.007 & -0.203 & -0.508 \\
\hline gha & 2002 & 8 & 1983 & 0.112 & -0.009 & -0.081 & 0.167 \\
\hline nam & 2002 & 8 & 1985 & 0.068 & -0.005 & 0.134 & 0.225 \\
\hline ven & 2002 & 8 & 1985 & 0.114 & -0.010 & 0.126 & -0.582 \\
\hline irl & 2002 & 8 & 1987 & 0.113 & -0.010 & 0.163 & -0.425 \\
\hline pry & 2002 & 8 & 1989 & 0.107 & -0.009 & 0.126 & 0.026 \\
\hline tto & 2002 & 8 & 1989 & 0.110 & -0.010 & 0.134 & -0.133 \\
\hline kor & 2002 & 8 & 1991 & 0.113 & -0.010 & 0.182 & 0.533 \\
\hline zwe & 2002 & 8 & 1991 & 0.113 & -0.010 & 0.187 & 0.565 \\
\hline eth & 2002 & 8 & 1992 & 0.107 & -0.010 & 0.143 & 0.213 \\
\hline ind & 2002 & 8 & 1993 & 0.107 & -0.008 & -0.055 & -0.295 \\
\hline arg & 2002 & 8 & 1994 & 0.107 & -0.009 & 0.083 & 0.270 \\
\hline col & 2002 & 8 & 1994 & 0.113 & -0.009 & 0.117 & -0.289 \\
\hline hkg & 2002 & 8 & 1994 & 0.060 & -0.005 & 0.249 & 0.391 \\
\hline $\mathrm{Ibr}$ & 2002 & 8 & 1994 & 0.056 & -0.004 & -0.195 & 0.393 \\
\hline rwa & 2002 & 8 & 1994 & 0.060 & -0.005 & 0.249 & 0.391 \\
\hline ury & 2002 & 8 & 1994 & 0.107 & -0.009 & 0.083 & 0.270 \\
\hline
\end{tabular}




\section{References}

Acemoglu, D. and J. Robinson. (2012). Why Nations Fail: The Origins of Power, Prosperity and Poverty. Random House.

Aguiar, M and G. Gopinath (2007) 'Emerging Market Business Cycles: The Cycle Is the Trend'. Journal of Political Economy, 115, 69-102.

Aizenman, J. and M.M. Spiegel. (2010) "Takeoffs." Review of Development Economics, 14(2), 177-96.

Arbache, J. S. and J. Page (2007) 'More Growth or Fewer Collapses? A New Look at Long Run Growth in Sub-Saharan Africa.' Policy Research Working Paper 4384, World Bank, Washington, DC.

Ben-David, D. and D.H. Papell. (1998) 'Slowdowns and Meltdowns: Postwar Growth Evidence from 74 Countries ' The Review of Economics and Statistics 80(4), 561-71.

Breuer, J. and J. McDermott (2013), 'Economic Depressions around the world", Journal of Macroeconomics, forthcoming.

Bai, J. and P. Perron (1998) 'Estimating and Testing Linear Models with Multiple Structural Change', Econometrica. 66, 47-78.

Berg, A., J. Ostry and J. Zettelmeyer (2012) 'What makes growth sustained?', Journal of Development Economics. 98, no. 2, 149-166.

Comin, D., W. Easterly and E. Gong, (2010) 'Was the Wealth of Nations Determined in 1000 BC?' American Economic Journal: 2(3), 65-97.

Easterly, W., M. Kremer, L. Pritchett and L. Summers (1993) 'Good Policy or Good Luck? Country Growth Performance and Temporary Shocks' Journal of Monetary Economics 32,:459-483.

Easterly, W. and R. Levine (2003) 'Tropics, germs, and crops: how endowments influence economic development.' Journal of Monetary Economics 50(1), 3-39

Hausmann, R., F. Rodriguez, and R.Wagner (2006) Growth Collapses. Kennedy School of Governance Working Paper RWP06-046.

Hausmann, R., L. Pritchett and D. Rodrik (2005), 'Growth Accelerations', Journal of Economic Growth. 10, 303-329.

Hicks, J.R. (1965), Capital and Growth, Oxford, UK: Oxford University Press. 
Jones, B. and B. Olken (2008), 'The Anatomy of Start-Stop Growth.' Review of Economics and Statistics 90(3), 582-587.

Kar, S., L. Pritchett, S. Raihan and K. Sen (2013a), The Dynamics of Economic Growth: A Visual Handbook of Growth Rates, Regimes, Transition and Volatility, ESID Publication: University of Manchester.

Kar, S., L. Pritchett, S. Raihan and K. Sen (2013b), Looking for a Break: Identifying Transitions in Growth Regimes. ESID Working Paper, forthcoming.

Lucas, Robert (1988) 'On the Mechanics of Economic Development.' Journal of Monetary Economics 22 (1): 3-42.

North, D. N., J. J. Wallis and B. R. Weingast (2009), Violence and Social Orders, Cambridge: Cambridge University Press.

Pritchett, L. (2000) 'Understanding Patterns of Economic Growth: Searching for Hills among Plateaus, Mountains and Plains', World Bank Economic Review, Vol. 14 , No. 2, pp. 221-250.

Rodrik, D. (1999) 'Where Did All the Growth Go? External Shocks, Social Conflict, and Growth Collapses.' Journal of Economic Growth 4(4):385-412.

Rodrik, D., A. Subramanian, and F. Trebbi (2004) 'Institutions Rule: The Primacy of Institutions Over Geography and Integration in Economic Development'. Journal of Economic Growth 9(2):131-165. 


\section{The Effective States and Inclusive Development Research Centre}

The Effective States and Inclusive Development Research Centre (ESID) aims to improve the use of governance research evidence in decision-making. Our key focus is on the role of state effectiveness and elite commitment in achieving inclusive development and social justice.

ESID is a partnership of highly reputed research and policy institutes based in Africa, Asia, Europe and North America. The lead institution is the University of Manchester.

The other founding institutional partners are:

- $\quad$ BRAC Development Institute, BRAC University, Dhaka

- Institute for Economic Growth, Delhi

- Department of Political and Administrative Studies, University of Malawi, Zomba

- $\quad$ Center for Democratic Development, Accra

- $\quad$ Center for International Development, Harvard University, Boston

In addition to its institutional partners, ESID has established a network of leading research collaborators and policy/uptake experts. 